Vol. 32, no 19. - Octobre 1925.

\title{
Beitrag zur Kenntnis der Schweizerischen Spinnenfauna.
} VON

\section{E. SCHENKEL}

mit 14 Textfiguren.

Zwei Ferienaufenthalte in Fiesch, dem Ausgangspunkt für lohnende Excursionen nach bekannten Punkten des Oberwallis, boten mir Gelegenheit, der Spinnenfauna dieser Gegend einige, durch anderweitige Verpflichtungen vielfach gehemmte Aufmerksamkeit zuzuwenden. Leider fallen meine Ferien auf die Monate Juli und August, während für die Spinnen der tiefern Lagen die Zeit der Geschlechtsreife vorzugsweise auf Mai und Juni, für die Bodenfauna auch auf Herbst, Winter und Vorfrühling fällt. Nicht geschlechtsreife Stücke wurden aber höchstens dann gesammelt, wenn Kennzeichen der Farbe und Zeichnung ein sicheres Bestimmen ermöglichten. So ist die Zahl der erbeuteten Arten: 208 ächte Spinnen, 11 Opilioniden und 3 Pseudoscorpione, eine recht bescheidene geblieben.

Zum Voraus möchte ich davon abraten, die im Verzeichnis angegebenen Stückzahlen zu Untersuchungen über relative Häufigkeit heranzuziehen; die "gemeinern " Arten wurden nämlich nicht quantitativ gesammelt, schon um Zeit zu sparen, namentlich wenn es sich um schnellfüssige Pardosa-Arten handelte, dann aber auch, weil diese Formen meist durch Weibchen mit Eiern oder Jungen oder aber durch unreife, Stücke vertreten waren.

Wie zu erwarten, macht sich die reiche Höhengliederung des Geländes in der Zusammensetzung der Spinnenfauna geltend. Neben Formen von weiter vertikaler Verbreitung (43 Ar., 3 Op.) finden sich Leitarten der alpinen und nivalen Zone (34 Ar., 2 Op.), ausserdem noch solche (18 Ar., 1 Op.), die zwar, wie die vorigen, den hochgelegenen Wohnraum bevorzugen, gelegentlich aber auch

Rev. SuIsSE de Zool. T. 32.1925. 
tiefer hinabsteigen. Auf subalpine und montane Lagen beschränkt sind relativ wenige Formen (17 Ar., 1 Op., 1 Ps.S.); der eigentliche Grundstock der Sammlung (84 Ar., 4 Op., 2 Ps.S.) umfasst solche, deren Heimat sich von der Ebene in die montane (47) oder gar in die subalpine Zone (43) hinein ausdehnt. Von 12 Arten liegen die bisher sicher nachgewiesenen schweizerischen Fundorte unter $800 \mathrm{~m}$ Meereshöhe; es sind dies: Atypus affinis (Eichw.), Dictyna latens (Fabr.), Drassodes microps (Menge), Prosthesima serotina (L. Koch), Pr. pusilla (C. L. Koch), Theridion tinctum (Walck.), Tetragnatha obtusa C. L. Koch, Araneus sturmi (Hahn), Chiracanthium lapidicolens Simon, Micaria chalybeia Kulcz., Trochosa robusta Sim., Heliophanus dubius C. L. Koch. Dass dieselben bei Fiesch in einer Höhenlage von 1000-1200 m. noch prosperieren, dürfte wohl auf Rechnung der bedeutenden Sommerwärme zu setzen sein.

Als südliche Formen haben nach DE Lessert (Catalogue des Invertébrés de la Suisse. Araignées, p. 603), Araneus circe (Sav.), Xysticus ninni Thorell und Thomisus albus (Gmel.) zu gelten. (Die letztgenannte Art dehnt übrigens ihren Wohnbezirk recht weit nach Norden aus!) Pholcus opilionides Schrank, Linyphia frutetorum C. L. Koch und Attulus histrio (Simon) scheinen der Nordschweiz zu fehlen oder sind wenigstens selten. Obisium lubricum (L. Koch) wird von DE LESSERT nur aus insubrischen Tälern gemeldet.

Eine Eigentümlichkeit des Walliser Haupttals, das kontinentale Klima, ist vielleicht die Ursache des spärlichen Vorkommens von Arten, die nördlich der Alpen reichlich zu finden sind. Beispielsweise war das Aussieben von Moos und Detritus in den Wäldern so ergebnislos, dass ich bald auf diese, sonst so ergiebige Fangmethode verzichtete. Es fehlen deshalb aus der Waldregion die kleinen Formen der Argiopiden fast gänzlich. Ganz auffallend war die Abwesenheit des andern Orts so gemeinen Amaurobius terrestris (Wider); diese Art findet sich sonst häufig, vom Jura bis zu den Alpen; hier bewohnt sie die Alpweiden, in der Tiefe zieht sie schattige Wälder vor; während nun für zahlreiche ihrer Wohngenossen die Eisfelder und Schneekämme der Berneralpen keine unübersteigbare Schranke bildeten, - Drassodes heeri, Dr. troglodytes, Dr. lapidosus, Gnaphosa badia, Gn. petrobia, Pardosa giebeli, P.ludovici, und andere finden sich am nördlichen und südlichen Abhang der- 
Kette in genau gleicher Weise - ist es mir nicht gelungen, in der Umgebung von Fiesch auch nur ein einziges Exemplar von Amaurobius terrestris zu erbeuten. Wohl fand sich eine Art der Gattung auf den Höhen der linken Rhonetalseite; letztere sind aber wohl schon dem Bereich des nach Aussage der Einwohner regenreichern Klimas des Binnentales zuzurechnen; der hier vorkommende Amaurobius ist anscheinend noch nicht beschrieben; er steht A. pastor (Simon) und A. mediocris (Kulcz.) nahe.

Erwähnenswert scheint mir schliesslich eine Beobachtung zu sein, die für einige Arten die Abhängigkeit der Reifezeit von meteorologischen Einflüssen darzutun scheint. Bekanntlich war der Sommer des Jahres 1924 in der nördlichen Schweiz aussergewöhnlich kühl; ich war deshalb nicht wenig erstaunt, in Fiesch den Zustand der Vegetation wie auch die Ausaperung der Schneedecke höherer Lagen viel vorgeschrittener zu finden als im vorangegangenen Jahr; auf entsprechenden Unterschieden in der Witterung beruht, wie ich vermute, der Umstand, dass 1924 einige kleine, bodenbewohnende Arten der alpinen Region, die sich 1923 häufig vorfanden, an den gleichen sowohl als an andern, ähnlich beschaffenen Orten kaum oder gar nicht zu finden waren; so erbeutete ich 1923: 22 Stück von Areoncus anguineus, 7 Typhochraestus paetulus, 84 Erigone remota, 12 Erigone cristatopalpus, 7 Macrargus adipatus und 4 Lycosa alpigena, hauptsächlich an den Hängen des Eggischhorns; 1924 war von all diesem Segen nur noch 1 Typhochraestus paetulus und 6 Erigone remota zu treffen.

Von 3 Arten der Fiescher Ausbeute: Diplocephalus foraminifer (Cambridge), Clubiona alpicola Kulczynski und Agroeca proxima Cambridge sind meines Wissens bisher noch keine schweizerischen Fundorte bekannt geworden; zwei weitere Arten von Fiesch, die Herr Dr. R. De Lessert auch in Haueten bei Zermatt auffand, Zora silvestris Kulczynski und Dipoena torva (Thorell) sind ebenfalls für die Schweiz neu; die letzt genannte Art kommt in den Nachbarländern vor; Diplocephalus foraminifer bewohnt nach Simon die französischen "Hautes Alpes" und "Hautes Pyrénées "; Clubiona alpicola stammt nach Kulczynski aus den Karpathen (Tatra); die Zugehörigkeit meines einzigen Exemplares scheint mir noch nicht unbedingt sicher; wohl aber passen die Exemplare von Zora silvestris recht gut zur Originalbeschreibung dieser sonst mehr östlichen, in Polen häufigen Art. Auch die Bestimmung von A groeca 
proxima lässt wegen der charakteristischen Epigyne dieser Species keine Zweifel aufkommen; nach Simon ist sie besonders in den Küstenregionen Westeuropas die gemeinste Form ihrer Gattung; es begegnen sich also hier im abgesehlossenen Hochtal der Rhone weit vorgeschobene Vorposten einer atlantischen und einer kontinentalen Species.

Einige Formen der Sammlung sind vielleicht neu: Echemus alberti unterscheidet sich durch den Bau der Epigyne sowohl von $E$. ambiguus Simon als von E. rhenanus Bertkau; E. castrodunensis Gétaz hat andere Bestachelung der Beine. Vorläufig kann also die Art als für das Wallis endemisch angesehen werden. Nach Simons Angaben zu schliessen, dürfte die Gattung ihr Verbreitungszentrum in Nordafrika haben. Aus Mitteleuropa werden nur 4 sicher gekennzeichnete Arten gemeldet: $E$. ambiguus aus den "Basses Alpes", E. angustifrons (Westring) aus Schweden, $E$. rhenanus aus Deutschland und Ungarn, und E. alberti aus dem Wallis; alle 4 Arten scheinen sehr selten zu sein; so kennt man von $E$. ambiguus nur 2 Stücke, von $E$. alberti nur 1 , von $E$. angustifrons sind in geschlechtsreifem Zustande nur $\hat{o} \hat{o}$ bekannt, einzig E. rhenanus scheint etwas reichlicher belegt zu sein; auch die Fundorte dieser 4 Arten sind weit auseinander gerissen.

Ein 9 von Brachycentrum de lesserti von Fiesch wurde von mir erst als $\mathrm{Br}$. ineditum (Cambridge) bestimmt; einige $\hat{o}$ ô und $q$ o 9 der gleichen Art, die mein verehrter Herr Kollege in Haueten bei Zermatt erbeutete und mir zur Beschreibung anvertraute, liessen erkennen, dass dieselbe eine Mittelstellung zwischen der erst genannten Species und Br. thoracatum (Cambridge) einnimmt. Herrn Dr. R. DE Lessert verdanke ich auch ein paar äusserst kleine Spinnchen von Haueten, die äusserlich der mitvorkommenden Diplocentria rivalis (Cambridge) ungemein ähnlich sind, deren abweichende Augenanordnung aber meines Erachtens das Aufstellen einer neuen Gattung rechtfertigt; ich nenne sie Microcentria pusilla.

Lephthyphantes jacksoni, vom Märjelensee, steht dem L. tenebricola sehr nahe, hat aber nur 1 Zahn am Paracymbium des $\hat{0}$. Sitticus muralis, von dem leider nur 1 gefunden wurde, ist dem Attulus histrio sehr ähnlich.

Anschliessend an die Liste der Fiescher Spinnen erwähne ich auf Wunsch von Herrn Dr. R. DE Lessert einige interessante 
Stücke von andern Walliser Standorten sowie aus Graubünden, die meistens durch Herrn Prof. W. Kulczynski bestimmt worden sind, über welche er aber nichts veröffentlicht hat; insofern als ein Teil des Materials verloren gegangen ist, kann ich über 3 dieser Arten nicht aus eigener Anschauung urteilen.

Ein weiterer Anhang enthält Berichtigungen früherer Angaben.

Ich gestatte mir, den Herren Dr. R. de Lessert in Buchillon und Dr. A. R. Jackson in Chester für gütige Beihilfe sowie für Ueberlassung von Material meinen verbindlichsten Dank abzustatten. Beim Einsammeln des Materials haben mich meine Knaben Hans Albert und Rudolf wirksam unterstützt. Um die Artenliste abzukürzen, sollen an Stelle ausführlicher Standortsangaben die Chiffren der nachfolgenden Fundortstabelle verwendet werden.

\section{Fundorts-Verzeichnis.}

Äa: Wald am linksseitigen Steilhang der Rhoneschlucht bei der "Lammenbrücke ", c. 1200 m.

Äb: Galgenhügel nördlich von Ernen, c. $1200 \mathrm{~m}$.

Äc: Linksseitiger Rhonetalweg von Mühlebach über Steinhaus, durchschnittlich $1250 \mathrm{~m}$.

Äd: Rücken des Erner Galen von Punkt 2264 ("Beim Schären ») bis Punkt $2743 \mathrm{~m}$.

Äe: Alpweg von Mühlebach nach dem untern Ende der Rappentaler Alpweiden, 1250-1650 m.

Äf: Neuer Alpweg von Ernen nach obigem Punkt, 1200-1650 m. Äg: Weg von Binneggen, 1353 m, über " Eggenalp » nach " Auf dem Fritt ", 1992 m.

Äh: Weg von "Auf dem Fritt », 1992 m, bis " Zu Moos » im Rappental, c. $1800 \mathrm{~m}$.

Ba: Bodmen-Eggen, 1380-1480 m.

Bb: Bellwald, Felsenheide beim Dorf.

Bc: Bellwald-Richinen, lichter Lärchenwald, 1500-2000 m.

$\mathrm{Bd}$ : Alpweiden zwischen Richinen und "Auf der Kuh ", 2100$2700 \mathrm{~m}$.

BIa: Landzunge zwischen Binna und Rhone, c. $1000 \mathrm{~m}$.

BIb: Kamm des felsigen, licht bewaldeten Rückens zwischen Binnachern und Rhone, 1000-1200 m.

BIc: Waldweg am Westabhang des obigen Rückens, c. $1000 \mathrm{~m}$. 
BId: Strasse von Binneggen bis Ausserbinn, 1353-1310 m.

BIe: Strasse von Ausserbinn bis Imfeld, 1310-1568 m, besonders Felswände der "Twingen " und Holzplatz bei Giessen.

BIf: Weg von Imfeld bis Tschampigenkeller, 1568-1884-m.

BIg: Weg zum Geisspfad (Blockhalde ob Maniboden, $2300 \mathrm{~m}$, Schneetälchen bei Punkt 2483, Passhöhe des Geisspfad, $2500 \mathrm{~m}$.)

BIh: Weg zum Ritterpass (Talboden des Kummen, südlich Kummenbord, c. $2100 \mathrm{~m})$.

Ea: Firnegarten-Fiescheralp, 1600-1900 m.

Eb: Fiescheralp-Hotel Jungfrau, 1900-2190 m.

Ec: Weg vom Hotel Jungfrau zum Märjelensee, 2190-2390 m.

Ed: Umgebung des Märjelensees, c. $2350 \mathrm{~m}$.

Ee: Weg vom Hotel Jungfrau zum Eggischhorn, unterer Teil, 2190-2400 m.

Ef: Weg vom Hotel Jungfrau zum Eggishorn, oberer Teil, 2400-2934 m.

Eg: Eggischhorn-Märjelensee, Westhang über dem Aletschgletscher, 2934-2350 m.

Fa: Fiesch, Ortschaft und nächste Umgebung, ca. $1050 \mathrm{~m}$.

Fb: Felsenheide östlich vom Dorf über der Rhoneschlucht, ca. $1095 \mathrm{~m}$.

Fc: Abkürzungen der Furkastrasse und südliches Ende des Giebeleggwaldes, ca. $1100 \mathrm{~m}$.

Fd: Wald am rechtsseitigen Steilhang der Rhoneschlucht, südlich Fürgangen, ca. $1100 \mathrm{~m}$.

Fe: Giebelegg, Kamm des bewaldeten Rückens, 1100-1300 m; lockerer Bestand von Föhren und Fichten.

Ff: Giebelegg, Abhang der Westseite, dichter-Bestand von Fichten und Lärchen.

Fg: Fieschertal, Mäuerchen am Weg, Weidengebüsch beim Mühlebach, Kiesinsel im Weisswasser, 1070-1100 m.

Fgg: Fieschertal, rechtsseitiger Talhang über dem Ende des Fieschergletschers.

Fh: Unter-Titer, Vorsässe zwischen beiden Quellarmen des Weisswassers, c. $1330 \mathrm{~m}$.

Fi: Rafgarten-Ober-Titer, nach Süden exponierter, felsiger Weidhang, darüber Wäldchen, 1350-1580 m.

Fk: Laueligraben (Weg zum Firnegarten), c. $1200 \mathrm{~m}$. 
Fl: Wald zwischen Wiler und Bärfet, 1200-1700 m.

Fm: Altbachgraben, Grenze Fiesch-Lax, kleine Lichtung mit Hauhechel, Wachholder und magerer Weide, c. $1200 \mathrm{~m}$.

Fn Altbachgraben, Fussweg von Fiesch nach Lax, c. 1100 m.

Ra: "Wurzenbord" südlich vom Hotel Bettmerhorn, 2230 m.

Rb: "Galverenbord " nordöstlich vom Bettmersee, 2100-2400 m.

Rc: Blockhalde am Hang des Bettmerhorns, über Galverenbord, c. $2400 \mathrm{~m}$.

Rd: Rücken zwischen Moosfluh (2331 m.) und Riederfurka (2078 m.).

Re: Oberer Saum des Aletschwaldes, am Hang von Rd, c. 2100 m. Rf: Weg über die Alpterrassen von Rieder-, Goppisberger-, Bettmer- und Laxeralp, 1900-2100 m.

\section{SPINNEN AUS DER UMGEBUNG VON FIESCH.}

\section{ATYPID AE}

Atypus sp. BIb, ein einziger Wohnschlauch am Waldrand, Insasse entkommen.

\section{ULOBORIDAE}

Hyptiotes paradoxus (C. L. Koch). BIb, c. 1200 m, 23. vir 1924: 1 ㅇ juv.

\section{Dicty nidae}

Ciniflo fenestralis (Ström). Fa, 24. vir 1923: 1 +, 2 juv.; Anf. viII 1923: 1 ㅇ. Fe, 13. viI 1924: 1 ㅇ. Fe, 12. vir 1923: 1 juv.; 25. viI 1923: 2 ㅇ, 2 juv.; 13. viI 1924: 1 ․ Ff, 14. vir 1924: 3 juv. Fg, 12. viI 1924: 1 ㅇ. Fm, 25. vil 1923: 2 ㅇ. Äa,

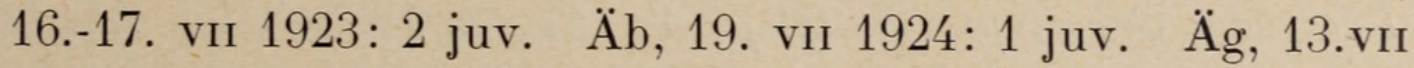
1923: 2 juv.; 2. viII 1924: 1 ㅇ. BIb: 23.-27. vir 1924: 5 juv. BId, 20. viI 1923: 1 ㅇ.

Im Mischwald von Fichten, Föhren und Lärchen unter Steinen, Moos und Rinde; wurde nicht quantitativ gesammelt. Dictyna latens (Fabricius). Fe, 12. vir 1923: 1 ㅇ.

Dictyna arundinacea (Linné). Fe, 13. viI 1924: 1 ㅇ. Bc, 15. viI 1924: 1 ㅇ․ Ra, 21. viI 1924: 1 우.

Das $q$ unter $\mathrm{Fc}$ ist beträchtlich kleiner als die andern, stimmt aber in Farbe und Behaarung des Cephalothorax mit diesen überein; auch die Epigyne ist ähnlich, nur sind die 
beiden Gruben neben dem schmalen Mittelkiel etwas weniger breit, auch ist das Geschlechtsfeld eher braun als schwärzlich. Das Sternum ist heller braun, seine Behaarung spärlicher und dunkler; die Hinterleibszeichnung ist undeutlich.

\section{DYSDERIDAE}

Harpactes drassö̈des (Simon). Ff, 25. viı 1923: 1 \%, 1 juv.; 14. viI 1924: 2 juv. Unter Moos und Steinen.

Harpactes hombergi (Scopoli). Fa, 7. viII 1924: 1 ․ BIb, 27. vII 1924: 3 juv. Unter Moos und Steinen.

Segestria senoculata (Linné). Fa, 24. vir 1923: 3 ㅇ, 3 juv.; Anf. VIII 1923: 2 ㅇ․ Fe, 12. VII 1923: 2 우 13 . VII 1924: 1 ㅇ. Fd, 16. vil 1923: 2 ㅇ. Fe, 12. viI 1923: 2 ; 13. vil 1924: 2 ; ; 17. vil 1923: 1 \%; 26 . viI 1924: 1 ㅇ. Äh, 2 . viII 1924: 1 ㅇ. Unter Coniferenrinde und Steinen.

Drassid AE

Drassodes lapidosus (Walckenaer). Fa, 17. vir 1923: 2 ㅇ (eines noch trächtig); 24. viI 1923: 3 ㅇ. Fb, 16. vir 1924: 1 ㅇ. $\mathrm{Fe}$,

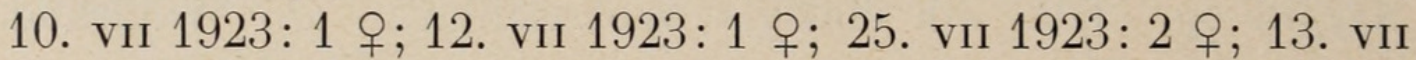
1924: 1 ㅇ․ Fh, 24. vir 1924: 1 우. Fi, 25. viI 1924: 2 ô, 1 우. Fk, 9. viI 1923: 1 ㅇ. Fm, 25. viI 1923: 1 우 ; 27. viI 1923: 2 ; 16. viI 1924: 1 ㅇ. Äb, 19.-22. viI 1924: 3 ㅇ․ Äc, 6 . viII 1924: 1 ㅇ. Äh, 2. viII 1924: 3 ㅇ․ BIb, 23.-27. viI 1924: 5 우 (Grösse variabel, ebenso der Keil der Vulva). BId, 20. viı 1923: 1 우. BIe, 26. viI 1923: 1 우. BIf, 19. viI 1924: 2 ㅇ․ $\mathrm{BIg}$, 4. viII 1924: 1 ㅇ. BIh, 7. viII 1923: 1 ․

Unter besonnten Steinen häufig; wurde nicht quantitativ gesammelt.

Drassodes pubescens (Thorell). Fg, 12. vil 1924: 1 q. Äb, 19. viI 1924: 1 ․ $\mathrm{Rd}, 9$. viII 1924: 1 ㅇ (albinotisch ? auffallend hellgelb !).

Drassodes heeri (Pavesi). Bd, 4. vin 1923: 1 ô. Ec, 21. vir 1923: 1 ㅇ juv.; 31. vir 1924: 3 ㅇ․ Ed, 21. viI 1923: 4 ô 3 ㅇ․ Ef, 10. vir 1923: 1 ô, 1 q; 7. viII 1924: 1 ․ $\mathrm{Eg}, 28$. viI 1923: 1 ô, 1 ㅇ․ $\mathrm{Rd}, 23$. vII 1923: 2 우 21 . VII 1924: 1 ㅇ; 6 . VIII 1923: 1 ô, 3 ㅇ. Äd, 31. vII 1923: 2 ô, 4 o , 2 juv.; 18. viI

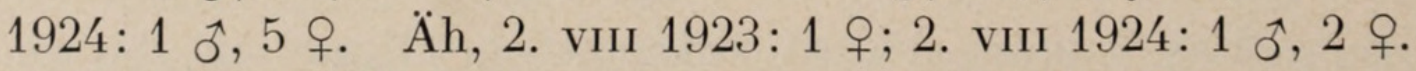
BIf, 11. viII 1924: 1 ô. BIg, 4. viII 1924: 2 ㅇ. BIh, 7. viII 1923: 8 ㅇ. Grösse bei beiden Geschlechtern sehr veränder- 
lich; unter Steinen der Alpweiden äusserst häufig, oft mehrere $q q$ bei den Eiern oder Pulli unter einem Stein; wurde nicht quantitativ gesammelt.

Drassodes troglodytes (C. L. Koch). Bd, 4. vin 1923: 1 ․ Eb, 11. vil 1923: 1 ô. Ed, 21. vil 1923: 2 ㅇ․ Ee, 9. vil 1923:

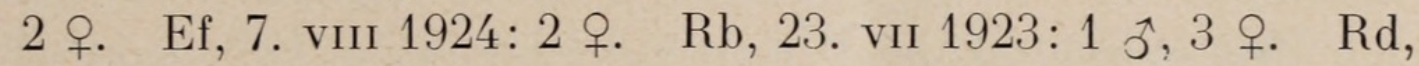
6. vili 1923: 1 ₹; 9. viII 1924: 1 ㅇ. Äd, 31. viI 1923: 6 우 18. VII 1924: 1 ô, 2 ㅇ. BIb, 23. viI 1924:1 ㅇ. BId, 20. viI 1923: 1 ô. Unter Steinen, auf den Alpweiden häufiger und stattlicher als im Tal. Grösse variabel. Die Längsfurche des Epigynenkiels ist zuweilen reduziert.

Drassodes microps (Menge). BIb, 23. viI 1924: 1 ․ $\mathrm{Zu}$ beiden Seiten des stumpfen Mittelkiels der Vulva finden sich unregelmässige, vorragende Massen aus hornhartem, schwarzem Exsudat.

**Echemus alberti n. spec. a. var. v. E. rhenanus. BIb, 27. viI, 1924: 1 \%, unter Stein.

Prosthesima subterranea (C. L. Koch). Fa, 24. vin 1923: 4 ㅇ. Ff, 25. viI 1923: 6 ․ $\mathrm{Fg}, 15$. viI 1923: 1 \% ; 12. vII 1924: 2 \%; 22. viI 1924: 1 ㅇ. Fl, 18. vil 1923: 3 ㅇ. Fm, 25. vil 1923: 1 ㅇ. Äc, 3. viII 1924: 1 ô; 6. viII 1924: 2 ㅇ. BIb, 27 . vII 1924: 3 ㅇ. BId, 28. viI 1924: 1 ㅇ․

Prosthesima apricorum (L. Koch). Fa, Anf. viı 1923: 1 ‥ Äb, 22. vil 1924: 2 ․ $\ddot{\text { Ac }} 6$. vili 1924: 2 ㅇ. BIb, 27. viI 1924: 1 ㅇ.

Prosthesima clivicola (L. Koch). Fgg, 15. viI 1923: 4 q; Anf. viII 1923: 1 ㅇ․ Ec, 21. vil 1923: 1 ㅇ. Ed, 31. vil 1924: 1 ㅇ. Äd, 31. vir 1923: 1 ㅇ. Äh, 2. vin 1924: 1 ㅇ.

Prosthesima serotina (L. Koch). BIb, 27. vir 1924: 1 ㅇ.

Prosthesima petrensis (C. L. Koch). Fa, Anf. vin 1923: 1 q. Fg, 5. viII 1924: 1 ô. Fi, 25. viI 1924: 2 q. Fm, 27. viI 1923: 2ㅇ. Äb, 22. viI 1924: $1 \hat{\jmath}, 1$ ㅇ․

Prosthesima talpina L. Koch. Ec, 31. vil 1924: 1 ․ Rd, 23. viI 1923: 1 ㅇ.

Prosthesima praefica (L. Koch). Fe, 12. vil 1923: 1 \%. Fm, 25.-27. viI 1923: 2 o ; 16 . viI 1924: 1 ㅇ. Be, 14. viI 1923: 1 o . BIb, 23.-27. viI 1924: 3 우 ; vili 1924: 1 ㅇ․

Prosthesima pusilla (C. L. Koch). Fe, 10. vir 1923: 1 ô.

Gnaphosa montana (L. Koch). Äb, 22. viI 1924: 1 q. 
Gnaphosa lugubris (C. L. Koch). BIb, 27. vir 1924: 2 ㅇ.

Gnaphosa badia (L. Koch). Bd, 14. viI 1923: 1 ᄋ; 15. vir 1924: 1 ㅇ. 4. vili 1923: 4 ㅇ. Ef, 7. vili 1924: 1 ㅇ. Ra, 21. vir 1924:

3 ㅇ. Rd, 23. vir 1923: 1 우 6. viII 1923: 1 \% ; 9. viII 1924: 3 ㅇ. Äd, 18. vil 1924: 1 ô, 5 우. Äh, 2. vili 1924: 11 ง (überaus häufig!). BIg, 4. viII 1924: 4ㅇ. BIh, 7. viII 1923: 3 우 (auf sterilem, altem Rüfenschutt, sehr klein!). Gleiches Vorkommen wie Drassodes heeri; nicht so allgemein verbreitet, dafür aber stellenweise noch häufiger; nicht selten mehrere Exemplare unter einem Stein; wurde nicht quantitativ gesammelt.

Gnaphosa petrobia (L. Koch). Ef, 7. vin 1924: 1 ㅇ. Äd, 31. viı 1923: 4 ㅇ, 1 juv.; 18. vil 1924: 2 ㅇ․

Gnaphosa bicolor (Hahn). Fe, 25. vir 1923: 1 ㅇ.

Pholcidae

Pholcus opilionides (Schrank). Fa und Fg, 14.-15. vir 1923: $3 \hat{\text { ô }}$,

5 ㅇ ; 12. vil 1924: $4 \hat{\jmath}, 3$; ; Anf. vili 1924: 5 ㅇ. In den Lücken der Grenzmäuerchen längs der Feldwege; nicht quantitativ gesammelt.

THERIDIIDAE

Episinus truncatus Latreille. BIb, 23. viI 1924: 1 q; 10. VIII 1924: 1 ऊ.

Theridion lineatum (Clerck). Fa, 14. viI 1923: 1 ô, 2 우. Fb, 24. vil 1923: $1 \hat{\jmath}$. Fe, 12. vir 1923: 1 juv.; 25. vir 1923: 1 q.

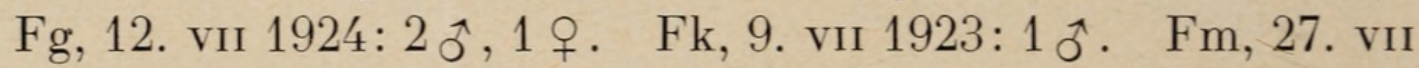

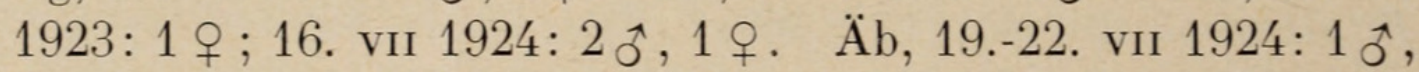
5ㅇ. Äc, 6. viII 1924: 1 ㅇ. BId, 28. vir 1924: 1 ô (nur 3 mm total). In Gras und Gebüsch häufig, wurde nicht quantitativ gesammelt.

Theridion lineatum var. redimita (Clerck). Fa, 14. viI 1923: 1 ㅇ. Ff, 25. vil 1923: 1 q. Äc, 6. viII 1924: 1 ㅇ. BId, 20. viI 1923: 1 ㅇ. .

Theridion lineatum var. ovata (Clerck). Fa, 14. vir 1923: 1 ㅇ. Theridion sisyphium (Clerck). Fc, 10.-17. viI 1923: 5 \%; Anf. viII 1923: 2 우 13. viI 1924: 1 ㅇ․ Fd, 15. vil 1923: 2 \%. Fg, 12. vir 1924: 1 ㅇ. Ba, 7. viII 1923: 1 ㅇ. BIb, 10. viII 1924: 1ㅇ․ BId, 20. u. 26. viI 1923: 4ㅇ․ BIg, 4. vili 1924: 1 ㅇ․ Auf jungen Nadelholzbüschen gemein. Wurde nur gelegentlich mitgenommen. 
Theridion impressum L. Koch. Ff, 25. vir 1923: 1 q .

Theridion nigrovariegatum Simon. Fe, 13.-17. vir 1924: 3 ot.

Theridion petraeum $\mathrm{L}$. Koch. Re, 9. viII 1924: 6 . . Wie das am Unteraargletscher, 29. vir 1916, von Dr. E. Handschin gefundene Exemplar gehören obige Stücke zur var $\gamma$ Simon; sie sind aber bedeutend grösser als jenes (bis $4 \mathrm{~mm}$ statt nur 2,5 mm), auch die Grundfarbe ist eine viel hellere, am Cephalothorax fast grünlich weiss. Die Tiere lebten beinahe unterirdisch in den tiefen, höhlenartigen Lücken der Blockhalde.

Theridion varians Hahn. BIe, 26. vil 1923: 1 ㅇ.

Theridion tinctum (Walckenaer). Fm, 16. viI 1924: 1 ㅇ.

Theridion denticulatum (Walckenaer). Fa, 18. vir 1923:1 ㅇ. Ff, 25. vII 1923: 1 ㅇ. Fg, 15. vII 1923: 5 q 17 . vII 1923: 1 ; ; 12. vil 1924: 2 ; Anf. vilI 1923: 1 ; ; 7. viI 1924: 1 q. Fi, 25. viI 1924: 1 \%. Die aus unbehauenen Steinen aufgeschichteten Grenzmauern der Grundstücke beherbergen in ihren Lücken sowohl diese als die folgende Art in ziemlicher Menge. Das Gewebe ist eine runde, senkrechte, durchsichtige Röhre, die das $q$ und seinen Eibündel umschliesst; wurden nicht quantitativ gesammelt.

Theridion formosum (Clerck). Fe, 13. viI 1924: 1 q. Fg, 15. vII 1923: 3 ㅇ, 2 juv., 1 pull.; 17 . vII 1923: 8 क , 1 juv.; 12 . vII 1924: 2 ․ Fm, 25. viI 1923: 2 ㅇ, 2 juv.; 16. viI 1924: 1 q. Äa, 15. VII 1923: 1 ô, 1 우. Äc, 3. viII 1924: 1 우. BId, 20. viI 1923: 1 ㅇ. Die Grundfarbe ist sehr veränderlich, hell-, rot- bis schwarzbraun; bei dunkeln Exemplaren sind die Beine geringelt. Das mitten im Gespinst hängende, glockenförmige Schutzdach für den Eibündel ist immer sehr geschickt mit Pflanzenresten maskiert. Wurde, weil häufig, nicht quantitativ gesammelt.

**Dipoena torva (Thorell). Bc, 14. vir 1923: 2 ㅇ.

Crustulina guttata (Wider). Fi, 25. vir 1924: 1 ㅇ.

Steatoda bipunctata (Linné). Fa, 17. vir 1923: 1 juv.; Anf. viII 1923: 1 ㅇ. Fb, 15. vil 1923: 1 ㅇ․ BIb, 27. viI 1924: 1 ㅇ․ BId, 28. vir 1924: 1 juv. Alle Exemplare wurden im Freien gefangen.

Lithyphantes corollatus (Linné) var. infuscata nov. var. Fi, 25. viI 1924: 8 ㅇ. 
Asagena phalerata (Panzer). Fg, 24. viI 1923: 1 ô; 5. viII 1924:

1 우. Fm, 25. vir 1923: 1 ô. BIe, 26. vir 1923: 1 ô.

Robertus lividus (Blackwall). Ed, 21. viI 1923: 1 ô. Rb, 6. viII 1923: 1 우. Äf, 10. viI 1923: 1 ๙.

Robertus truncorum (L. Koch). Fi, 25. vir 1924: 1 oิ, 3 ㅇ. Re, 6. viII 1923: 1 우.

Argiopid AE

Ceratinella brevis (Wider). Ff, 14. vII 1924: 1 ô, 3 ㅇ. Fi, 25. vII 1924: 1 우. Äb, 19. viI 1924: 1 ㅇ․ BIc, 30. viI 1924: 1 ㅇ․

Ceratinella brevipes (Wider). Bd, 4. viII 1923: 1 ㅇ. Ef, 7. viII 1924: 1 ㅇ.

**Brachycentrum de lesserti nov. spec. Fi, 25. vir 1924: 1 ․ Areoncus anguineus (L. Koch). Fe, 18. vir 1923: 1 ô. Ee, 9. viI 1923: $16 \widehat{\jmath}$. Ef, 10. viı 1923: 5 ô. Auf nackten, durch alten Humus schwarz gefärbten Stellen zwischen Polsterpflanzen; in Gesellschaft von Erigone remota und kleinen Collembolen.

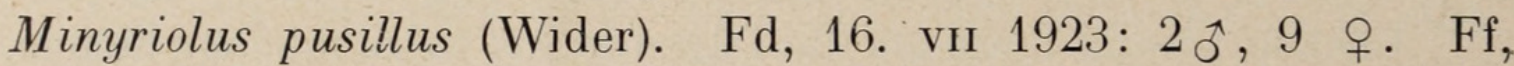
14. vil 1924: 12 ㅇ. Äf, 10. viI 1923: $2 \hat{\jmath}, 1$ ㅇ․ BIb, 23.-24.

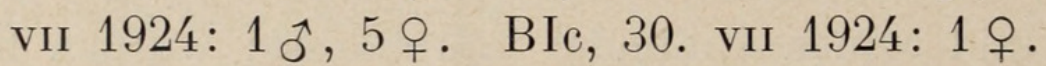

**Diplocephalus foraminifer (Cambridge) a. sp. aff. Ec, 31. viI 1924: 1 오.

Diplocephalus eborodunensis (Cambridge). Ef, 7. viII 1924: $1 \hat{\jmath}$.

$\mathrm{Eg}, 28$. vir 1923: 3 ๙ै, 3 ㅇ․ $\mathrm{BIg}$, 4. vili 1924: 2 ㅇ․

Diplocephalus helleri (L. Koch). Ee, 9. viI 1923: 1 \%. Rd, 6. viII 1923: 1 우 ; 9. viII 1924: 1 ㅇ․

Tapinocyba pallens (Cambridge). Fd, 16. vin 1923: 1 §ै, 1 우. Ff,

14. VII 1924: 1 o. BIb, 23. VII 1924: 1 ㅇ.

Tapinocyba affinis de Lessert. Fi, 25. vir 1924: 3 ㅇ.

Styloctetor brocchus (L. Koch). Ef, 7. vin 1924: 1 ô.

Scotinotylus antennatus (Cambridge). Eg, 28. vir 1923: 1 ㅇ. Rd, 9. viII 1924: 1 ㅇ. Äd, 31. viI 1923: 1 q ; 18. viI 1924: 1 ㅇ. Walckenaera cucullata (C. L. Koch). var. ? Ff, 14. vir 1924: 1 ㅇ. BIb, 24. vir 1924: 1 ㅇ.

Walckenaera cuspidata Blackwall. Re, 6. viı 1923: 2 ㅇ. Äf, 10. VII 1923: 2 ㅇ.

Walckenaera vigilax (Blackwall). Ed, 28. viI 1923: 1 ㅇ ; 31. vII 1924: 1 ㅇ. Ef, 9.-10. viI 1923: 2 ô, 1 ㅇ․

Typhochraestus paetulus (Cambridge). Bd, 4. vin 1923: $2 \hat{\jmath}$. Ee, 


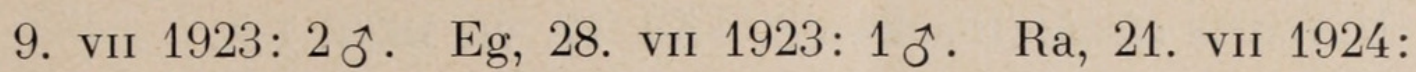
1 ڤิ. Äd, 31. vir 1923: $1 \hat{\jmath}, 1$ ㅇ․

Gonatium rubens (Blackwall). Rd, 23. vil 1923: 1 q (dunkler als norddeutsche Exemplare; der Bau der Epigyne stimmt aber überein).

Oedothorax retusus (Westring). Fg, Kiesinsel im Weisswasser, unter Steinen und Anspülicht sehr häufig, weshalb nicht quantitativ gesammelt: 5. vilı 1924: $15 \hat{\jmath}, 5$ q, 2 juv.

Erigone remota L. Koch. Bd, 4. viII 1923: 27 §ิ, 6 ㅇ. Ed, 21.-28. vil 1923: 7 ô, 3 ㅇ. Ef, 2400-2600 m, 9.-10. vil 1923:

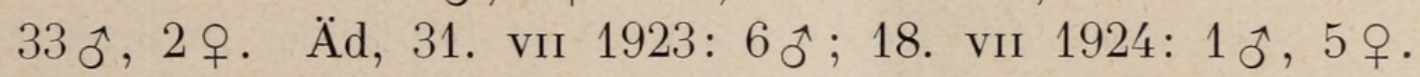
1923 sehr zahlreich; die Tiere liefen meist auf noch nicht lange ausgeaperten, ebenen, mit schwarzem Humus bedeckten Stellen, die sich zwischen die Vegetationspolster einschoben, im grellen Sonnenlicht umher, teilweise in Gesellschaft von E. cristatopalpus, Areoncus anguineus und zahlreichen kleinen Collembolen. Auf "Auf der Kuh " fanden sie sich auch unter Steinen, die in den Polytrichiumrasen verlandeter Tümpel eingestreut waren. 1924 war an den gleichen oder analogen Stellen gar nichts, nur an einem Ort wenige $q$ 우 und $1 \hat{\sigma}$ aufzufinden; in diesem Jahr war aber sowohl die Ausaperung als auch die Vegetation viel vorgeschrittener trotz dem kühlen, feuchten Vorsommer.

Erigone cristatopalpus Simon var. leptocarpa Simon. Ef, 9.-10. viI 1923: $12 \hat{\sigma}$.

Erigone dentipalpis (Wider). Bd, 4. viII 1923: 1 ․ $\quad$ Rd, 23. viI 1923: 1 ठิ.

Hilaira montigena (L. Koch). Ef, 7. vin 1924: 1 ㅇ․ Eg, 28. viI 1923: 8 ㅇ. Re, 6. viII 1923: 1 ô. BIg, 4. viII 1924: 4 ㅇ.

Hilaira rudis (Cambridge). Re, 6. viII 1923: 3 ㅇ (sehr klein). Äf, 10. viI 1923: 3 ㅇ.

Centromerus affinis (Wider). Ec, 31. viI 1924: 3 \%. Ee, 9. viI 1923: 2 ㅇ. Ef, 7. vin 1924: 2 ㅇ․ Re, 6. viri 1923: 1 ㅇ.

Macrargus adipatus (L. Koch). Ef, 9.-10. vir 1923: 1 고 3 우. Eg, 28. vil 1923: 1 우. Bd, 4. viII 1923: 2 ㅇ.

Leptorhoptrum huthwaithi (Cambridge). Ed, 21. vil 1923: 2 ㅇ. $\mathrm{Eg}, 28$. viI 1923: 1 ๙ิ, 3 ㅇ․

Microneta glacialis (L. Koch). Bd, 4. vin 1923: 1 ô, 9 守, 1 juv.

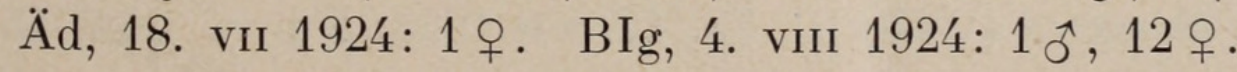


Microneta viaria (Blackwall). Äd, 17. vir 1923: 1 ․

Microneta subtilis (Cambridge). Fd, 16. vir 1923: 1 $\widehat{0}, 1$ ㅇ․ Ff, 14. viI 1924: 7 ㅇ. BIb, 23. vil 1924: 2 q.

Micryphantes gulosus (L. Koch). Ef, 7. vin 1924: 1 ๙ , 1 ․ . Äh,

2. VIII 1924: 1 우. BIh, 7. viII 1923: 1 ô, 1 우.

Bathyphantes concolor (Wider). Fa, 24. vil 1923: 2 ㅇ․

Bathyphantes gracilis (Blackwall). Äf, 10. viı 1923: 1 ㅇ. Das

Exemplar zeigt geringe Unterschiede im Bau der Epigyne:

Die gewölbte Decke des Geschlechtsfeldes hat hinten eine seichte Einbuchtung in der Mitte. Die Rinne auf der Hinterseite unter der Decke ist nicht so breit; der in ihrer Mitte emporragende Zapfen steht mehr gerade auf und deckt die mittlere Oeffnung teilweise zu; bei typischen B. gracilis ist derselbe mehr nach hinten gerichtet und lässt die Oeffnung meist frei; ob individuelle Abweichung?

Lephthyphantes leprosus (Ohlert). Fg, 15. vir 1923: 1 우 (ziemlich klein).

Lephthyphantes terricola (C. L. Koch). Äf, 10. vir 1923: 1 ô, 1 q. Lephthyphantes frigidus Simon. Ed, 21. vil 1923: 1 오 Ee, 9. viI 1923: $2 \hat{\jmath}, 2$ ㅇ. Rd, 6. viII 1923: 1 ㅇ. Äd, 18. viI 1924: 1 우.

Lephthyphantes monticola (Kulczynski). Re, 6. viII 1923: 1 ㅇ.

Lephthyphantes lepidus (Cambridge). Fi, 25. viI 1924: 2 ㅇ. Lephthyphantes mughi (Fickert). Äf, 10.viI 1923:2 ㅇ.

Lephthyphantes tenebricola (Wider). Ff, 14. viI 1924: 1 ô, 4 q. Fi, 25. viI 1924: 1 ㅇ. Äa, 17. vir 1923: 1 ô, 1 q.

**Lephthyphantes jacksoni nov. spec. Ec, 21. viI 1923:1 §. Ef, 7. viII 1924: 1 ㅇ․

Lephthyphantes flasipes (Blackwall). Fb, 16. viI 1924: 1 ๙ .

Lephthyphantes mengei Kulczynski. Fg, 12. viı 1924: 1 ô. Fi, 25. VII 1924: 1 ㅇ.

Lephthyphantes keyserlingi (Ausserer). BIb, unter Stein, 27. viI 1924: 1 ô. Ich finde nirgends erwähnt, dass der absteigende Gabelast der Lamella characteristica des Bulbus seinerseits ein kleines Endgäbelchen besitzt.

**Lephthyphantes pinicola Simon. var. valesiaca nov. var. BIb, 23. VII 1924: 1 ㅇ․

Lephthyphantes handschini Schenkel, Var. Ef, 10. viI 1923: 1 ㅇ. Labulla thoracica (Wider). Fa, 17. viI 1923: 2 juv. Fm, 15. viI 
1923: 1 juv. Äa, 17. vil 1923: 1 juv. BIb, 8. vili 1924:

1 juv. BId, 20. vir 1923: 1 juv.

Linyphia phrygiana C. L. Koch. Bc, 15. viI 1924: 1 ㅇ.

Linyphia triangularis (Clerck). Fa, 14. viI 1923: 3 juv. Fe, 10. viI 1923: 1 juv.; 25. vir 1923: 1 juv.; 13. vir 1924: 1 juv. Fl, 18. vir 1923: 2 juv. Fm, 27. vir 1923: 1 juv.; 16. vir 1924: 1 juv.; 26. viI 1924: 3 ๙ิ. Äb, 19. viI 1924: 1 juv. BIb, 10. viII 1924: 1 ô. BId, 20. vir 1923: 1 juv.

Linyphia marginata C. L. Koch. Fa, 14.-17. viI 1923: $4 \hat{0}, 4$ q ;

Anf. vili 1923: 1 ô, 2 ㅇ․ Fb, 24. viI 1923: 1 ㅇ ; 16. vil 1924: 3 ㅇ. Fe, 10.-12. viI 1923: 4 우 25 . viI 1923: 1 q ; 13.-14. viI 1924: 2 ๙ิ, 2 ㅇ․ Fg, 12. vir 1924: 1 ㅇ. Fm+n, 25. viI 1923: 1 우 16. vil 1924: $2 \hat{\jmath}, 6$ q. Fl, 18. viI 1923: 1 ㅇ. Äc, 6. vili 1924: 1 q. Ä, 10. vil 1923: 1 q. BIb, 23.-27. viI 1924: 2 ㅇ. Die Gewebe dieser und der vorhererwähnten Art waren auf jungen Coniferen häufig; beide Species wurden nicht quantitativ gesammelt.

Linyphia frutetorum C. L. Koch. Fc, 12. viI 1923: 1 q ; 13. vII 1924: 6 ㅇ․ Fm, 17. vil 1923: 1 q; 16. viI 1924: 2 ㅇ․ Mit den beiden vorhergehenden Arten zusammen, aber viel seltener.

Linyphia peltata Wider. Fa, 17. vir 1923: 2 q. Fl, 18. vir 1923:

1ㅇ. Äb, 19. viI 1924: 1 ㅇ..

Linyphia pusilla Sundevall. BIe, 26. vir 1923: 1 ㅇ.

Bolyphantes alticeps (Sundevall). Äc, 3. viı 1924: 1 q, 1 juv.

Bolyphantes luteolus (Blackwall). BIg, 4. vin 1924: 1 ㅇ.

Pachygnatha degeeri Sundevall. Fa, 15. vil 1923: 1 ㅇ.

Tetragnatha extensa (Linné). Fa, 17. vir 1923: 1 \%; Anf. viri 1923:

1 ․ $\mathrm{Fg}, 12$. VII 1924: 1 ๙ิ, 1 q ; 5 . VIII 1924: 1 \%; 24 . VII

1924: 4 q (ob dem Weiler Platten; Netze quer über einem

Wässerungsgraben).

Tetragnatha obtusa C. L. Koch. Fm, 25. vir 1923: 1 ㅇ.

Meta segmentata (Clerck). Fa, 17. viI 1923: 1 juv. Bc, 14. viI 1923: 1 juv. BId, 28. vir 1924: 1 ô. BIe, 26. vir 1923: 1 우. Meta merianae (Scopoli). Fa, 15.-17. viI 1923: 1 ô, 1 \% ; Anf. viII 1923: 2 ․ BIc, 30. vir 1924: 1 juv.

Cyclosa conica (Pallas). Fa, Anf. vin 1923: 1 ㅇ. Fe, 12. vir 1923: 1 ㅇ ; 13. viI 1924: 1 ․ Ff, 25. VII 1923: 1 q. Bc, 14. viI 1923: 1 ㅇ. Äh, 2. viII 1923: 1 ㅇ. BIb, 10. viII 1924: 1 ㅇ․ 
BId, 20. vir 1923: 2 ㅇ. BIe, 26. vir 1923: 1 ㅇ. Wurde nicht quantitativ gesammelt.

Mangora acalypha (Walckenaer). Fb, 24. vil 1923: 1 ․ . Fe, 12. viI 1923: 1 ㅇ ; 13. viI 1924: 1 우. Fm, 27. viI 1923: 1 ㅇ․ BId, 20. viI 1923: 1 q.

Araneus (Epeira) circe (Savigny). "Bei den hohen Flühen " unterhalb Mörel, unter Felsblock, 14. viı 1924: 1 \% .

Ar. (Epeira) omoedus (Thorell). Fe, 10. vir 1923: 3 juv. Fm, 25. vir 1923: 1 우 (im Versteck, im Wipfel eines hochgewach-

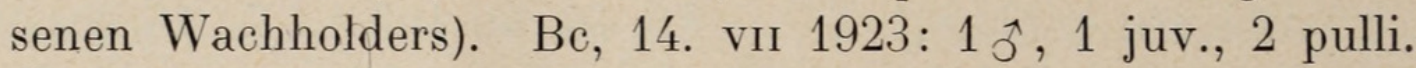
Äf, 10. vir 1923: 1 juv. BIe, 26. viı 1923: 1 ๙ै.

Ar. (Epeira) diadematus Clerck. Fa, 15. vi 1923: 1 q. Fc, 12. vir 1923: 1 juv. Ff, 25. vir 1923: 1 q. Fm, 27. vir 1923: 1 ๙ิ,1 1 . . Weg Märjelensee-Fieschergletscher-F.-Tal, 21. viı 1923: 1 ㅇ, 2 juv. (bei zwei Exemplaren aus Geröllhalden erinnert die Färbung an Ar. carbonarius). Äf, Blockhalde am untern Ende der Alp bei einer Quelle, 1650 m, 2. viII 1924: 1 ㅇ (graue Farbe dem Substrat sehr angepasst). BIa, 1. vilI 1924: 1 ㅇ, 1 juv. BIe, 26. vir 1923: 2 ㅇ. . BIf, 11. viII 1924: 1 ๙ิ. BIh, 7. vin 1923: 1 q (dunkelbraun, Beine rötlich). Die häufige Art wurde nicht quantitativ gesammelt.

Araneus (Epeira) quadratus Clerck. Ba, 7. viı 1923: 4․ Ra, 21. vil 1924: 1 q. $\mathrm{Rd}, 23$. viI 1923: 1 ^^. Re, 6.-9. viII 1924: 5 ․ (Am obern Saum des Aletschwaldes waren die Netze in den Alpenrosenbüschen sehr häufig.) Äd, 31. vir 1923: $1 \widehat{\jmath}$. BIf, 11. viII 1924: 1 ㅇ. BIg, 4. viII 1924: 1 ㅇ. An denselben Fundorten fanden sich sowohl gelbbraune wie rotbraune Exemplare. Der Clavus der Epigyne ist zuweilen abgebrochen oder eingeschrumpft. Wurde nicht quantitativ gesammelt.

Ar. (Epeira) cucurbitinus Clerck. Fe, 12. vir 1923: 1 $\hat{0}, 1$ \% ; 13. vil 1924: $1 \hat{\jmath}$. Fg, 5. viII 1924: 1 ๙ै. Fm, 27. viI 1923: 1 q ; 16. vir 1924: 1 ㅇ․ Fn, 26. vir 1924: 1 ㅇ․ Be, 14. vir 1923: 1ㅇ. Äb, 19. viI 1924: $1 \hat{\jmath}, 2$ ㅇ. BIe, 26. viI 1923: $1 \hat{\jmath}$. Wurde nur gelegentlich mitgenommen.

Ar. (Epeira) cucurbitinus Clerck, subsp. opisthographa Kulczynski. Fe, 10. viI 1923: $1 \hat{\jmath}$. Fk, 9. viı 1923: 1 ․ Fm, 27. VII 1923: 1 오.

Ar. (Epeira) alpicus L. Koch. Fa, 17. vil 1923: 1 ㅇ․ Bc, 15. VII 1924: 1 우. 
Ar. (Epeira) sturmi (Hahn). Fe, 10. vII 1923: 1 q ; 25. vir 1923: 1 t.

Ar. (Epeira) ceropegius Walkenaer. Fa, 14.-17. vir 1923: $2 \hat{0}$, 3 ㅇ. $\mathrm{Fb}, 15$. VII 1923: 1 ; ; 16. VII 1924: 1 o . Fe, 12. vII 1923: 1 क , 1 juv., 1 pullus; 13. vir 1924: 1 o . Fg, 12. vir 1924: $3 \hat{\jmath}, 4$ + ; 5. viII 1924: 1 ô. Be, 14. viI 1923: 1 q, 2 juv. Ec, 21. vir 1923: 1 oै. Ed, 21. vir 1923: 1 क , 1 juv. Rd, 23. vir 1923: 5 ㅇ ; (ein Exemplar ist kleiner und dunkler, ähnlich A. carbonarius). Äb, 19. vil 1924: 1 q. Äh, 2. viII 1923: 2 ㅇ. BIb, 12. viI 1923: 1 ㅇ․ BId, 20. vil 1923: 1 ô, 2 ㅇ. BIe, 26. viI 1923: 3 ô. BIa, 1. viII 1924: 1 q. Wurden nicht quantitativ gesammelt.

Ar. (Epeira) carbonarius (L. Koch). Ed, 21. viI 1923: 5 juv.; 31. vil 1924: 1 q. Re, 6. viII 1923: 4 juv. Re, 6. viII 1923 (keins erwischt!). Wenn sich die Tiere im Versteck neben dem Rad aufhalten, lassen sie sich bei drohender Gefahr sofort in die Tiefe der Blocklücken fallen.

Ar. (Epeira) patagiatus Clerck. BIf, 11. vin 1924: $1 \hat{\jmath}$.

Ar. (Singa) albovittatus (Westring). BIe, 26. viI 1923: 1 \% ; die Blattzeichnung des Hinterleibs ist breit, fast so hell wie die weissen Seitenbinden; die trennenden Grenzen sind schwach ausgeprägt.

Araneus (Zilla) montanus (C. L. Koch). Fg, 15. vir 1923: 1 juv. $\mathrm{Ba}$, 7. viII 1923: 1 \& 1 juv. Be, 14. vir 1923: 2 juv. Ea, 11. vir 1923: 1 o. Ec, 31. vir 1924: 2 juv. Äf, 10. viI 1923: 2 sิ, 2 q, 2 juv. BIg, 4. virI 1924: 2 q. Wurde nur gelegentlich mitgenommen.

THомisidae

Thomisus albus (Gmelin). Fb; 24. viI 1923: 1 \%, 1 juv. Fe, 13. viI 1924: 1 స. BIa, 1. viII 1924: 2 juv.

Misumena vatia (Clerck). Fb, 16. vir 1924: 1 juv. Fe, 12. viI 1923: 1 ô, 6 juv. Ff, 25. vir 1923: 1 juv; 13. vir 1924: 1 q. Fg, 12. vir 1924: 2 ㅇ. Fm, 27. viI 1923: 2 juv. Äb, 19. viI 1924: 2 ऊิ. Äc, 6. viII 1924: 1 juv. BIb, 10. viII 1924: 1 ․ BId, 20. vir 1923: 1 juv. Nur gelegentlich gesammelt.

Diaea dorsata (Fabricius). Fe, 12. viI 1923: $1 \mathrm{o}^{\hat{0}}$. Fm, 27. vII 1923: 1 juv. BIb, 23. vir 1924: 1 ; 10 . virI 1924: 1 juv. Oxyptila trux (Blackwall). Ff, in Moos, 14. vII 1924: $3 \hat{0}, 5$ ㅇ.

Rev. Suisse de Zool. T. 32. 1925. 
Xysticus gallıcus Simon. Fe, 12. viI 1923: 1 ㅇ. Ea, 11. viI 1923: 1 ô. Ee, 21. viI 1923: $3 \hat{o}, 1$ ㅇ. Äh, 2. viII 1924: 1 오, sehr dunkel, an $X$. robustus erinnernd.

Xysticus kochi Thorell. Fb, 15. vir 1923: $1 \hat{\jmath}$, sehr klein. Xysticus kochi, Var. BIb, 27. viI 1924: 1 ㅇ.
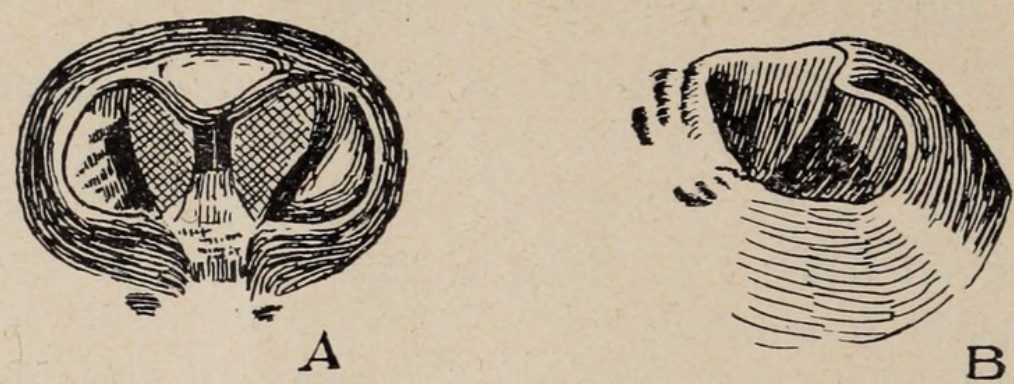

FIG. 1.

Xystıcus kochi Thorell, var. ㅇ.

$\mathrm{A}=$ Epigyne von unten. $\mathrm{B}=$ Epigyne von der Seite.

Der Vorderrand der Epigynengrube bildet zunächst einen stumpfwinkligen Vorsprung in der Mitte; rechtwinklig zu dessen abgerundeter Spitze senkt sich der Mittelkiel steil in die Tiefe der Grube hinunter. Aehnlich verhalten sich 3 Exemplare aus der Umgebung Basels; bei einem derselben sind, wie beim Fiescher Exemplar, die absteigende Partie des Mittelkiels und die Seitenwände der Grube schwarz.

Xysticus cristatus (Clerck). Fg, 12. viI 1924: $1 \overbrace{}^{\star}$. BId, 20. viI 1923: 2 수, 1 우.

Xysticus pini (Hahn). Fa, Anf. vin 1923 und 1924: $2 \hat{\jmath}$. Fd,

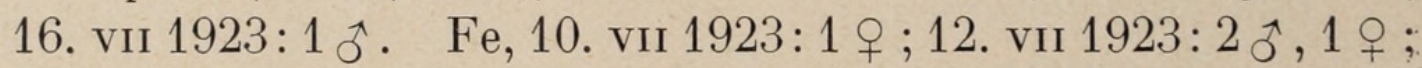
25. VII 1923: 1 ô; 13. VII 1924: 1 ㅇ․ Fm, 25. VII 1923: 1 우, 1 juv. Bc, 14. vir 1923: 1 ๙ิ. Äb, 19. vir 1924: $1 \hat{\jmath}$. Äc, 3. viII 1924: 1 ㅇ. BIg, 4. viII 1924: 1 ㅇ․

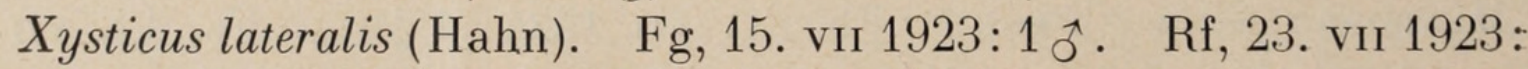

$1 \hat{\sigma}$, sehr klein und dunkel.

Xysticus glacialis L. Koch. Bd, 15. vin 1924: 1 ㅇ ; 4. vili 1923: 1․ ․ Ec, 21. viI 1923: 1 \%. Ed, 21. vil 1923: 5 q. Ef, 10. vil 1923: 3 ㅇ․ $\mathrm{Eg}, 28$. viI 1923: 1 ㅇ․ Ra, 21. vir 1924: 2․ Rb, 6. viII 1923: 2 ㅇ. Rd, 23. viI 1923: 1 ㅇ ; 9. viII 1924: 5 ㅇ. Äd, 31. viI 1923: 6 ㅇ ; 18. viI 1924: 2 ․ BIg, 4. viII 1924: 4 ? . Stellenweise überaus häufig, oft mehrere 
q $q$ mit Eierbündeln unter einem Stein; wurde nicht quantitativ gesammelt. Vor der Eiablage ist die Epigyne normal gestaltet, nach diesem Zeitpunkt meist \pm beschädigt, verharzt, zuweilen sogar verdreht; davon abgesehen, ist die Epigyne auch sonst sehr variabel, namentlich die Breite des Mittelkiels. Die Grundfarbe des Körpers ist sehr unterschiedlich, hellbraun bis fast schwarz.

Xysticus erraticus (Blackwall). Fa, 14. vir 1923: 1 ô, 1 o ; Anf. vin 1923: 1 ô. Fe, 26. vir 1924: 1 우. Fk, 9. vir 1923:1 수. Fm, 16. VII 1924: $1 \hat{0}$.

Xysticus ninnii (Thorell). Fb, 24. vir 1923: 1 o ; 16. vir 1924: 1 ô,

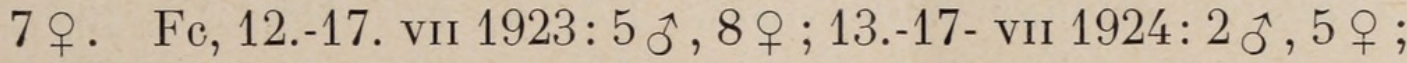
Anf. viII 1923: 1 ภ , 1 ㅇ. Fm, 27. viI 1923: 1 ㅇ. Bb, 14. viI

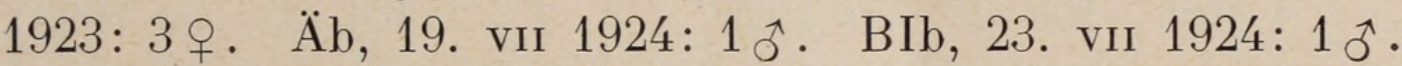
BId, 20. vir 1923: 3 q ; 28. viI 1924: 1 ô. BIf, 11. viII 1924: 1 ㅇ.

Xysticus robustus (Hahn). BIb, 23. vir 1924: 1 q. Die Epigyne dieser Art ist nicht immer gleichgestaltet. Aut die Vulva des vorliegenden Exempląres passt die Beschreibung in DE LESSERT, Catalogue p. 378, nicht aber die Fig. 18a, Taf. III, der Araneæ Hungariæ von Kulczynski. 2 q $q$ aus der Maingegend (Unterfranken), die ich sah, repräsentieren gerade beide Typen. Synaema globosum (Fabricius). Fb, 24. vil 1923: 1 q, 2 juv.; 16. viI 1924: 1 juv. Fl, 18. vir 1923: 1 juv. Fm, 27. viI 1923: 1 juv. BIa, 1. viII 1924: 2 juv. BIb, 27. vir 1924:

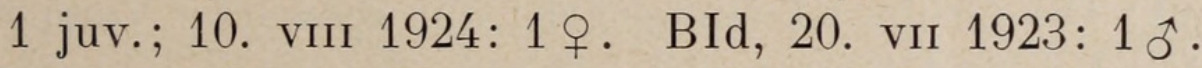

Philodromus dispar Walckenaer. Fk, 9. vil 1923: 1 ․ BIa, 1. viI 1924: 1 q, klein, Zeichnung erinnert an Ph. alpestris.

Philodromus margaritatus (Clerck), var. tigrina (de Geer). Fe, 10. vir 1923: 1 juv.; BIb, 27. vir 1924: 1 juv.

Philodromus emarginatus (Schrank). BId, 28. viI 1924: 1 ㅇ. BIf, 11. VIII 1924: 1 ㅇ.

Philodromus alpestris, L. Koch. Fi, 25. viI 1924: 3 . $\mathrm{Ba}$, 7. viII 1923: 1 q. Äh, 2. viII 1924: 1 o. BIe, 26. vil 1923: 6 ㅇ. BIf, 11. viII 1924: 2 q. BIg, 4. viII 1924: 1 q. Besonders häufig in kleinen Nischen an Felswänden. Das den Eiersack deckende, seidig glänzende Gewebe schmiegt sich dicht der Felsfläche an; die $q$ \& sitzen mit gespreizten Beinen mitten drauf. 
Philodromus collinus C. L. Koch. Fe, 10.-12. viI 1923: $1 \hat{\jmath}, 1$ ㅇ 13. viI 1924: $2 \hat{\circ}$. Fh, 9. vir 1923: 1 ㅇ. Ec, 21. viI 1923:

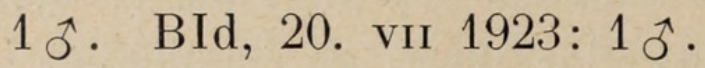

Philodromus aureolus (Clerck) subsp. similis Kulczynski ?. Äc,

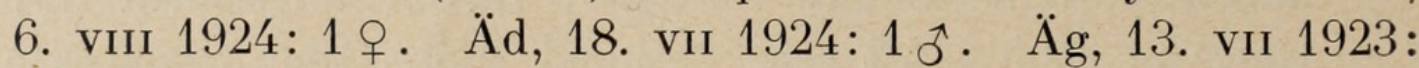
1 역 $\mathrm{BIe}_{i}$ 26. viI 1923: 1․ BIf, 11. viII 1924: 4 우. Die $ㅇ+$ passen nicht ganz zu der Beschreibung in Aran. Hungar. p. 109: In der dunkeln Seitenbinde der Kopfbrust fehlen die 3 weissen Flecke. Die Femora sind zwar verdunkelt, aber nicht eigentlich geringelt; dagegen ist ein dunkler Mittelstrich in der weissen Thoraxbinde \pm erkennbar.

Thanatus alpinus Kulczynski. Bd, 4. viII 1923: 1 juv. Ec, 21. VII 1923: $1 \hat{\jmath}$ (frei am Weg). Eg, 28. viI 1923: $1 \hat{\jmath}$, 1 juv. Ra, 21. viI 1924: 1へิ, 2 ㅇ. Rd, 23. vir 1923: $1 \hat{\jmath}$, 2 juv.; 9. vin 1924: 1 q, 2 juv. Rf, 23. vir 1923: 1 q. Äd, 18. VII 1924: $1 \hat{\jmath}$.

Tibellus oblongus (Walckenaer). BIe, 26. viI 1923: 1 ô.

Chubionidae

Micrommata virescens (Clerck). BId, 20. vir 1923: $1 \hat{\jmath}, 1$ ․ Bif, 11. viII 1924: 1 ․ $\mathrm{BIg}$, 4. viII 1924: 1 juv.

Clubiona corticalis (Walckenaer). Fe, 26. viI 1924: 1 ㅇ. Fm, 25.-27. vil 1923: 1 q, 1 juv. BIb, 27. vir 1924: 1 ․ Die Tiere befanden sich unter Steinen bei frisch geschlüpften Jungen im Gewebe. Die Epigynen sind nicht ganz normal gebaut: Die Grube ist einheitlich; nur schwache Vorsprünge des Vorder- und Hinterrandes deuten die Zweiteilung an.

Clubiona reclusa Cambridge. Fa, 17. viI 1923: 1 ㅇ. Äc, 6. viII 1924: 1 ㅇ․ BIe, 26. vir 1923: 1 ô, 1 오. BIf, 11. viII 1924: 1 oิ, 12 ㅇ․ Die meisten Exemplare sind sehr dunkel gefärbt; einige fanden sich in zusammengerollten Blättern eingesponnen.

**Clubiona alpicola Kulczynski a. sp. affinis. BIh, 7. vin 1923: 1 ‥

Clubiona hilaris Simon. Fa, Anf. viII 1923: 1 q . Fi, 27. viI 1924: 1 ㅇ․ Ra, 21. vil 1924: 2 ô. BIe, 26. viI 1923: 2 ㅇ․ BIf, 11. viII 1924: $1 \hat{\jmath}, 1$ ㅇ․

Clubiona neglecta Cambridge. Äc, 6. viII 1924: 1 \% . BIe, 26. viI 1923: $1 \hat{\jmath}$. Die beiden rundlichen Oeffnungen am Hinterrand 
der Epigyne sind ganz wenig grösser und näher beisammen als bei einem Exemplar aus der Umgebung Basels; die runden Samentaschen schimmern nicht so deutlich durch; die in der Ventralansicht linksseitige ist etwas kleiner als die rechte. Die winklig gebogenen Gänge, die zu den erst erwähnten Oeffnungen führen, lassen sich mehr ahnen als wirklich sehen; offenbar sind sie leer.

Clubiona compta C. L. Koch. Fe, 10. vir 1923: 1 ㅇ.

Chiracanthium punctorium (Villers). Äc, 3. vin 1924: $1 \hat{\jmath} ; 6$. vIII 1924: 2 ㅇ. BIf, 11. viII 1924: 2 ․

Chiracanthium lapidicolens Simon a. sp. aff. BIf, 11. vin 1924: 1 ㅇ.

**Zora silvestris Kulczynski. Fe, 12. viI 1923: 1 ㅇ․ Fm, 16. viI 1924: 2 ㅇ. BIb, 27. viI 1924: 2 오.

Zora nemoralis (Blackwall). Fa: 1 ․ Ff, 14. viI 1924: 1 juv. BIc, 30. viI 1924: 2 juv.

Zora spinimana (Sundevall). BIc, 30. vir 1924: 1 juv.

**A groeca proxima Cambridge. Äc, 6. vilI 1924: 1 + . BIc, 30. VII 1924: 1 ㅇ.

Phrurolithus festivus (C. L. Koch). Fi, 25. viı 1924: 1 ô. Micaria chalybeia Kulczynski. Fg, 12. viI 1924: 1 Pärchen ( ô reif, q unreif) zusammen im Gespinst in zusammengerolltem, dürrem Blatt. Äc, 3. viII 1924: 1 ô. BId, 28. viI 1924: 10 .

Micaria formicaria (Sundevall). Fa, 25. vil 1923: 1 q (frei auf der Strasse). Fg, 4. viII 1924: 1 q (in Himbeerblattrolle). Die beiden Arten wurden nach Kulczynski (Ar.Hung.) und nach DE Lessert (Catalogue) bestimmt; dass das zuletzt erwähnte $q$ genau am gleichen Ort wie das Pärchen der andern Art, und unter denselben Umständen nur 1 Monat später gefunden wurde, ist auffällig.

Micaria scenica Simon. Rd, an sonnigen Stellen, 23. vir 1923: 2ㅇ. BIf, 11. vin 1924: 1 ㅇ․ Die Epigyne passt besser zur Beschreibung als zur Zeichnung in DE LEssert, Catalogue; weisse Streifen an den Beinen sind \pm verschwindend.

Micaria breviuscula Simon. Bd, 4. viII 1923: 1 . . Ec, 21. viI

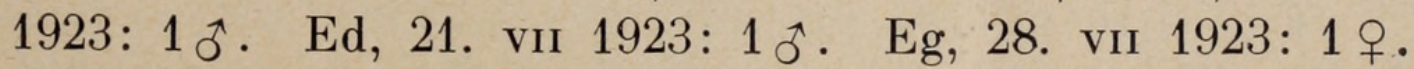

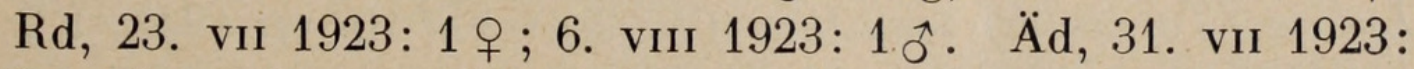
2 수, 1 우; 18. VII 1924: 1 우. 


\section{Agelenidae}

Textrix denticulata (Olivier). Fa, 14.-18. vir 1923: 1 ô, 1 \& , 2 juv. Fe, 1. viII 1924: 1 ㅇ. Fg, 15. viI 1923: 1 q ; 12. viI 1924: 1 ภิ, 1 ㅇ. Fm, 25. vir 1923: 1 ๙ै. BIe, 26. viI 1923: 1 juv. In Mauerlücken von Einfriedigungen und Häusern, wurde nicht quantitativ gesammelt.

Agelena labyrinthica (Clerck). Fa, 17. vir 1923: 1 ㅇ. Fe, 10. viI 1923: 1 q; 13. VII 1924: 1 ․ Fg, 15. VII 1923: 1 ․ $\mathrm{Bc}$, 14. viI 1923: 1 ㅇ. B BIb, 27. viI 1924: 1 ㅇ․ BId, 28. viI 1924:

1 ․ Ueberaus häufig! Wurde nur gelegentlich mitgenommen, einmal hoch oben ab einem Busch.

Tegenaria silvestris L. Koch. Fa, 14. viI 1923: 1 q. Ff, 25. viI 1923: 1 ○. Fg, 15. vil 1923: 1 q. Äc, 3. vill 1924: 1 ○. BIb, 23. vil 1924: 1 ㅇ. BId. 20. viI 1923: 1 ㅇ. BIe, 26. viI 1923: 1 우.

**Amaurobius rudolfi nov. spec. Äd, 31. vil 1923: 3 \%. 18. viI 1924: $2 \hat{\jmath}, 1$ ㅇ, 3 juv. Äh, 2. viII 1924: 1 ㅇ. BIg, 4. viII 1924: 2 juv.

Cicurina cicur Menge. Ff, 25. vil 1923: 1 ㅇ.

Cryphoeca sylvicola. (C. L. Koch). Fd, 16. vil 1923: 2 + , 1 juv. Äf, 10. viri 1923: $1 \hat{\jmath}, 1$ \&, 1 juv. Äg, 13. vil 1923: 1 ㅇ. BIb, 23. viI 1924: 1 ㅇ (sehr klein).

\section{Pisaurid ae}

Pisaura mirabilis (Clerck). Fe, 12. vil 1923: 2 ㅇ (zahlreiche Exemplare bei den Eibündeln). Fg, 15. vir 1923: 1 $\hat{\jmath}$. Fi, 25. viI 1924: $1 \hat{\jmath}$. BIb, 27. viI 1924: 1 juv. BId, 20. viI 1923: 1 ․ Wurde nur gelegentlich gesammelt.

\section{LYCOSIDAE}

Lycosa (Tarentula) nemoralis Westring. Fa, 17. viI 1923: 2 个; Anf. viII 1923: 1 ․ Fc, 12. viI 1923: 2 ô, 1 o ; 13. viI 1924: 1 ๙ิ; 26. vir 1924: 2 ๙ิ, 2 ㅇ (unter Steinen bei den Eibündeln).

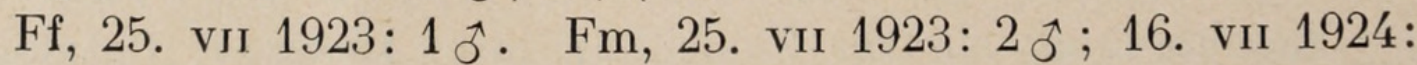
2 ๙ै. Bc, 14. viI 1923: 1 ô. Äf, 10. viI 1923: 1 ㅇ․ Äg, 13. vir 1923: 1 ठ․ BIb, 27. viI 1924: 3 ô. BId, 20. vir 1923: 1 ‥ BIf, 11. viII 1924: 1 个.

Lycosa (Tarentula) inquilina (Clerek). Fe, 10. viı 1923: 1 q mit Jungen. Ff, 14. viI 1924: 1 q. 
Lycosa (Tarentula) barbipes Sundevall. Fe, 13. vil 1924: 1 ㅇ. Fi, 25. viI 1924: 1 \%. Fm, 25. vil 1923: 1 q; 16. viI 1924: 1 ․ Bc, 14. viI 1923: 1 ; 15 . viI 1924: 1 ㅇ. Äh, 2 . viII 1924: 1 ‥ BIb, 27. vil 1924: 1 juv.

Lycosa (Tarentula) trabalis (Clerek). Fb, 15. vir 1923: 1 ㅇ, 1 juv.

Fe, 10. vir 1923: 1 ㅇ. Ba, 7. viI 1923: 1 ㅇ. Be, 14. vir 1923:

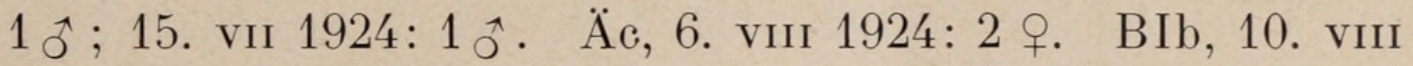
1924: 1 juv. BId, 20. viI 1923: 1 ㅇ. Der Pfeilfleck des Hinterleibs ist bei der Mehrzahl der $q$ q verwischt, seltener wohl ausgeprägt.

Lycosa (Tarentula) cuneata (Clerck). Äh, 2. vin 1923: 1 \%. Lycosa (Tarentula) pulverulenta (Clerck). Fe, 18. viI 1923: 1 ㅇ․ Ra, 21. vil 1924: 1 q. Äh, 2. vilI 1923: 1 q. Äd, 18. viI 1924: 1 ㅇ.

Lycosa (Tarentula) aculeata (Clerck). Bc, 14. viı 1923: 1 ô. Ec,

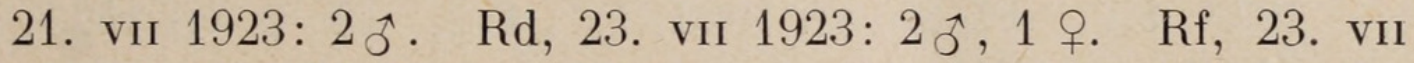
1923: $2 \hat{\jmath}$. Äg, 12. viI 1923: 1 ๙ै. Äh, 2. viII 1924: 1 ㅇ.

In der Zuteilung der Exemplare zu den beiden eben aufgezählten Arten war ich meiner Sache nicht immer sicher.

Lycosa (Trochosa) terricola (Thorell). Fa, 24. vir 1923: 1 ㅇ. Fi, 25. viII 1924: 1 \%. Äc, 6. viII 1924: 2 q.

Lycosa (Trochosa) robusta Simon. Fc, 13. vir 1924: 1 ㅇ․

Lycosa (Trochosa) alpigena Doleschal. Bd, 4. vin 1923: 2 ㅇ.

Äd, 31. vir 1923: $2 \hat{\jmath}$, frei auf dürrem, mit Krustenflechten bedecktem Boderi, Schutzfarbe!

Pardosa torrentum Simon. Fg, beim Weisswasser, 12. vil 1924: 1 ㅇ.

Pardosa mixta (Kulczynski). Bd, 15. viı 1924: 1 ô; 4. viıI 1923: 10 oิ, 7 우. Ec, 21. viI 1923: 1 ô; 31. VII 1924: 1 ô. Ed, 21. VII 1923: $10^{\hat{*}}$. Fl, 19. VII 1924: 1 ô. Ra, 21. VII 1924:

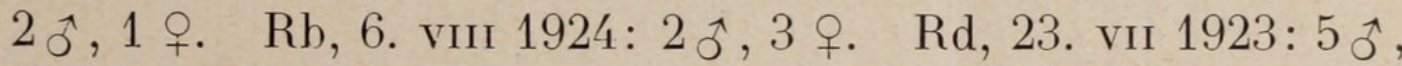
2 ㅇ․ Rf, 23. vir 1923: 1 ô, 1 ㅇ. Äh, 2. viII 1923: 4 ․ . Äd, 31. VII 1923: 2 ô, 1 क; 18. VII 1924: $2 \hat{\jmath}, 1$ ㅇ. BIh, 7. VIII 1923: 1 ㅇ․

Pardosa saltuaria (L. Koch). Ee, 11. vir 1923: $2 \hat{\jmath} ;$ 21. vir 1923: $2 \hat{\jmath}$. Ef, 7. vini 1924: $1 \hat{\jmath}$.

Pardosa tarsalis (Thorell). Fa, Anf. viII 1923: 1 ㅇ. Fd, 15. viI 1923: 1 ô. Äg, 12. viI 1923: 1 ㅇ.

Pardosa blandx (C. L. Koch). Fa, 17. vir 1923: 1 ^ै; 24. vir 1923: 
1 ㅇ. Ff, 25. viI 1923: 1 ․ $\mathrm{Fg}$, beim Weisswasser, 15. vII 1923: 1 우; 5. vili 1924: 2 ․ $\mathrm{Fi}, 25$. vil 1924: 2 ๙ै, 7 ㅇ. Bd,

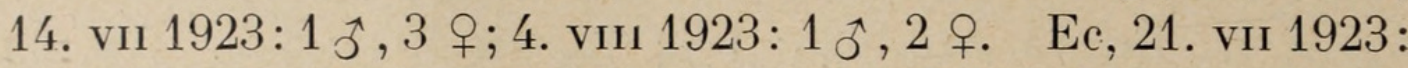
5 ô; 31. viI 1924: 1 ㅇ. Ed, 21. viI 1923: 1 ô. Ef, 10. vII 1923: 2 ๙ै, 1 juv. Ra, 21. vir 1924: 1 ․ Rd, 23. viI 1923:

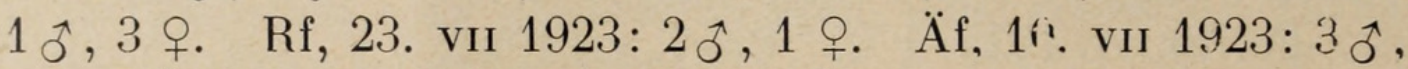
1 ㅇ. Äg, 13. viI 1923: 1 ô. 1 ㅇ․ Äh, 2. viII 1923: 5 ô, 3 우 ; 2. vili 1924: 1 ô, 1 ․ BIe, 26. viI 1923: 1 ‥ BIf, 11. viII 1924: 5 ㅇ. BIh, 7. viII 1923: 1 ๙ิ, 3 ㅇ. BIg, 4. viII 1924: 1 ô, 2 ㅇ.

Pardosa cursoria (C. L. Kach). F६, 5. vir 1924: 1 ․ . Fi, 25. vil

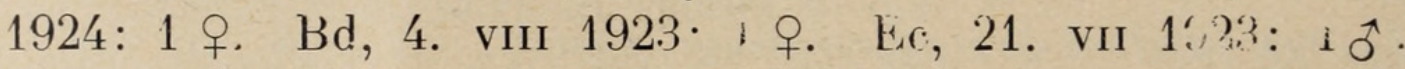
Äc, 6. viII 1924: 1 ․ Äh, 2. viII 1924: 1 ․ BIe, 26. viI 1923: 1 ô.

Pardosa lugubris (Walckenaer). Fa, 14.-17. viI 1923: 2 ऽิ; 24. viI

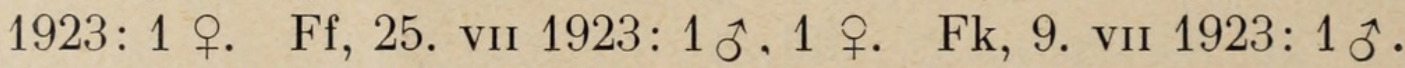
Äh, 2. vin 1923: 1 ๙ิ, 1 ㅇ.

Pardosa amentata (Clerck). Fa, 17. viI 1923: 1 q. Fg, 15. viI 1923: 2 ㅇ; 12. vir 1924: 1 ㅇ. Fl, 18. vil 1923: 3 ô, 2 ․ $\mathrm{Bc}$, 14. viI 1923: 1 ô, 1 ‥ Bd, 4. viII 1923: 1 ô. Ed, 21. VII 1923: 1 ㅇ․ Ra, 21. viI 1924: 1ô. Rd, 23. viI 1923: 3 ㅇ․ Äc, 6. viII 1924: 1 ㅇ. Äe, 10. viI 1923: 2 ô. BIe, 26. viI 1923: 1 ․ BIf, 11. viII 1924: 1 ㅇ. BIh, 7. vili 1923: 1 ․ Pardosa ferruginea (L. Koch). Bc, 14. vir 1923: 2 ㅇ. Ec, 21. viI

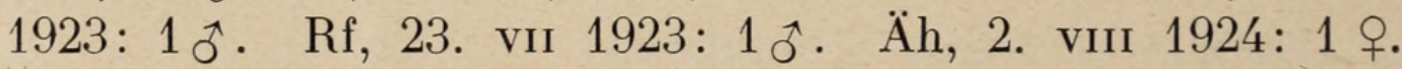
BIh, 7. viII 1923: $1 \hat{\jmath}$.

Pardosa giebeli (Pavesi). Bd, 15. vir 1924: 1 ; 4. vili 1923: 18 ô, 9 ㅇ. $\mathrm{Eb}, 11$. viI 1923: 1 ㅇ. Ed, 21. viI 1923: 1 $\widehat{0}$. Ee, 9. viI 1923: 1 ㅇ. Ef, 10. vir 1923: $4 \hat{\text { ô }}, 1$ + ; 7. viII 1924: 1 ㅇ.

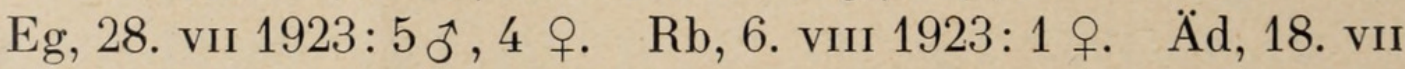
1924: 2 ઠิ, 3 ㅇ; 31. viI 1923: 5 ๙ิ, 5 우.

Pardosa ludovici (Dahl). Eb, 11. vir 1923: 1 ค. Ec, 31. vir 1924: 1 $\widehat{\jmath}$. Ed, 21. viı 1923: $1 \hat{\jmath}$. Ef (häufig in den Blöcken des Gipfels), 10. vir 1923: 2 ․ Eg, 28. vir 1923: 2 ㅇ, 2 juv. Äd, 18. vil 1924: 1 ô. BIg, 4. vili 1924: 1 ô, 1 q, 2 juv.

Pardosa wagleri (Hahn) var. nigra (C. L. Koch). Fa, 17. vir 1923: 1 ㅇ.; viII 1924: 1 ô. Fg, 5. viII 1924: 1 ㅇ. Fi, 25. viI 1924: 2 아 Fk, 9. viI 1923: 2 ô, 2 ․ Äe, 10. viI 1923: $2 \hat{\jmath}$. Äh, 2. vili 1923: 2 ㅇ. 
Die $\hat{o} \widehat{o}$ sind leicht von denjenigen der Stammform zu unterscheiden: Die hakenförmige Apophyse des Bulbs ist viel plumper; sie ragt endwärts viel weiter über die basale Bulbpartie vor, und ihr distaler Rand ist viel stärker, fast halbkreisförmig gebogen.

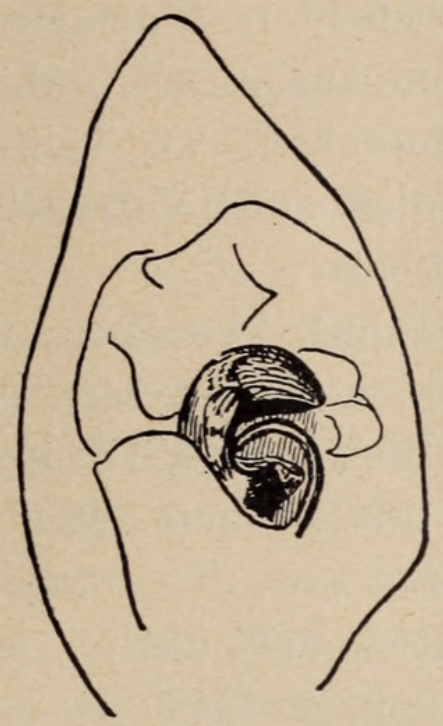

FIG. 2.

Pardosa wagleri var. nigra (C. L. Koch). $\sigma^{7}$.

Linker Bulb von unten.

Pardosa bifasciata (C. L. Koch). Fm, 25. vII 1923: 1 q; 16. vII 1924: 5 ㅇ. Äc, 6. viII 1924: 1 ․ BIb, 27. viI 1924: 1 ㅇ.

\section{Salticid AE}

Heliophanus cupreus (Walckenaer). Fa, 17. vir 1923: 1 ․ Fb, 24. vII 1923: 1 \% ; 1 . vIII 1924: 1 o, 1 \&, $(1 *$ *) Fe, 12. viI 1923:

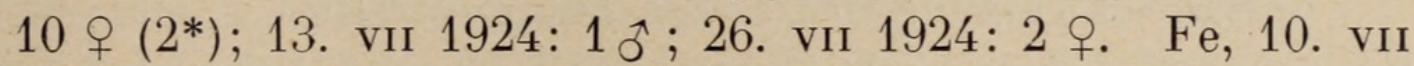
1923: 1 o . Ff, 25. viI 1923: 1 q. Fm, 25. vII 1923: 3 q*; 16. vII 1924: 3 ㅇ $(2 *)$. Äb, 19. vII 1924: 1 ‥ BIa, 1. vIII 1924: 1 ㅇ. BIb, 27. VII 1924: 1 ㅇ. BIc, 30. viI 1924: 1 ㅇ. BId, 20. vir 1923: $1 \delta^{*}$. Bei den $\mathrm{mi}^{*} *$ bezeichneten Exemplaren sind die Extremitäten \pm geschwärzt; bei einigen sind die Palpen und Beine noch gelb; die letzteren haben aber schwarze Längslinien an der Vorder- und Hinterseite, und der Femur IV ist fast schwarz; diese schwarze Zeichnung kann auch ausgedehnter sein; schliesslich finden sich Stücke mit ganz schwarzen Extremitäten, an denen nur noch die Hüften und Trochanter gelbe Flecken aufweisen.

Heliophanus aeneus (Hahn). Fa, 14. vir 1923: 1 q; 24. vII 1923: 1 ô, 5 q; Anf. viII 1923: 3 ๆ. Fb, 12.-17. vil 1923: 5, 5 juv. 
Ff, 25. vir 1923: 3 ㅇ, 1 juv. Fg, 15. vil 1923: 4 q; 12. viI

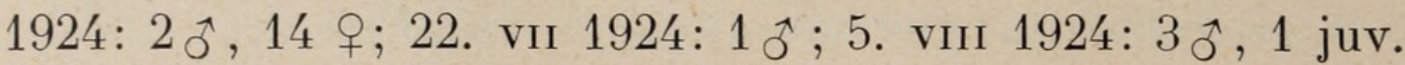
Fh, 24. vir 1924: 1 ô, 1 ㅇ, 1 juv. Fi, 25. viI 1924: 3 ऽิ, 5 ㅇ․ Fk, 9. vir 1923: 3 ㅇ, 1 juv. Fm, 16. vil 1924: 1 ㅇ. $\mathrm{Bd}$, 4. viII 1923: $1 \hat{\jmath}$. Äc, 3 . viII 1924: 6 ô, 2 f. Wie überall in den von mir durchsuchten Alpengegenden ist diese Art an Stellen, die der Sonne ausgesetzt sind, sehr häufig, so namentlich auf Weidemäuerchen, wo beim Aufdecken passender Steine ganze Kolonien zum Vorschein kommen; Sammlung darum nicht quantitativ.

Heliophanus flavipes (Hahn). Fa, 14. vir 1923: 1 \% Anf. vin 1923: 1 \%. Fb, 16. viI 1924: 1 ․ Fm, 27. vil 1923: 1 \%; 16. viI 1924: 1 ㅇ. Bc, 14. VII 1923: 1 ㅇ. Die Stücke stimmen im Bau der Vulva mit solchen aus der Nähe Basels überein aber die Extremitäten sind \pm verdunkelt: Bei 3 Stücken sind die Palpen grösstenteils hell, nur an den Femurseiten schwach angeraucht; bei einem weitern ist dieses Glied schon recht dunkel, nur unten und oben etwas aufgehellt. Bei einem Exemplar greift die Schwärzung sogar auf die distalen Palpenglieder über; etwas heller sind nur die Patella und die Oberseite der Tibia; die Unterseite der letztern und der ganze Tarsus sind verdunkelt. Auch die Beine zeigen eine entsprechende Stufenleiter der Schwärzung: Beim hellsten Stück sind nur die Seiten, beim dunkelsten die ganzen Femora schwarz; in ähnlicher Weise sind die distalen Beinglieder entweder gelb oder durch Schwärzung der Seiten längsgestreift.

Helicphanus dubius C. L. Koch. Fb, 12. viI 1923: 1 §ै. Fm, 16. viI 1924: 1 ㅇ.

Heliophanus lineiventris Simon. Fb, 17. vil 1923: 10ิ. Das Exemplar ist etwas kleiner als das von E. Handschin auf dem vordern Triftgletscher gefundene, stimmt aber sonst mit diesem überein.

Evophrys erratica (Walckenaer). Fa, 24. vir 1923: 1 o . Fe, 10. viI 1923: 1 ô, 1 ㅇ. Fg, 15. viI 1923: 1 ㅇ (sehr klein).

Evophrys petrensis C. L. Koch. Ra, 21. vil 1924: 3 q. Rd, 23. vil 1923: 1 ô, 3 ㅇ. Äd, 31. vil 1923: 3 \%; 18. viI 1924: 5 ․ BIa, 27. vir 1924: 1 q. Die "Augenwimpern " sind oft eher gelbbraun als rötlich. Stellenweise nicht selten, wurde nicht quantitativ gesammelt. 
Neon reticulatus (Blackwall). Rf, 14. viI 1924: $2 \hat{\circ}, 1$ ․ BIe, 30. viI 1924: 1 ô.

Sitticus longipes (Canestrini). BIf, 11. vin 1924: 1 ơ (tiefe Lage!). BIg, Blockhalde und Passhöhe, 4. vin 1924: 1 ô, 2 + immatur. Sitticus pubescens (Fabricius). BIb, 8. vin 1924: 1 ô, 1 ㅇ. BIe, 26. vir 1923: $20^{\wedge}$.

Sitticus cingulatus (Simon). Fa, Anf. vin 1923:1 §ิ . Fb, 12. viI 1923: $1 \hat{0}$.

Sitticus rupicola (C. L. Koch). BId, 28. viı 1924: 1 ô, 1 ㅇ. BIf, 11. viII 1924: 6 ô, 8 ․ . BIh, 7. viII 1923: 2 ô, 3 ㅇ. Oft mit Heliophanus aeneus zusammen und fast noch häufiger, wurde nur gelegentlich gesammelt.

Sitticus muralis nov. spec.? BIf, 11. vili 1924: 1 ㅇ. Attulus histrio (Simon). Fk, 9. vir 1923: 40ิ . Äc, 6. vin 1924: 1 ㅇ, 1 juv.

Salticus scenicus (Clerck). Fa, 24. viI 1923: 2 ․ $\mathrm{Fb}, 12$. viI 1923: 2 ․ Fg, 12. viI 1924: 1 ․ $\mathrm{Fi}, 25$. viI 1924: 1 ㅇ. BIb, 8. viı 1924: 1 ㅇ. Bei den "hohen Flühen " unterhalb Mörel, 14. viıI 1924: 1 ㅇ.

Aelurillus insignitus (Olivier). Fb, 15. vir 1923: 1 ㅇ. Fe, 13. viI 1924: 1 f. Fg, 12. vil 1924: 1 q; 22. vir 1924: 1 juv. Bc,

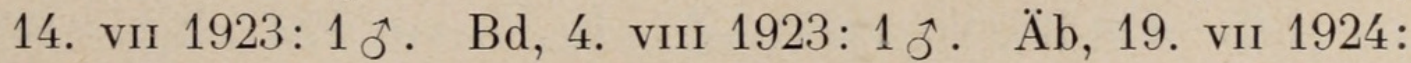

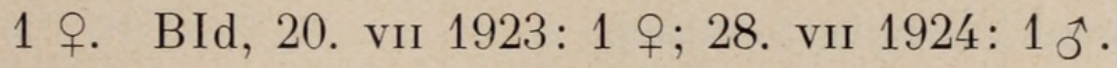

Phlegra fasciata (Hahn). Fa, 17. viI 1923: 1 ô. BIb, 27. viI 1924: $10^{\hat{0}}$.

Pellenes tripunctatus (Walckenaer). Äg, 13. viI 1923: 1 q.

Evarcha falcata (Clerck). Fe, 12. vir 1923: 1 juv. BIb, 27. viI, 1924: 1 q.

\section{Phalangitdae}

Liobunum limbatum L. Koch. Fa, 20. viI 1924: 1 \%; 7. viII 1924: 1 ㅇ. Fd, 15. viI 1923: 2 ô; 1. viII 1924: 1 juv. Fg, 15. VII 1923: 1 oิ, 2 ㅇ. $\mathrm{BIe}, 26$. VII 1923: 1 ô, 2 †; 28. VII 1924: 2 q; 7. vili 1923: 1 q. BIf, 11. viII 1924: 1 ô. BIg, 4. viı 1924: 1 q. Besonders häufig an den Felswänden des Binnentalsträsschens; wurde nicht quantitativ gesammelt. Nelima aurantiaca (Simon). Äf, 10. viı 1923: $1 \hat{\jmath}$.

Dicranopalpus gasteinensis Doleschal. Bd, 4. vin 1923: 1 juv. BIg, 4. viII 1924: 1 juv. 
Mitopus morio (Fabricius). Fa, 2. viII 1924: 1 \%. Fe, 12. viI

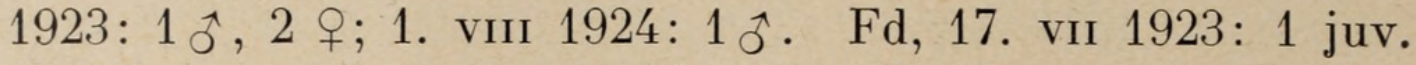
Ff, 25. vir 1923: 1 ô. Fg, 12. vir 1924: 1 juv.; 5. viII 1924:

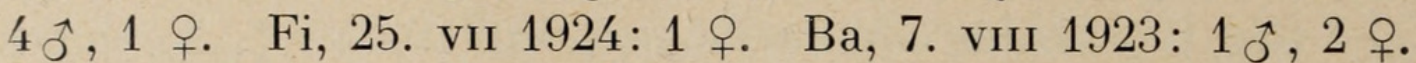
Bd, 4. viII 1923: 1 oิ, 1 ㅇ. Ec, 31. viI 1924: 1 ô, 2 ๆ. Ee, 9. viI 1923: 1 jüv. Eg, 28. viI 1923: $1 \hat{\jmath}, 1$ ㅇ. Rd, 23. vir 1923: 1 \%; 9. viII 1924: 1 ㅇ. Re, 6. viII 1923: 2 juv. Äb, 19. viI 1924: 1 ô. Äh, 2. viII 1923: $1 \hat{\jmath}, 1$ o; 2. viII 1924: 4 +. Äd, 31. vir 1923: 2 juv.; 18. vir 1924: 4 juv. BIc, 30 . viI 1924: 2 ô. BIe, 26. viI 1923: 1 ô, 2 ㅇ, 2 juv. BIh, 7. viII 1923: 3 ऽ, 5 ㅇ. Der Unterschied zwischen langbeiniger Talform und kurzbeiniger Varietät des alpinen Weidengürtels macht sich auch in der Umgebung von Fiesch sehr auffallend geltend. Die alpine Form ist stattlicher, bunter und oft sehr reich an Individuen; diese wurden nicht quantitativ gesammelt.

Strandibunus glacialis (Heer). Bd, 4. viII 1923: 1 +. Ed, 21. viI 1923: 1 ㅇ. Ee, 9. viI 1923: 1 juv. Ef, 7. vini 1924: 1 ㅇ, 2 juv. BIg, 4. vin 1924: 1 juv.

Phalangium cornutum Linné. Fa, 17. vil 1923: 1 q, 1 juv. Fe, 13. vir 1924: 2 ㅇ. Fe, 10. viI 1923: 2 ․ Fg, 15. viI 1923: 1 ․ Fn, 26. viI 1924: $1 \hat{\jmath}$. Ba, 7. viII 1923: $2 \hat{\jmath}$. Wurde nur gelegentlich mitgenommen.

Platybunus bucephalus (C. L. Koch). Fe, Anf. viII 1923: 1 +

Platybunus pinetorum (C. L. Koch). Fe, 10. vir 1923: 1 f. Ff, 25. viI 1923: 1 juv. BIe, 26. viI 1923: 1 juv. BIf, 11. viII 1924: 1 ․

Megabunus rhinoceros (Canestrini). Äh, unter Stein bei der Passhöhe, 2. viII 1924: 1 ô. BIe, 26. vir 1923: 1 St. BIg, 4. viIr 1924: 1 St.

\section{Nemastomidae}

Nemastoma dentipalpe (Ausserer). Fd, 16. vir 1923: 3 ô, 3 ㅇ․ Ff, 25. VII 1923: $1 \hat{\jmath}, 1$ ㅇ 14 . VII 1924: $2 \hat{\text { o }, ~} 1$ ㅇ. Äa, 17. viI

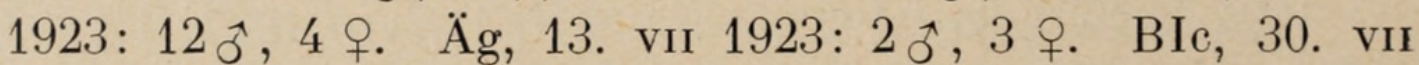
1924: 1 ㅇ. Diese im Moos häufige Art wurde nicht quantitativ gesammelt.

Nemastoma chrysomelas (Hermann). Fi, 25. viI 1924: 1 $\hat{o}$. Ec, 31. vII 1924: 1 ô; 1 ㅇ. Äa, 17. viI 1923: 1 ‥ Äh, 2 . vIII 1924: 1 ㅇ. 


\section{OBISIID AE}

Obisium (Roncus) lubricum (L. Koch). Äa, 17. vir 1923: 2 St. Obisium muscorum Leach. Äa, 17. viI 1923: 2 St.

Chthonitdae

Chthonius tetrachelatus (Preyssler). Ff, 14. viI 1924: 1 St.

\section{SPINNEN AUS DEM WALLIS UND AUS GRAUBÜNDEN,}

gesammelt von Dr. R. de Lessert und Dr. J. Carl.

Theridion petraeum L. Koch. Findelental bei Zermatt, 2300 m, vir : $\hat{\sigma} q$ in Kopula (gesammelt von Dr. De Lessert, bestimmt von W. Kulczynski, von mir nicht eingesehen.)

Dipoena torva (Thorell). Haueten bei Zermatt, $1770 \mathrm{~m}$, vII: 1 ? (gesammelt von Dr. DE Lessert).

Brachycentrum elongatum (Wider). Haueten bei Zermatt, $1770 \mathrm{~m}$, auf Wachholder, 10. vir 1909: 2 우 (DE LESsERT gesammelt). Brachycentrum de Lesserti n. sp. Haueten, in Moos, 1900 m, viI: $1 \hat{\jmath}, 2$ 우 (von de Lessert gesammelt).

Trichopterna blackwalli (Cambridge). Sierre, Iv: $1 \hat{0}, 1$ 우 (von DE LEssert gesammelt).

**Microcentria pusilla nov. gen., nov. spec. Haueten, $1900 \mathrm{~m}$, vir 1909: 3 ô, 2 우 (von de Lessert gesammelt).

**Diplocentria rivalis (Cambridge). Haueten, 1900 m, vir 1909: 3 ㅇ, 1 ô (von DE LESSERT gesammelt). ( $\hat{o}$ nach brieflicher Mitteilung des Authors $=\hat{\sigma}$ von Centromerus subalpinus de Lessert.)

Micryphantes gulosus (L. Koch). Minschun, Unter-Engadin, 2000 m, unter Stein: 1 q, 1 juv. (gesammelt von Dr. CARL).

**Lephthyphantes cacuminum Jackson. Minschun, Unter-Engadin, $2000 \mathrm{~m}$, unter Stein: $1 \hat{\jmath}$ (gesammelt von Dr. CarL). **Araneus displicatus Kulczynski. Haueten, 1770 m, auf Arve, vir: 7 (gesammelt von de Lessert, bestimmt von Kulczynski, von mir nicht eingesehen).

Zora silvestris Kulczynski. Haueten, 1770-2000 m, vir: $1 \hat{\jmath}$, 4 우 (von DE LEssert gesammelt).

**Sitticus saxicola (C. L. Koch). Arolla, $1962 \mathrm{~m}$ : ๙ే. Findelental bei Zermatt, im Wald bei $2100 \mathrm{~m}$, vII : $q$ (gesammelt von $\mathrm{DE}$ Lessert, bestimmt von Kulczynski, non vidi). 
**Sitticus hungaricus (Kulczynski). Buchillon, Seeufer, v: ô ㅇ (gesammelt von de Lessert, bestimmt von Kulczynski).

\section{BERICHTIGUNG FRÜHERER ANGABEN.}

**Gnaphosa occidentalis Simon für Gn. lugubris, Verh. Nat. Ges. Basel, V. XXIX, p. $73 . \quad$ Claro ob Bellinzona, v-vı: 15 ot, 31 q. Herr Dr. A. R. Jackson, der Exemplare von Claro eingesehen, hat obige Bestimmung bestätigt. Bisher bekannte Verbreitung: Dép. Morbihan und Charentes, Frankreich; Kynance Cove, Cornwall, England; und Claro, Tessin.

**Macrargus firmus Cambridge für $M$. pusillus Schenkel, Verh. Nat. Ges. Basel, V. XXXIV, p. 99. Altzellen, Nidwalden, 900-1300 m, viI-viII: ô ㅇ. Herr Dr. A. R. Jackson war so freundlich, meine Bestimmung zu berichtigen, auch verdanke ich ihm Exemplare dieser Species aus England behufs Vergleichung.

Hypomma fulvum (Bösenberg) für $H$. bituberculatum, Verh. Nat. Ges. Basel, V. XXIX, p. 78. Sümpfe der Umgebung von Neudorf, Elsass, Iv-vi: $14 \hat{\jmath}, 13$ ㅇ.

\section{NAEHERE ANGABEN UEBER EINIGE SPECIES.}

Echemus alberti nov. sp. oder Var. von E. rhenanus Bertkau.

Im trockenen, hie und da von Granitfelsen und Felsenheide unterbrochenen Wald ob Binnachern fand sich unter einem Stein das einzige Exemplar.

Gesamtlänge $8^{\mathrm{mm}}, 5$, Cephalothorax c. $2^{\mathrm{mm}}, 8$ lang, $2^{\mathrm{mm}}$ breit. Die vordere Augenreihe ist stark procurv; die untere Tangente der Mittelaugen schneidet die Seitenaugen über deren Centrum. Die vordern Mittelaugen sind sehr gross, rund; ihr Zwischenraum ist etwa gleich dem Halbmesser, der Abstand von den Seitenaugen fast gleich Null; letztere sind heller, kleiner, schräg-oval. Der Clypeus ist unter den Mittelaugen etwa gleich deren Durchmesser, unter den Seitenaugen nur halb so hoch. Von oben betrachtet erscheint die vordere Augenreihe fast gerade, die hintere aber so sehr 
procurv, dass die vordere Tangente der Mittelaugen durch das Centrum der Seitenaugen geht. Beide Augenreihen sind annähernd gleich breit. Die 4 Hinteraugen sind fast gleich gross, kleiner als die vordern Mittelaugen; ihre 3 Zwischenräume sind ebenfalls subegal, gleich dem Radius der hintern Mittelaugen; letztere sind am ausgeprägtesten nocturn, fast kreisrund, aber hinten-aussen mit einem dunkeln Segment, weshalb die hellen Partien nach hinten convergieren. Das Rechteck der Mittelaugen ist deutlich länger als breit.

Die Stirne ist sehr schmal. Der lebhaft lehmbraune, fast orangegelbe Cephalothorax hat eine sehr ausgeprägte dunkle Mittelritze und lange, anliegende, seidenartige Behaarung.

Die Mundteile, das Sternum und die Hüften sind wie die Kopfbrust gefärbt und zum Teil ebenso behaart; auch die Beine sind

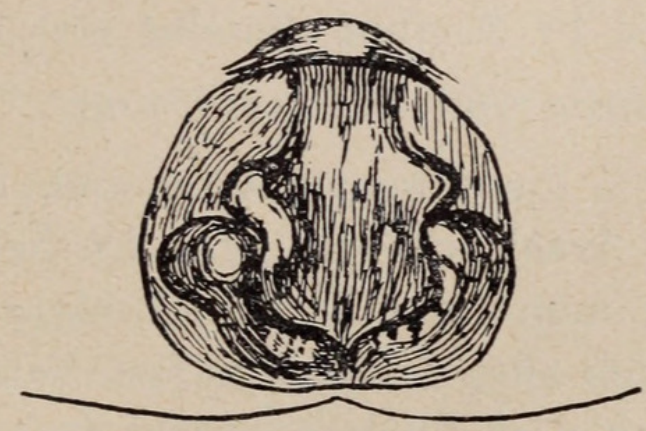

FIG. 3.

Echemus alberti n. sp. @.

Epigyne.

ähnlich; die Tibien, noch mehr die Metatarsen und Tarsen sind durch reichliche Behaarung etwas verdunkelt. Der Hinterleib ist weisslichgrau, die Haare abgerieben.

Die Epigyne unterscheidet sich von derjenigen des E. rhenanus (Aran. Hungar. Taf. vin, Fig. 44) wie folgt: Das Feld ist nicht so breit; der dunkelbraune, bogenförmige, erhabene Vorderrand der Grube reicht seitlich nicht so weit nach aussen und hinten; der Sehne nach gemessen ist er kürzer als der Abstand seiner Mitte von der Bauchfalte. Wie bei E. rhenanus ist die Grube hinten durch eine 3-teilige Platte abgegrenzt; die Tuberkel der beiden Seitenteile sind aber kleiner, und die mittlere Partie ist breiter; letztere trägt ausserdem weiter vorn ein Paar tiefer liegender, kleinerer, nach 
aussen gerichteter Knötchen, die bei E. rhenanus zu fehlen scheinen.

Der Klauenfalzrand der Mandibeln hat vorn 3 Zähnchen, deren mittleres das dickste und längste, deren oberes das kleinste und schlankste ist; letzteres steht etwas isoliert; bie beiden untern berühren sich an der Basis. Der Hinterrand der Klauenfurche hat nur 1 Zähnchen.

Bestachelung: Femur I und II oben 1-1, vorn 1; Tibia I und II unten 1-1; Metatars I und II unten 1 (Basis); Femur III oben mit 3 Reihen: in der Mitte 1-1-1, vorn und hinten je 1-1; Patella III vorn und hinten je 1; Tibia III oben 1, vorn 1-1-1, hinten 1-1, unten 1-2-2; Metatars III vorn und hinten je 1-1-1, unten 2-2-2. Femur IV oben 1-1-2; Patella IV hinten 1; Tibia IV oben 0, vorn und hinten je 1-1-1, unten 2-2-2; Metatars IV oben 2-2-2, unten 2-2-2.

Die Unterseite von Tars und Metatars I und II hat dichte Scopula; an Metatars III und IV beginnt dieselbe erst am distalen Ende. Prosthesima subterranea und Pr. apricorum.

Ich vermag die $q$ 우 dieser beiden Arten nicht sicher von einander abzugrenzen. Die Areola der Epigyne ist bei jedem Exemplar etwaś verschieden; man kann fast lückenlose Uebergangsreihen zusammenstellen. Von allen Stücken meiner Sammlung wurden die Geschlechtsfelder mit dem Zeichenapparat genau skizziert und an den Zeichnungen die Winkel gemessen, welche die freien Vorderenden der ritzförmigen Areolagrenze miteinander bilden; ebenso wurde der Index Breite: Länge der Areola auf nachfolgender Tabelle in Klammern beigefügt; da die Enden der Areolagrenzen in verschiedenem Grade nach vorn verlängert sind, haben letztere Zahlen weniger Wert. Hinsichtlich der Krümmung dieser Enden sind 3 Typen (mit Uebergängen) zu erkennen: 1. Enden nach vorn (aussen) gekrümmt, 2. gerade, 3. 土 nach innen gebogen, entweder der ganzen Länge nach fast gleichförmig oder nur am vordern Ende; in diesem 3. Fall war die Winkelbestimmung schwierig und bezieht sich mehr nur auf die eigentlichen Enden. Der Bestimmungstabelle in "Aran. Hungar. " folgend, halte ich die Individuen des 3. Typus meist für $P$. apricorum, die des 1 . und 2. Typus im wesentlichen für $P$. subterranea; wegen der unmerklichen Uebergänge macht diese Trennung den Eindruck des Willkürlichen.

Ganz anders verhalten sich die $\hat{\jmath}$ ô aus meiner Sammlung: 5 Exemplare von Grindelwald, 1 von Adelboden und 2 aus der Um- 
gebung Basels stimmen hinsichtlich der Struktur ihrer Palpen untereinander sowohl als mit Aran. Hungar. Taf. VIII, Fig. 26 überein; 2 andere, von Claro und von Fiesch, gehören zu P. subterranea; Uebergangsformen besitze ich keine.

Nach Untersuchung der $q$ q glaubte ich erst eine einzige, weitgehend veränderliche Art annehmen zu müssen; dem widerspricht aber der Befund bei den $\hat{\sigma} \hat{\sigma}$. Sollten etwa beide Arten sich kreuzen ? Dann wären aber bisher nur weibliche, keine männlichen Bastarde beobachtet worden.
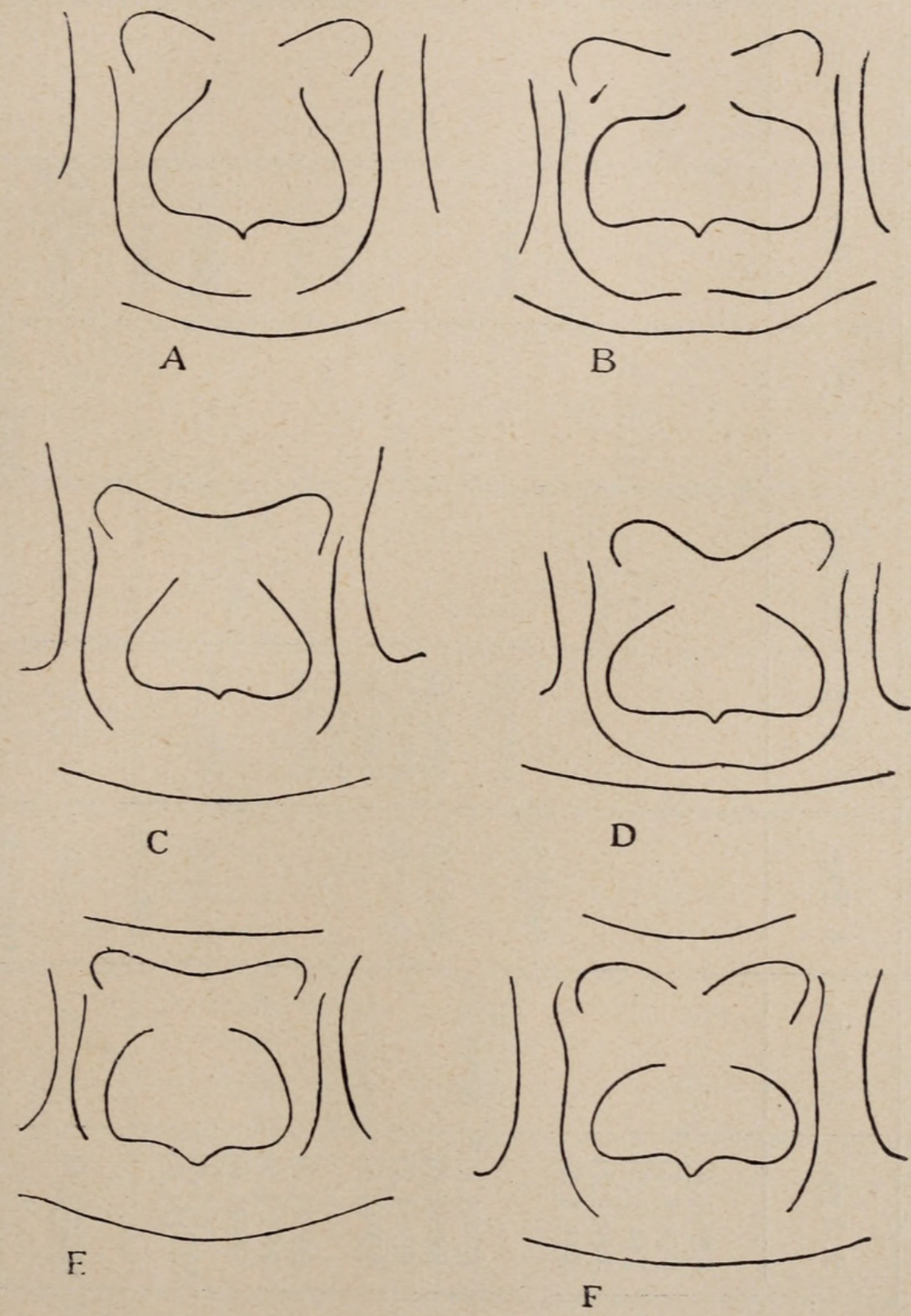

FIG. 4.

Prosthesima subterranea (C. L. Koch) und P. apricorum (L. Koch). $\&$.

Epigyne. $\mathrm{A}$ und $\mathrm{B}=1$. Typ; $\mathrm{C}$ und $\mathrm{D}=2$. Typ; $\mathrm{E}$ und $\mathrm{F}=3$. Typ.

Rev. Suisse de Zool. T. 32.1925 


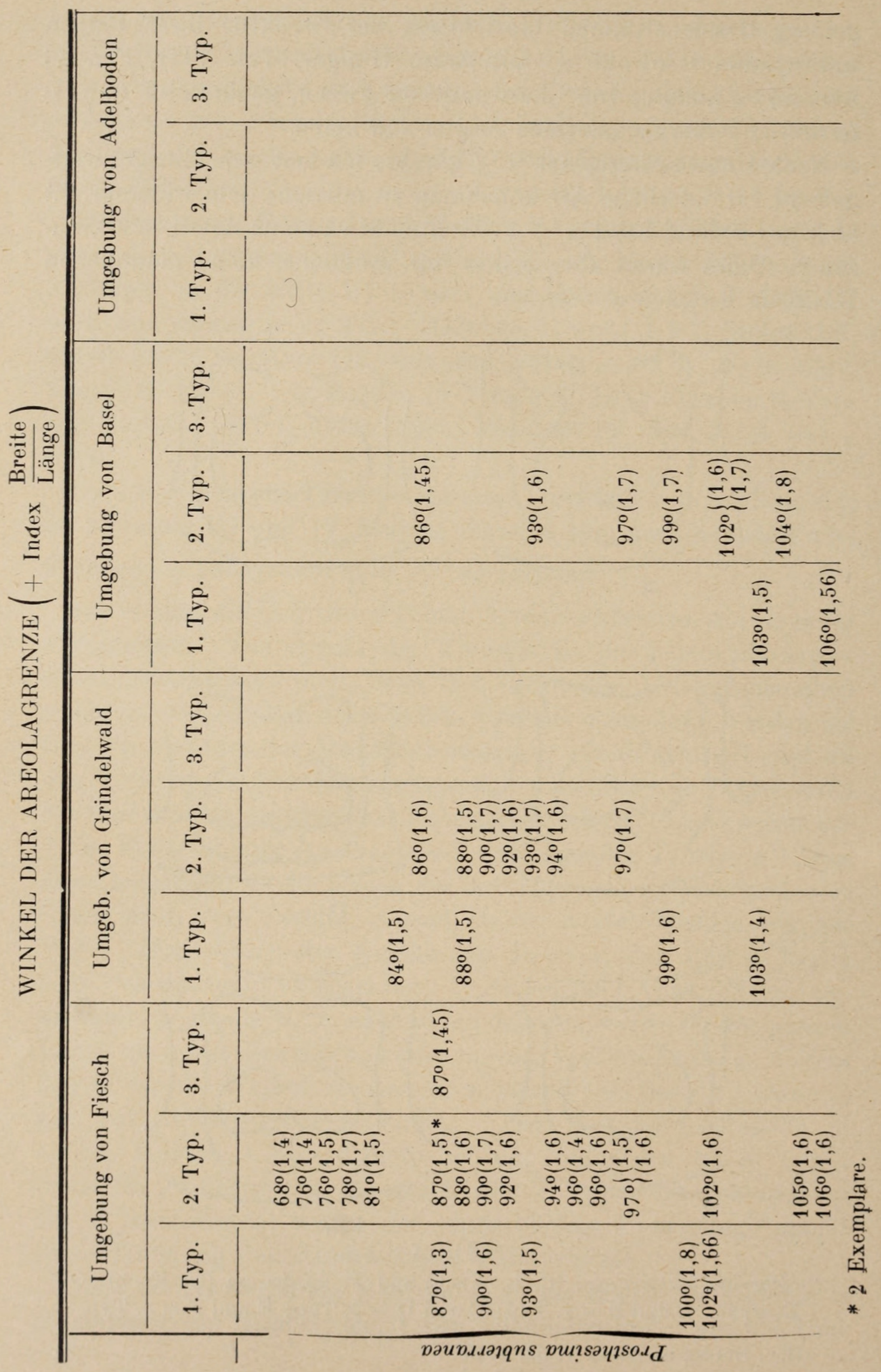




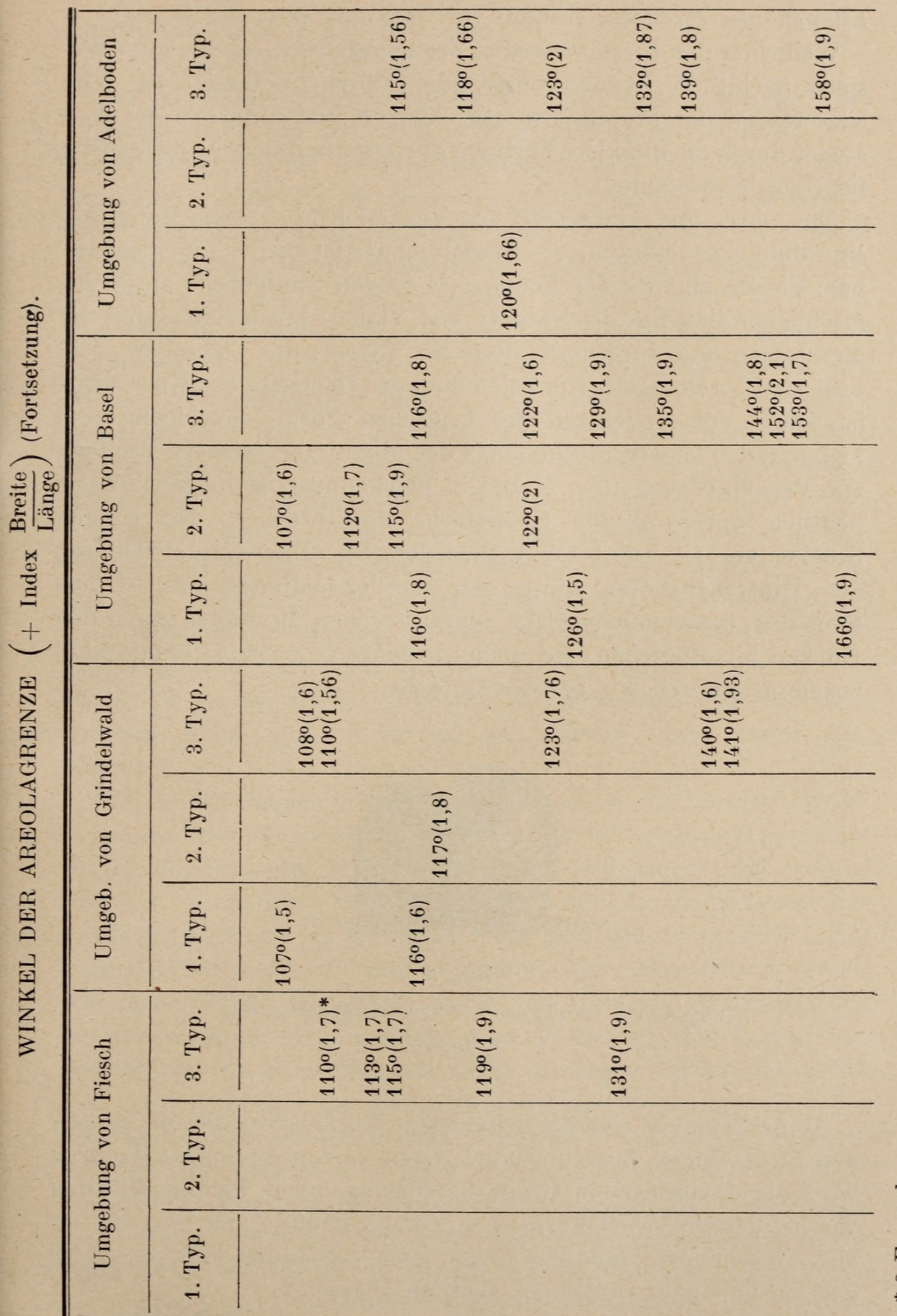


Lithyphantes corollatus (Linné) var. infuscata nov. var.

Weibchen mit Eiern waren an der angegebenen Stelle, einer felsigen, nach S.-W. exponierten Weide, zablreich unter Steinen. Die Varietät ist der Stammform sehr ähnlich und unterscheidet sich ausser durch die dunklere Färbung durch geringfügige Unterschiede im Bau der Epigyne.

Die Ober- und Unterseite des Vorderkörpers, sowie die Beine sind dunkel sepiabraun, die Ringelung der letztern kaum bemerkbar; die Basalhälfte der Femora ist schwach aufgehellt, noch unmerklicher diejenige der Patellen und Tibien; am hellsten sind die Metatarsen und die Basalhälften der Tarsen; die Enden der letztern sind geschwärzt. Die Zeichnung der Oberseite des Hinterleibs ist kaum von derjenigen der typischen Form verschieden; die Doppelreihe weisser Flecke längs der Mitte zeigt weniger Tendenz zur Verschmelzung; das 2. und 3. Fleckenpaar ist median immer deutlich durch dunkle Grundfarbe unterbrochen; bei einigen Stücken verhält sich das 1.-4. Paar derartig. Die weisse Zeichnung der Hinterleibsseiten hinter der Vorderrandbinde besteht aus schmalen, etwas geschweiften Schrägstrichen, die weiter gegen den Rücken hinaufreichen und nicht so deutlich zu einer Längsbinde zusammenfliessen wie bei der typischen Form.

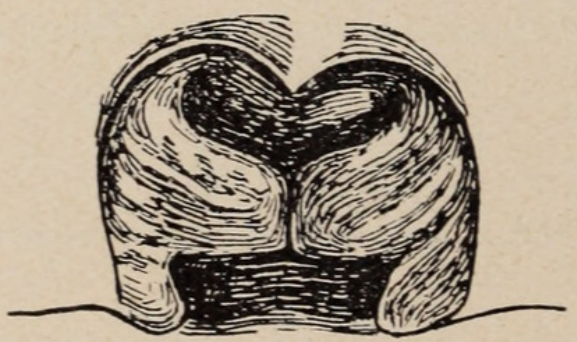

FIG. 5 .

Lithyphantes corollatus (L.) var. infuscata n. var.

Epigyne.

An der Epigyne sind die Seitenecken des Querwulstes, der hinten den rechteckigen Ausschnitt hat, nach vorn ausgezogen; dadurch wird die davorliegende Grube herzförmig, nicht halbmondförmig wie bei der typischen Form; bei genauer Prüfung der letzteren ist aber zu erkennen, dass jene Ecken auch vorhanden sind, nur tiefer gelegen und vom Querwulst deutlich abgesetzt. 
Brachycentrum de lesserti nov. spec.

$\hat{o}$ : Totallänge ca. $1^{\mathrm{mm}}, 4$.

Die Profillinie des Cephalothorax steigt vom Unterrand des Clypeus annähernd senkrecht und geradlinig an, beginnt dann etwas unterhalb der vordern Mittelaugen sich bogenförmig nach hinten zu wenden bis zur Basis des Kopftuberkels; dieses beginnt hinter dem Vorderrand des Kopfes und ist durch eine Querfurche von der Stirne getrennt, ähnlich, nur nicht gar so ausgeprägt, wie bei $\mathrm{Br}$. ineditum Cb. (Simon, Arachn. de France, Vol. V 3, p. 659, Fig. 495) In Seitenansicht erscheint das Kopftuberkel bedeutend länger als hoch; der Umriss ist etwas halbkreisförmig oder eher flacher. Die Seitengrube ist tief, von rundlichem Umriss, etwas länger als hoch und von der hinten anschliessenden, flachen Rinne, die sich acbn der Hinterwand des Kopftuberkels hinzieht, durch einen Querhügel abgegrenzt. Von oben betrachtet ist die Länge des Kopfaufsatzes etwa so gross wie seine grösste Breite; er ist also schmaler als bei $\mathrm{Br}$. thoracatum, breiter als bei $\mathrm{Br}$. ineditum; wie bei letzterer Art hat er keine mittlere Längsrinne; seine Seiten sind fast geradlinig und convergieren ein wenig nach vorn; der Vorderrand ist schwächer, der Hinterrand stärker convex gebogen. Der Cephalothorax ist breiter als derjenige von $\mathrm{Br}$. thoracatum und die Seiten weichen schon vom Stirnrand an stärker nach hinten auseinander.

Die vordere Augenreihe ist deutlich procurv; die vordern Mittelaugen sind viel kleiner als die seitlichen; ihr Intervall ist eher kleiner als ihr Durchmesser, ihr Abstand von den Seitenaugen fast dreimal so gross. Die hintern Mittelaugen haben annähernd die Grösse der vordern seitlichen; sie stehen auf dem Kopfaufsatz und ihr Intervall ist etwas mehr als 3 mal so gross wie einer ihrer Durchmesser, was mehr mit $\mathrm{Br}$. thoracatum als mit $\mathrm{Br}$. ineditum übereinstimmt; bei diesen beiden Arten scheinen aber die hintern Mittelaugen dem Vorderrand des Kopftuberkels näher zu liegen als bei der neuen Art. Die Thoraxseiten sind sehr dicht und rauh, fast schuppig reticuliert; Radiärlinien grober, vertiefter Punkte sind nicht erkennbar. Das Sternum ist glatt, glänzend, mit zerstreuten, grübchenartigen Punkten (Haarinsertionen) wenig dicht besät. Das stark grubig punktierte Schild des Hinterleibrückens reicht scheinbar bis zum Hinterende; in Wirklichkeit ist über den Spinnwarzen ein breiter Gürtel weicheren Teguments vorhanden, der aber von 
oben nicht sichtbar ist. Die Unterseite des Hinterleibs zeigt keine Verbärtungen.

Die Palpen gleichen auffällig denjenigen von Br. thoracatum. Die Apophysen der Tibien stimmen fast völlig überein, höchstens ist die kürzere äussere bei der neuen Art etwas plumper. Der
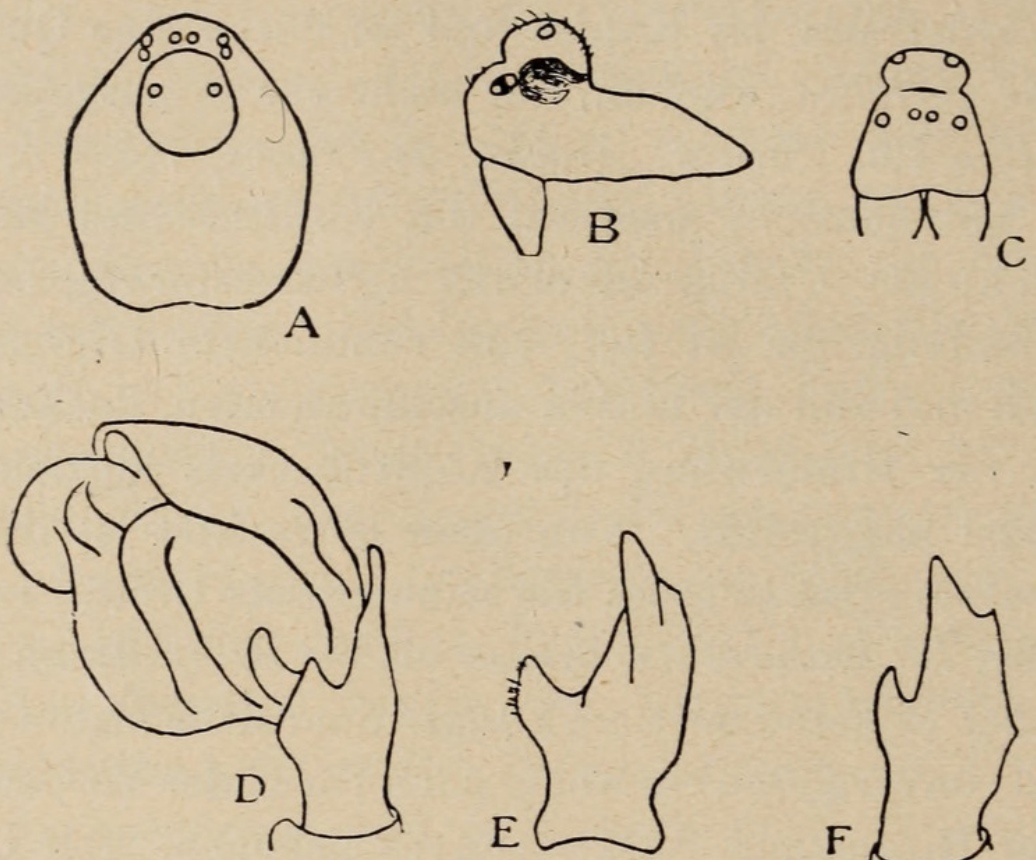

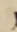
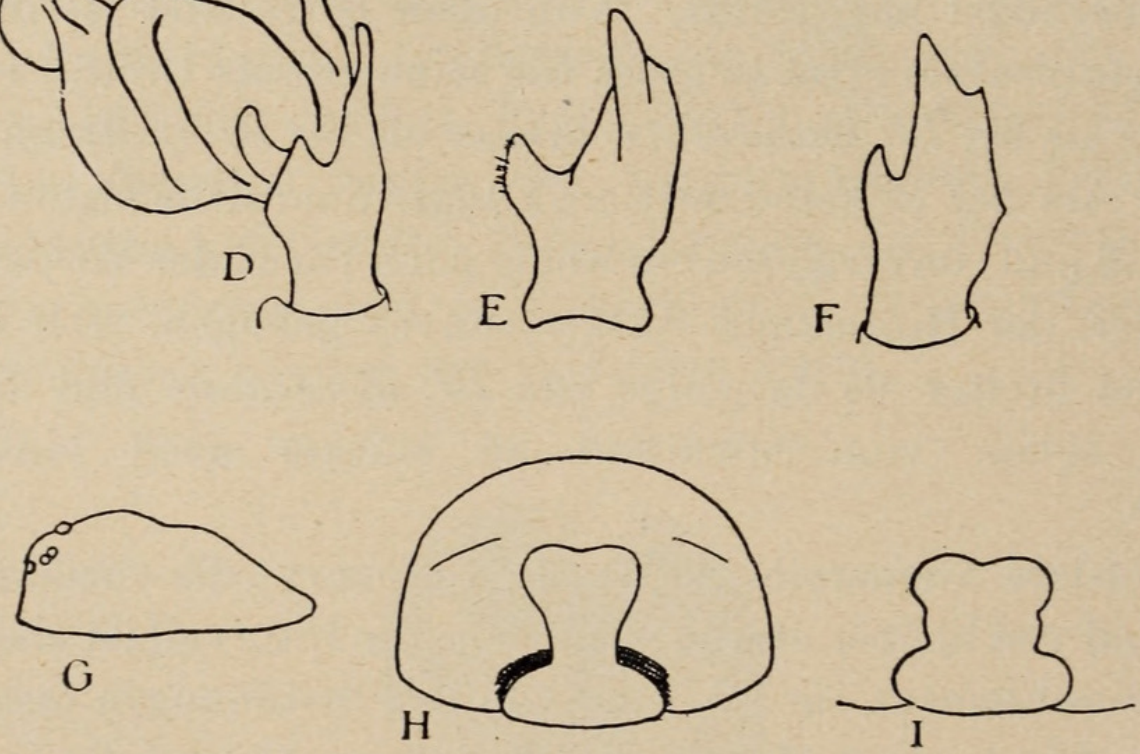

FIG. 6.

Brachycentrum de lesserti n. sp.

$\mathrm{A}=\sigma^{x}$. Cephalothorax von oben. $\mathrm{B}=\sigma^{x}$. Cephalothorax von der Seite. $\mathrm{C}=$ $\sigma^{x}$. Cephalothorax von vorn. $D=\sigma^{x}$. Linker Palp von aussen. $E=\sigma^{x}$. Tibia des linken Palps von oben. $F=\sigma^{*}$. Tibia des linken Palps von innen. $G=$ Q . Cephalothorax von der Seite. $\mathrm{H}=$ ᄋ von Fiesch. Epigyne. $\mathrm{I}=$ Q Epigyne.

Embolus ist, vielleicht zufällig, in einem weissen, häutigen Konduktor mehr oder weniger verborgen; er scheint aber ähnliche Form zu haben, wie der frei sichtbare von Br. thoracatum; er ist eine dunkle, sinuose Spina.

Der Cephalothorax ist etwas heller braun als bei Br. thoracatum; 
das Kopftuberkel hebt sich durch weisslich-gelben Farbton vom Rest deutlich ab; ähnlich hellgefärbt sind auch die Beine.

o : Der Cephalothorax ist ziemlich breit, das Verhältnis der Länge zur Breite gleich $6: 5$. Der Stirnrand ist convex gebogen, die Seitenecken sind abgerundet; die Stirne hat etwa die Hälfte der grössten Brustbreite. Die Seitenränder divergieren von den Vorderecken bis zur Mitte und sind soweit fast geradlinig. Im Profil erscheint der Clypeus senkrecht, die Augenarea etwas gewölbt. Der Kopf ist hinter den Augen flach domförmig gewölbt, dann bis zur hintern Abdachung auf eine kurze Strecke fast wagrecht; die Richtungsänderung zur hintern Abdachung ist eine ziemlich scharfe Knickung; sie befindet sich etwa auf $2 / 3$ der Länge.

Die vordere Augenreihe ist procurv, selbst die hintere Tangente; die Seitenaugen sind fast doppelt so gross als die mittleren; das Intervall der letztern ist sehr gering, kleiner als der Radius; der Abstand von den Seitenaugen ist mehr als doppelt so gross als der Zwischenraum der mittleren. Die Augen der hintern Reihe sind etwa so gross als die vordern Seitenaugen; die Hinteraugenreihe ist stark procurv; die vordere Tangente der mittleren berührt kaum den Hinterrand der Seitenaugen. Das Intervall der hintern Mittelaugen ist eher etwas grösser als ein Augendurchmesser, der Abstand von den seitlichen etwas kleiner. Das Mittelaugentrapez ist höher als hinten breit, etwa so hoch als der Clypeus.

Die Grenzfurche zwischen Kopf und Brust ist sehr deutlich, läuft aber nicht ganz bis zum Aussenrand des Thorax herab; die hintern Radiärfurchen sind viel seichter. Die seitliche Abdachung der Kopfbrust ist besonders gegen den Rand hin rauh retikuliert, ausserdem mit einigen grossen, vertieften Punkten versehen, die aber nicht in streng radiäre Reihen angeordnet und gegen den Rand hin durch die starke Retikulierung verdeckt sind; es finden sich auch solche zwischen den Radiärfurchen. Die Mitte der Oberseite namentlich des Kopfes, ist glatt und glänzend. Bei dem Exemplar von Fiesch sind die vertieften Punkte deutlicher in Reihen geordnet und durch längsrissige Rauhigkeiten verbunden, auch ist die Retikulierung der Seiten weitläufiger und weniger rauh.

Das Sternum ist breit, herzförmig, gewölbt, glänzend, mit zerstreuten Punkten besät. Das breite, quergestutzte Hinterende trennt die Hinterhüften voneinander. 
Die vordersten $2 / 3$ bis $3 / 4$ des Hinterleibrückens sind von einer verkehrt herzförmigen, dicht punktierten, hornigen Platte bedeckt.

Färbung: Bei einem Exemplar von Haueten ist der Cephalothorax und das Abdominalschild ziemlich rein rostbraun, der est des Hinterleibs grau; zwischen Schild und Spinnwarzen täuschen 3 feine, weissliche Querbogen eine Segmentierung vor. Das schwärzlichbraune Sternum ist der dunkelste Körperteil. Die Hüften und Beine sind lehmgelb, die Femora etwas lebhafter und dunkler gefärbt. Bei einem andern Exemplar von Haueten ist die Kopf brust trüber braun und zeigt deutliche dunkle Radiärstreifen, ausserdem auf dem Kopf 2 etwas gebogene Längslinien, die vorn bis zu den Seitenaugen, hinten bis zur Kopffurche reichen; eine äusserst feine Mittellinie zieht sich über Kopf und Rücken; bei diesem Exemplar ist das Rückenschild länger; es bedeckt fast die ganze Oberseite des Abdomens und lässt hinten nur etwa $1 / 7$ frei. Das Exemplar von Fiesch hat dunkleren, russbraunen Cephalothorax; auch der Hinterleibsschild ist dunkler.

Epigyne: Das dunkle, runzlig punktierte Geschlechtsfeld hat in der Mitte eine helle, ziemlich breite Platte, die etwas gewölbt und durch eine feine, eingeritzte Linie nicht allzu scharf von der Umgebung abgegrenzt ist; sie erinnert etwas an diejenige der Dismodicus-Arten; nach vorn ist diese Platte etwas verbreitert, und der Vorderrand ist nicht sehr tief herzförmig eingebogen. Die Länge dieser Area ist etwas veränderlich; am bedeutendsten ist sie beim Exemplar von Fiesch. Da wo die Unterseite des Geschlechtsfeldes in die Hinterseite umbiegt, sind die Grenzfurchen der Area scharf recht- bis spitzwinklig nach aussen gebogen; die Platte greift also auf die Hinterwand des Geschlechtsfeldes über, nur ist sie hier breiter, quer oval.

\section{Diplocephalus foraminifer (Cambridge).}

Der Cephalothorax ist glatt, glänzend, dunkelbraun. Die hintere Augenreihe ist so stark procurv, dass die hintere Tangente der Seitenaugen etwa durch die Centren der Mittelaugen geht. Die Epigyne gleicht derjenigen von D. cristatus, aber das auf die Längsspalte folgende hintere Dreieck ist kürzer, wohl aber weniger stumpfwinklig als bei $D$. latifrons. Die Spaltenränder sind im vordern Drittel etwas wulstig erhaben; das Quergrübchen davor, beziehungsweise sein erhabener Vorderrand, dehnt sich nicht soweit 
in die Quere aus wie bei $D$. cristatus. Beim Bestimmen nach der Tabelle in den Aran. Hungar. kommt man auf D. crassiloba. Simon vermutet, dass $D$. crassiloba eine Lokalform von $D$. foraminifer sei. Fundorte der letztern Art (Hautes-Alpes) liegen demjenigen meines Exemplares am nächsten.

\section{Walckenaera cucullata (C. L. Koch), var. ?}

In Gestalt, Grösse und Färbung mit der typischen Form übereinstimmend. Die Epigyne ist etwas abweichend gebaut: Die braunen Samentaschen sind weniger in die Quere ausgedehnt und stehen nicht so dicht am Rande der hintern, breiten Grube; letztere, beziehungsweise die sie ausfüllende Platte, ist im Verhältnis zur Länge weniger breit als bei der Stammform; der Vorderrand dieser Grube ist bei der Varietät eine etwas erhabene, kurze und sehr stumpfwinklig gebogene Leiste, die mehr vorsteht, am Rande stärker aufgerichtet ist als bei der Stammform.

\section{Hypomma fulvum (Bösenberg).}

Gonatium fulvum. Bösenberg. Die Spinnen Deutschlands,p. 162, Taf. XIV, Fig. 219.

Der Autor hat nur Weibchen dieser Art gekannt. Beschreibung und Zeichnungen, besonders Fig. $219 \mathrm{~B}^{2}$, passen sehr gut auf die Exemplare von der Rheinebene bei Neudorf; die $\hat{\sigma} \hat{\sigma}$ lassen die Zugehörigkeit zur Gattung Hypomma sofort erkennen; ihre Unterschiede von denjenigen der Hyp. bituberculatum sind sehr geringe.

๙ิ: Länge des Cephalothorax 1,1 $\mathrm{mm}$; grösste Breite $1 \mathrm{~mm}$; grösste Höhe $0,7 \mathrm{~mm}$; Breite der Stirn 0,6 mm; Länge des Kopfaufsatzes $0,35 \mathrm{~mm}$; Breite desselben $0,45 \mathrm{~mm}$.

Bein I $3^{\mathrm{mm}}, 35 \quad(1+0,3+0,85+0,7+0,5) ; \quad$ II $\quad 2^{\mathrm{mm}, 9} \quad(0,8+0,3$ $+0,7+0,6+0,5) ; \quad$ III 2, mm $55 \quad(0,75+0,3+0,5+0,6+0,4) ; \quad$ IV $3^{\mathrm{mm}}, 2(0,9+0,25+0,8+0,75+0,5)$.

Der Cephalothorax ist kaum länger als breit; die Stirne breit; der Kopfaufsatz besteht aus einem Paar ovaler Tuberkel; von der Seite gesehen erscheinen diese unten begrenzt durch eine tiefe Grube, die nach hinten gabelförmig ausläuft, weil eirıe stumpfe Vorragung sich einschiebt; diese Beule ist auch von der Stirnseite her sichtbar, ragt aber nicht so kräftig, konsolenartig vor wie bei $H$. bituberculatum; auch die eigentlichen Kopftuberkel sind kleiner 
als bei letzterer Art. Die beiden stark procurven Augenreihen liegen unterhalb des Kopfaufsatzes. Die vordern Mittelaugen sind auf einer gemeinsamen, querovalen, niedrigen Erhabenheit eingepflanzt; sie sind klein; ihr Intervall beträgt etwa das $1 \frac{1}{2}$-fache eines Durchmessers. Die vordern Seitenaugen sind etwa doppelt so gross als die mittleren und weiter von ihnen entfernt; der Abstand ist etwa gleich dem doppelten Durchmesser eines Mittelauges. Die hintern Mittelaugen sind nicht viel grösser als die vordern, queroval; ihr Intervall ist etwa 1 1/2 mal so gross als dasjenige der vordern; noch grösser ist der Abstand der hintern Seitenaugen; diese sind ganz auf die Seiten des Kopfes verschoben und darum von vorn kaum sichtbar. Das Trapez der Mittelaugen ist hinten
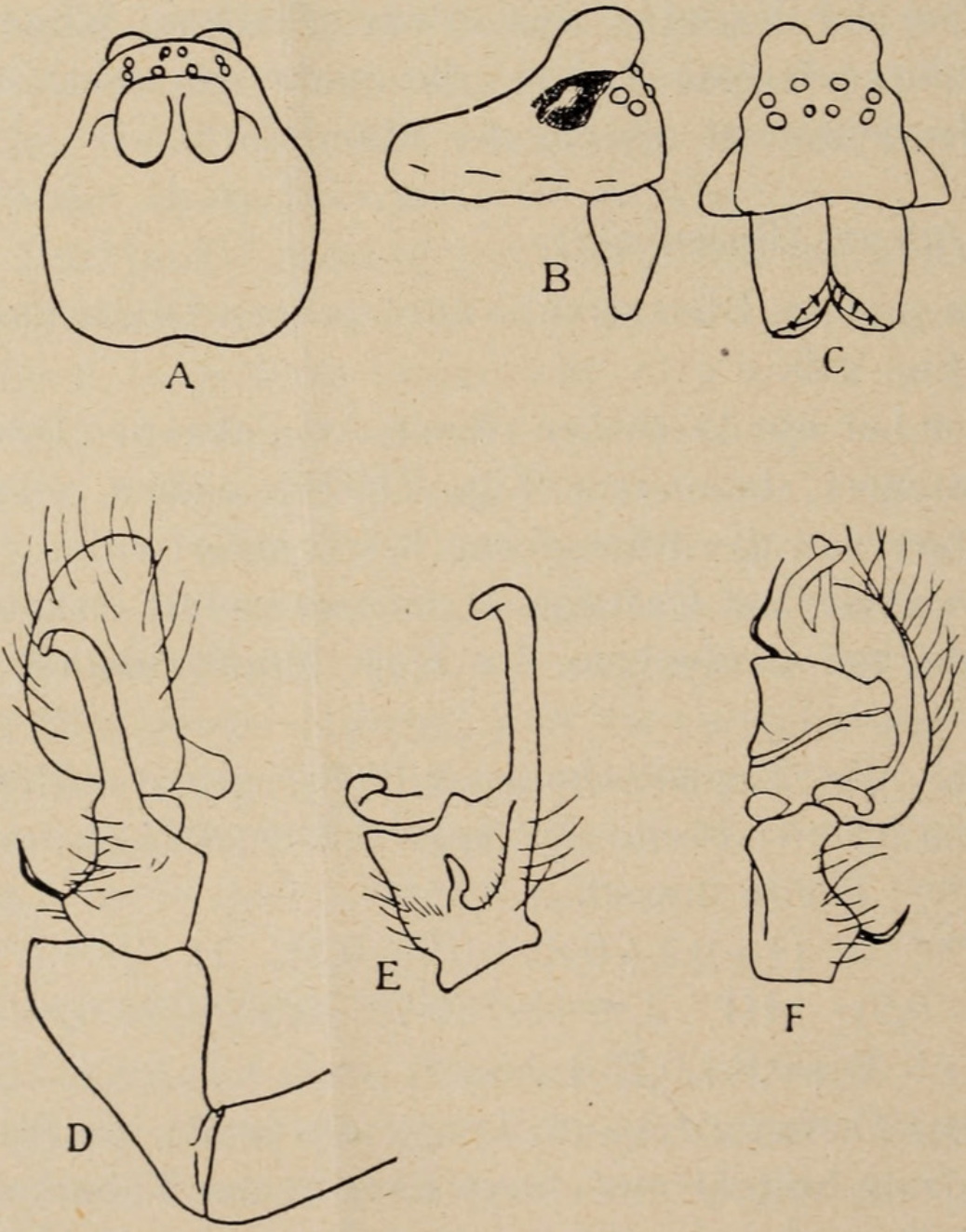

FIG. 7 .

Hypomma fulvum (Bösenberg).

$\mathrm{A}=\sigma^{x}$. Cephalothorax von oben. $\mathrm{B}=\sigma^{x}$. Cephalothorax von der Seite. $\mathrm{C}=\sigma^{x}$. Cephalothorax von vorn. $\mathrm{D}=\sigma^{*}$. Linker Palp von innen. $\mathrm{E}=\sigma^{*}$. Tibia des linken Palps von oben. $F=\sigma^{x}$. Linker Palp von aussen. 
viel breiter als vorn, beträchtlich breiter als lang. Der Clypeus ist annähernd senkrecht, nur schwach convex, gerade halb so hoch als der ganze Cephalothorax bis zum Scheitel der Kopfhöcker und etwa dreimal so hoch als das Mittelaugentrapez. Die Mandibeln sind etwas länger als der Clypeus hoch; der vordere Rand der Klauenfurche hat 3 Zähne, von welchen der oberste am grössten ist.

Der Palp ist demjenigen von $H$. bituberculatum äusserst ähnlich; die Unterschiede liegen hauptsächlich im Bau der Tibia; diese ist verhältnismässig länger und distal weniger verbreitert; sie ist etwas mehr als halb so lang wie die Patella und am distalen Ende nicht viel breiter als lang (ohne Innenapophyse). Die Ansatzstelle der kleinen, abstehenden Apophyse auf der Oberseite der Tibia ist stark nach hinten gegen die Basis des Gliedes verschoben; die Apophyse selbst ist länger als bei der verwandten Art und schwächer nach aussen gekrümmt; von ihr zieht sich ein scharfer, schwarz gerandeter Kiel nach der Basis der langen, dem Bulb anliegenden Innenapophyse; auf der äussern Kante ist ein derartiger Kiel erst vor der distalen äussern Ecke der Tibia deutlich. Der Teil der Tibiaoberseite, und das ist der grössere, der zwischen jenen Kielen vor der kleinen Apophyse liegt, ist stark wannenförmig ausgehöhlt glatt und unbehaart. Die der Lamina tarsalis anliegende Innenapophyse der Tibia ist kürzer und weniger regelmässig gebogen als bei $H$. bituberculatum; sie wendet sich erst etwas vor dem distalen Ende fast rechtwinklig in die Höhe und ist vorher fast gerade. Die Lamina tarsalis ist etwas kleiner als bei der verwandten Art.

Die Farbe stimmt bei beiden Spezies überein: Der ganze Vorderkörper mit Einschluss der Extremitäten ist rein und mehr oder weniger lebhaft rötlichgelb, der Hinterleib dunkel schiefergrau bis - schwarz.

ㅇ: Länge des Cephalothorax $1 \frac{1}{4} \mathrm{~mm} ;$ Breite $1 \mathrm{~mm}$; Höhe $1 / 2 \mathrm{~mm}$; Breite der Stirn $0 \mathrm{~mm}, 7$, vordere Augenreihe $0 \mathrm{~mm}, 4$; Hinterleib $2 \mathrm{~mm}$ lang, $1 \frac{1}{2} \mathrm{~mm}$ breit.

Bein I $3^{\mathrm{mm}}, 4(0,95+0,35+0,85+0,7+0,55)$; II $3 \mathrm{~mm}^{\mathrm{mm}}, 15(0,9+$ $0,3+0,8+0,65+0,5) ;$ III $2^{\mathrm{mm}}, 65(0,75+0,3+0,6+0,6+0,4) ; \mathrm{IV}$ $3^{\mathrm{mm}}, 3(1+0,3+0,8+0,7+0,5)$.

Die hintere Abdachung des Cephalothorax ist mässig steil; vor derselben ist die Profillinie für eine kurze Strecke fast eben, um dann in eine sehr regelmässige, flach kuppelförmige Wölbung 
überzugehen, die bis zum Augenfeld reicht, welch letzteres also tiefer liegt, als der Scheitelpunkt der Kuppel.

Die vordere Augenreihe ist, von vorn betrachtet, schwächer procurv als beim $\hat{\jmath}$; das Intervall der vordern Mittelaugen ist etwas grösser als ein Radius, aber kleiner als ein Durchmesser; die Seitenaugen sind grösser; ihr Abstand von den Mittelaugen ist etwa doppelt so gross als das Intervall der letztern. Von oben betrachtet ist die hintere Augenreihe kräftig recurv; die hintere Tangente der Mittelaugen geht etwa durch die Centren der Seitenaugen. Die subegalen Augen der hintern Reihe sind etwas grösser als die vordern Mittel-, aber kleiner als die vordern Seitenaugen; die Abstände sind annähernd gleich und betragen etwa $1 \frac{1}{2}$ Hinteraugendurchmesser. Das Trapez der Mittelaugen ist hinten beträchtlich breiter als lang. Der Clypeus ist fast doppelt so hoch als dos Mittelaugentrapez. Die Länge der Mandibeln kommt ungefähr der Höhe des Cephalothorax gleich. Der Vorderrand des Klauenfalzes hat 3 Zähne.

Das Labium ist sehr breit und kurz, nicht halb so lang als die Maxillen; diese convergieren nach vorn sehr stark. Das glatte, gewölbte Sternum ist etwa so lang wie breit, wappenschildförmig; es dringt mit schmaler, scharfer Spitze zwischen die Hinterhüften ein.

Der Stachel auf dem Rücken von Tibia IV steht etwas vor der Mitte des Gliedes und ist etwas kürzer als dessen Breite. Das Hörhaar an Metatars IV steht genau auf 2/3 der Länge.

Epigyne: An Stelle des ovalen von $H$. bituberculatum zeigt vorliegende Art ein annähernd rechteckiges Feldchen, das seitlich von 2 dünnen, schwarzen Rändern (? Kielen) begrenzt ist; diese sind fast parallel und gerade; das Feldchen selbst ist längs der Mitte etwas rinnenförmig vertieft; es setzt sich auf die der Bauchfalte zugekehrte Hinterwand des Geschlechtsfeldes fort; seine Grenzlinien divergieren an dieser Stelle. Vor dem eben geschilderten Feldchen zeigt die Epigyne eine etwas heller, gelblicher gefärbte Area, die eine flachrunzlige Oberfläche besitzt; nur unter Flüssigkeit getaucht erscheint dies Partie deutlich umgrenzt; die dunkel durchschimmernden Samentaschen haben annähernd dieselbe Form wie bei der verwandten Art, ragen aber nach vorn nicht über das Niveau der Vorderenden der Mittelfeldgrenzen hinaus (vergl. l. c., Fig. $219 \mathrm{~B} 2$ ).

Die Farbe stimmt mit derjenigen des $\hat{o}$ überein. 
Microcentria nov. gen.

Cephalothorax, von oben betrachtet, ohne Einbuchtung der Randlinie auf der Grenze von Kopf und Thorax, ohne Kopf- und ohne deutliche Radiärfurchen. Im Profil sind beim $\widehat{0} 2$ niedrige mediane Emporwölbungen erkennbar, deren vordere hinter dem Augenfeld, deren zweite vor der hintern Abdachung gelegen ist; diese zweite bildet wohl den höchsten Punkt des Cephalothorax und ist von der vordern durch eine sehr schwache Einsattelung getrennt; beim $q$ sind dieselben nur eben angedeutet.

Vordere Augenreihe beträchtlich schmaler als die hintere; die Enden der ersteren sebr stark nach oben, die der zweiten ebenso nach unten gebogen, so dass das ganze Augenfeld in der Vorderansicht fast elliptischen Umriss hat.

Der Vorderrand der Mandibelfurche hat 4 Zähne. Das Sternum ist fast dreieckig; sein schmales, scharfes Hinterende trennt die Hüften des 4. Beinpaares von einander.

Der Palp des $\hat{\sigma}$ ist sehr nahe verwandt mit demjenigen von Diplocentria. Die Tibia und das Paracymbium stimmen fast vollkommen überein.

Im allgemeinen Habitus ist die neue Gattung mit Diplocentria (Hull) so nahe verwandt, dass man beide Genera verschmelzen könnte, nur müsste dann die Diagnose des zweiten abgeändert werden, auch ist die Augenstellung der beiden zu sehr verschieden.

\section{Microcentria pusilla nov. spec.}

$\hat{0}$ : Cephalothorax $0^{\mathrm{mm}}, 6$ lang, $0^{\mathrm{mm}}, 4$ breit, somit $1 \frac{1}{2} \mathrm{mal}$ so lang wie breit. Von oben betrachtet ist keine Grenze von Kopf und Brust zu erkennen; die Randlinie zeigt nirgends eine Einbuchtung, sondern ist überall, wenn auch verschieden stark, convex gebogen, in der Mitte der Länge am ausgeprägtesten, in der Kopfhälfte unmerklich. Die Kopffurchen fehlen, die Radiärgruben sind kaum erkennbar. In der Seitenansicht erscheint der Cephalothorax nicht sehr hoch; zwischen der Augengegend und der hintern Abdachung folgen sich nacheinander 2 durch eine seichte Einsattelung getrennte Emporwölbungen, von denen die hintere eher etwas höher zu sein scheint als die vordere; jene geht dann hinten ohne Unterbrechung in die ziemlich steile Abdachung über.

Der niedrige Clypeus weicht unter der Augenarea etwas zurück, 
so dass letztere am weitesten vorragt, was entfernt an Areoncus humilis erinnert.

Die vordere Augenreihe ist stark recurv; die untere Tangente der vordern Seitenaugen liegt eher noch höher als die Centren der vordern Mittelaugen; diese stehen sehr nahe beisammen; ihr Intervall ist kleiner als ihr Radius; der Abstand der vordern Seitenaugen von den mittleren ist immer noch kleiner als deren Durchmesser, etwa doppelt so gross als das Intervall der vordern Mittelaugen. Die ganze vordere Augenreihe ist auffallend weniger breit als die hintere, nicht viel breiter als der Abstand der Innenränder der hintern Seitenaugen. Von vorn betrachtet erscheint die hintere Augenreihe kräftig abwärtsgebogen, das ganze Augenfeld darum quer elliptisch; von oben gesehen, erscheint die zweite Augenreihe merklich procurv. Die 4 Hinteraugen sind subegal, etwas grösser als die vordern Mittelaugen; ihre 3 Zwischenräume sind eher etwas kleiner als ihre Durchmesser. Das Trapez der Mittelaugen ist länger als hinten breit, der Clypeus unter den vordern Mittelaugen niedriger als jenes.
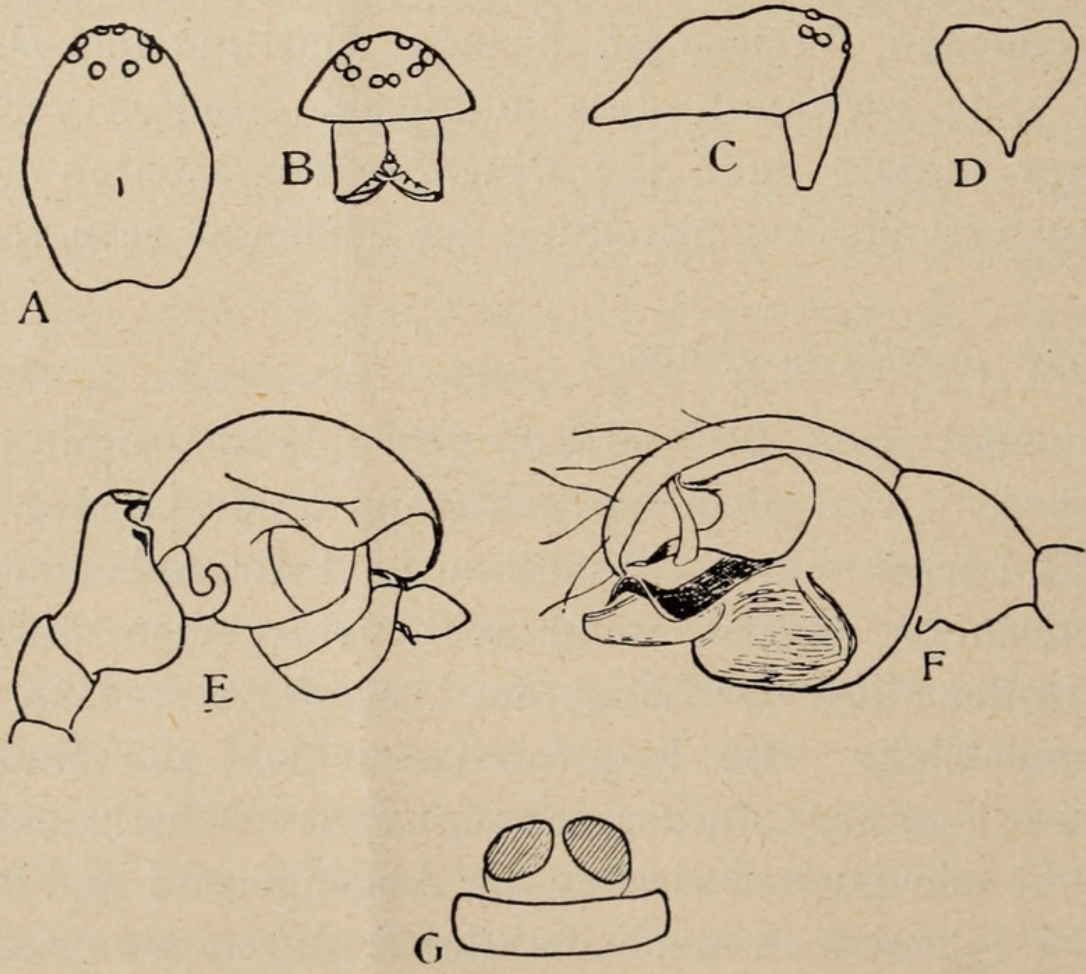

FIg. 8.

Microcentria pusilla n. g., n. sp.

$A=\sigma^{x}$. Cephalothorax von oben. $B=\sigma^{x}$. Cephalothorax von vorn. $\mathrm{C}=\sigma^{x}$. Cephalothorax von der Seite. $\mathrm{D}=\sigma^{x}$. Sternum. $\mathrm{E}=\sigma^{x}$. Rechter Palp von aussen. $\mathrm{F}=\sigma^{x}$. Rechter Palp von unten. $\mathrm{G}=$ Q . Epigyne. 
Das Sternum ist fast dreieckig, vorn etwa so breit wie lang; das die Hüften IV trennende Hinterende ist schmal und hinten zugespitzt.

Die Farbe des Vorderkörpers mit Einschluss der Extremitäten ist mehr oder weniger hell lehmbraun, das Sternum ist dunkler, mehr graubraun.

Palpen: Sowohl die Seiten- als die Unteransicht zeigt Aehnlichkeiten mit Diplocentria rivalis (vergl. de Lessert, Catal. des Araignées, p. 223, fig. 125, 126, 128). Die Tibia ist kurz, distal stark verbreitert; von oben betrachtet hat sie etwas verschoben viereckigen Umriss, ein schiefes Parallelogramm, dem beide spitzen Ecken abgestutzt sind. Am distalen Ende ragt die innere Ecke am weitesten vor, scharf, aber nicht eigentlich zahnförmig; etwas weiter zurückliegend, aber schärfer ausmodelliert, ist die äussere Ecke; zwischen beiden, fast in der Mitte des obern, distalen Endrandes befindet sich ein eigentliches, scharfes, gerades Zähnchen, dessen Richtung fast einen rechten Winkel mit der obern Profillinie der Tibia bildet; es ist gegen die Basis der Lamina tarsalis hinunter gebogen; letztere ist gewölbt aber ohne Höcker; ihr Aussenrand hat nahe der Basis eine tiefe Einbuchtung. Das Paracymbium ist klein und sehr vereinfacht, wie etwa bei Erigone. Der Bulb zeigt auf der Unterseite mehrere schwärzliche, hornige Fortsätze, die aber anders gestaltet sind als diejenigen von Diplocentria rivalis. Von den 2 grössern, distalen ist der äussere der stärkere; er ragt distal auch weiter vor und ist korkzieherartig gewunden; sein distales Ende ist nicht sichtbar, weil es in einen weissen, häutigen Conductor eintaucht; letzterer ist in der Seitenansicht allein richtig sichtbar, der Embolus schimmert höchstens durch; der Conductor überragt vorn sowohl den Bulb als die Lamina tarsalis. Neben, d. h. innerhalb des eben geschilderten Embolus ist noch eine zweite Spina; die ist aber dünner, kürzer und gestreckter, darum auch undeutlicher gewunden; sie hat als Basis eine quere, fast ovale Platte, die vor dem eigentlichen Körper des Bulbs liegt und innen fast bis an den Rand der Lamina tarsalis reicht; diesem Rand genähert, sitzt jener Basalplatte noch eine dritte kürzere Spina auf.

ㅇ: Der Cephalothorax ist ähnlich demjenigen des $\widehat{\jmath}$, nur niedriger; der Clypeus ist annähernd senkrecht.

Die vordere Augenreihe ist wie beim $\widehat{\jmath}$ stark recurv; die untere 
Tangente der Seitenaugen geht eher noch über den Centren der Mittelaugen durch; letztere sind die kleinsten von allen; ihr Intervall ist kleiner als der Radius; der Abstand von den Seitenaugen ist etwa doppelt so gross als der Zwischenraum der mittleren, kleiner als deren Durchmesser. Das Trapez der Mittelaugen ist höher als hinten breit, etwa doppelt so hoch als der Clypeus unter den Mittelaugen. Die bintere Augenreihe erscheint, von oben betrachtet, kräftig procurv; ihre Augen sind subegal, etwa gleich gross wie die vordern Seitenaugen; die Intervalle sind kleiner als die Durchmesser; auch beim $q$ ist die hintere Augenreihe auffällig breiter als die vordere. Der vordere Klauenfalzrand der Mandibel hat wie beim ô 4 Zähne, deren dritter der grösste ist; der proximale vierte hat etwas weitern Abstand als die drei andern unter sich. Das Sternum ist gleich geformt wie beim $\hat{0}$. Der Hinterleib ist etwas graulich gefärbt.

Im Geschlechtsfeld erhebt sich hinten eine quere, spangenartige Zone fast dachförmig über das Niveau des Feldes; letzteres bildet vor dieser Spange eine etwas sattelförmig vertiefte Fläche, die zwei braune, ovale Samentaschen durchschimmern lässt, welche sich vorn in der Mittellinie des Körpers berühren, nach hinten aber breit auseinander weichen.

Diplocentria rivalis (Cambridge).

Eine Beschreibung dieser Species war mir nicht zugänglich. Herr Dr. DE LESSERT war so freundlich, mir ein ebenfalls in Haueten erbeutetes $\hat{\sigma}$ dieser Art behufs Vergleichung anzuvertrauen.

+: Cephalothorax $0 \mathrm{~mm}, 7 \mathrm{lang}$, (mm, 45 breit.

Den am gleichen Ort vorkommenden Microcentria pusilla ist diese Art sehr ähnlich, nur etwas grösser und satter gefärbt. Von oben betrachtet zeigt der Seitenrand auf der Grenze von Kopf und Thorax eine leichte Einbuchtung oder vielmehr Richtungsänderung. Die Kopffurchen sind deutlich, wenn auch seicht und verschwommen. Der Cephalothorax ist niedrig. Der Clypeus weicht nicht zurück, eher das Gegenteil; er ist über dem Unterrand ganz leicht convex. Die höchste Stelle des Vorderkörpers liegt etwas hinter dem Augenfeld; dann folgt, aber wenig auffällig abgegrenzt, eine annähernd ebene Partie, darauf die nicht sehr steile hintere Abdachung. Die ganze Profillinie weicht nur sehr wenig von einer gleichförmig gebogenen ab. 
Die vordere Augenreihe ist nur wenig gebogen; die untere Berührungslinie der vier Vorderaugen ist fast gerade, nur die obere Tangente deutlich recurv. Die vordern Mittelaugen sind die kleinsten; ihr Intervall ist etwas grösser als ihr Radius, ihr Abstand von den Seitenaugen etwa gleich dem Durchmesser der Mittelaugen. Die ovalen Seitenaugen sind beträchtlich grösser, schon der kürzere Durchmesser. Die hintere Augenreihe erscheint, von oben gesehen, gerade. Die Hinteraugen sind annähernd gleich gross und gleich weit, etwa um ihren Durchmesser, von einander entfernt. Das Mittelaugentrapez ist etwa so lang wie hinten breit; seine Höhe verhält sich zu der des Clypeus wie $5: 3$.

Der vordere Klauenfalzrand der Mandibel hat fünf Zähne; auch hier ist der vierte der längste und der oberste etwas weiter von den übrigen abstehend als diese unter sich. Die fünf Zähne des hintern Randes sind viel kleiner, subegal.

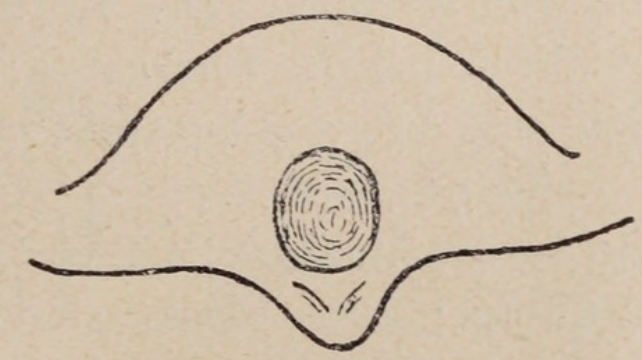

FIG. 9.

Diplocentria risalis (Cambridge). $\%$

Epigyne.

Die Epigyne bildet eine etwas querrunzlige Platte, die hinten in der Mitte in ein stumpfes Zipfelchen ausgezogen ist; vor diesem zeigt die Oberfläche eine ziemlich grosse und wohlumgrenzte, längsovale, grubenförmige Vertiefung.

Lephthyphantes frigidus Simon.

Die 우우 stehen, was den Bau der Epigyne anbetrifft, zwischen den Formen, die Kulczynski (Bull. de l'Acad. des Sc., Crac. 1904, Pl. XIV) als L. frigidus (Fig. 13-14) und L. Kotulai (Fig. 9-10) bezeichnet: Die blasenförmigen Gebilde an den Seiten des Clavus sind grösser als bei Fig. 14, aber beträchtlich kleiner als bei Fig. 10; doch sind sie, direkt ventral beobachtet, halbrund wie bei

Rev. Suisse de Zool. T. 32. 1925. 
Fig. 13, nicht nierenförmig wie bei Fig. 9. In der Seitenansicht passt Fig. 10 besser als Fig. 14, nur sind die erwähnten Blasen nicht so stark aufgetrieben wie jene angibt.

Lephthyphantes jacksoni nov. spec.

ô: Totallänge ca. $2^{\mathrm{mm}}$, Cephalothorax ca. $1 \mathrm{~mm}$.

Vordere Augenreihe beinahe gerade, kaum recurv; die Mittelaugen sind beträchtlich kleiner als die seitlichen; ihr Zwischenraum ist etwas kleiner als ihr Durchmesser, ihr Abstand von den Seitenaugen eher grösser als deren Breite, mehr als doppelt so gross als der Zwischenraum der Mittelaugen. Die hintere Augenreihe ist ebenfalls fast gerade; ihre Augen sind subegal, wie auch ihre Zwischenräume; diese sind eher etwas kleiner als die Augendurchmesser.

Der Cephalothorax ist dunkelbraun; die Mandibeln sind heller; die Beine mit Einschluss der Hüften sind lehmgelb, die Brustplatte und der Bauch sind schwarz. Der Rücken des Hinterleibs ist ähnlich gezeichnet wie bei L. tenebricola: In gelblichgrauer Grundfarbe zeigt sich eine breite Längsreihe schwarzer Winkelflecke eingebettet; diejenigen der vordern Hälfte des Rückens kann man auch als ein vorn schmaleres, aus vier rundlichen Flecken gebildetes Trapez auffassen; diese Flecke sind sowohl unter sich als auch mit einer dunkeln Mittellinie mehr oder weniger ausgedehnt verbunden; der nächstfolgende Winkelfleck ist sehr flachwinklig und plump, beinahe wie ein kräftiger Querbalken ausgebildet; der nächste Chevron ist bei sonst ähnlicher Gestalt viel schlanker. Die Grundfarbe zwischen diesen Zeichnungen ist stark reduziert; dagegen umgibt sie seitlich als ziemlich breiter Rahmen die mittlere Fleckenbinde; sie ist teilweise mit kreideweissen Flecken übersät, die jederseits zu einer Art Längsbinde zusammenfliessen. Auf den schwarzen Seiten des Hinterleibs findet sich eine weitere, stellenweise kreideweiss gefärbte Längsbinde, die hinten winklig nach oben umbiegt und sich oben mit dem entsprechenden Ast der Gegenseite verbindet, also ein äusserer Rahmen um die Rückenzeichnung, der zum innern annähernd concentrisch ist; bei L. tenebricola finden sich an Stelle dieser Seitenbinde jederseits nur zwei helle Flecke. Beim $q$ ist die Zeichnung ähnlich, nur sind die Winkelflecke viel dünner, die Grundfarbe viel ausgedehnter und die kreideweissen, zusammenfliessenden Flecke bilden nicht 
nur zwei nach vorn verbreiterte Längsbinden, sondern erstrecken sich auch, allerdings weniger zusammenhängend, in die Zwischenräume der schwarzen Winkelflecke hinein, besonders auf der hintern Hälfte des Rückens.
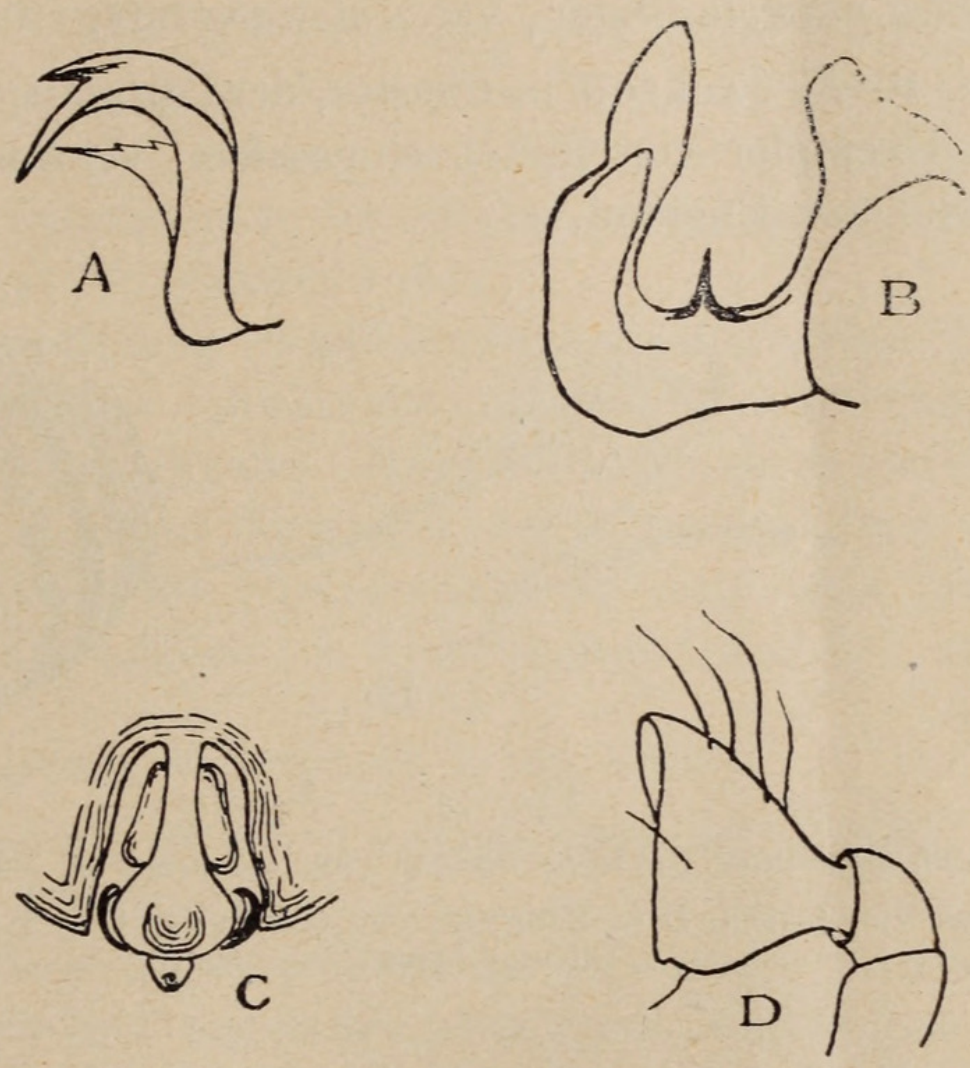

FIG. 10.

Lephthyphantes jacksoni n. sp.

$\mathrm{A}=\sigma^{*}$. Lamella characteristica des linken Palps. $\mathrm{B}=\sigma^{7}$. Paracymbium des linken Palps. $\mathrm{G}=\varnothing$. Epigyne. $\mathrm{D}=\sigma^{\top}$. Tibia des linken Palps.

Die Palpen der $\hat{o} \widehat{o}$ zeigen viel Aehnlichkeit mit denjenigen von L. tenebricola; so ist z. B. die Lamella characteristica bei beiden Arten kaum zu unterscheiden; dagegen hat das Paracymbium nur einen einzigen, sehr grossen Zahn, der sich etwa in der Mitte der untern, wagrechten, mittleren Partie erhebt und zwar mehr über der innern, dem Bulb zugewendeten Kante des Organs. Die Palpentibia ist distal stark, fast becherförmig verbreitert und hat mehrere stärkere Borsten; diese sind aber viel schwächer und kürzer als die lange und starke Stachelborste des L. tenebricola. Die Epigyne des $q$ gleicht sehr derjenigen von L. zimmermanni, nur hat die hintere Verbreiterung des Clavus eine etwas grössere, auch 
längere Fläche und vor dem Hinterrande eine ziemlich grosse, rundliche Vertiefung; die schalenförmigen Partien zur Seite dieses Hinterrandes schmiegen sich diesem enger an und sind deshalb schwerer sichtbar.

Lephthyphantes pinicola Simon, var. valesiaca nov. var. ?

Herrn Dr. R. A. JACKson in Chester, der das einzige, leider arg beschädigte Exemplar von Fiesch eingesehen, verdanke ich Vergleichsmaterial aus England.

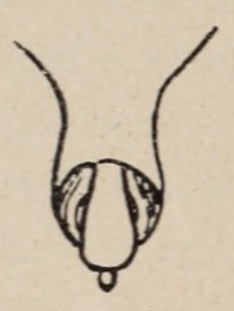

A

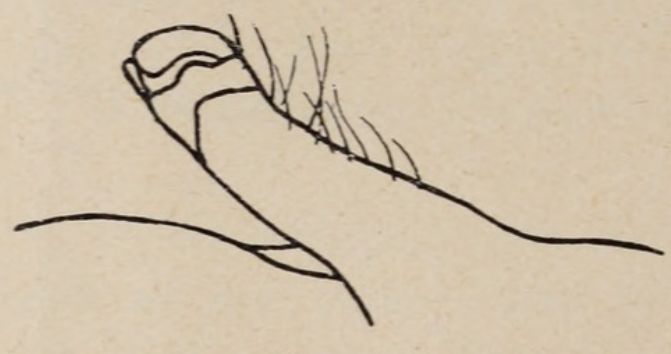

B

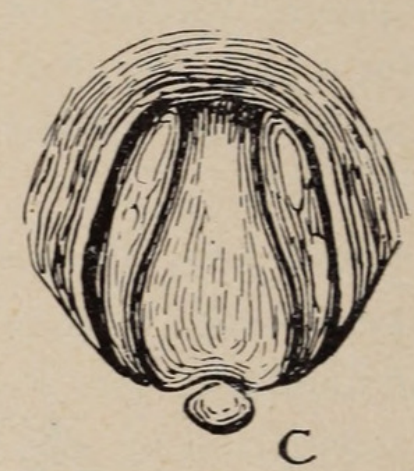

FIG. 11.

Lephthyphantes pinicola Simon var. valesiaca n. var. Q.

$\mathrm{A}=$ Epigyne von unten. $\mathrm{B}=$ Epigyne von der Seite. $\mathrm{G}=$ Epigyne von unten-hinten.

Bei beiden Formen stimmen die Längen der Epigynenkörper überein; beim Exemplar von Fiesch ist aber die Breite des Epigynenvorsprungs geringer, der Clavus länger und schmaler uns oben nicht vertieft, sondern gleichmässig gewölbt; er steht etwad schiefer und ragt, direkt von unten betrachtet, weiter über den Hinterrand des Epigynenkörpers vor; die vom Clavus überlagerte Abstutzungsfläche desselben hat nicht rundlichen, sondern länglich trapezförmigen Umriss. Der braune "Kragen », der zwischen dem Clavus und dem schwärzlichen Basalteil des Epigynenkörpers eingeschaltet ist, hat einen unebenen Endrand. Es scheint mir nicht wahrscheinlich, dass die angegebenen Unterschiede nur individuelle seien.

Lephthyphantes handschini Schenkel, var. ?

Synonym: Lephthyphantes sp. in "E. Handschin, Beiträge zur Kenntnis der wirbellosen terrestrischen Nivalfauna der schweiz. Hochgebirge ", p. 81, Taf. 8, Fig. 8. 
Totallänge des Exemplars vom Eggischhorn ca. $3 \mathrm{~mm}, 8$, Cephalothorax ca. $1 \mathrm{~mm}, 4$.

Vordere Augenreihe gerade; Mittelaugen kleiner als die seitlichen, sehr nahe beisammen, fast sich berührend; der Abstand von den Seitenaugen ist dagegen eher grösser als der Durchmesser eines Mittelauges. Die hintere Augenreihe ist ebenfalls gerade; ihre Augen sind annähernd gleich gross. Der Zwischenraum der Mittelaugen ist merklich kleiner, der Abstand von den Seitenaugen fast gleich dem Durchmesser der ersteren. Der Clypeus ist beträchtlich höher als das Mittelaugentrapez.

Der Cephalothorax ist gelbbraun, nach den Seiten etwas dunkler. Das Abdomen ist schwärzlich, ohne Spur weisslicher Zeichnung. Die Beine sind rotgelb. (Die Bestachelung schlecht erhalten!) Die Epigyne gleicht derjenigen der typischen, auch etwas veränderlichen Form; die Hinteransicht ist bei beiden kaum verschieden; die Unterschiede der Ventralansicht sind $l . c$. angegeben.

\section{Clubiona alpicola Kulczynski, a. sp. affinis.}

Totallänge ca. $8^{\mathrm{mm}}, 1$; Cephalothorax $3^{\mathrm{mm}}, 2$ lang, $2^{\mathrm{mm}}, 5$ breit; Stirnbreite $1 \mathrm{~mm}, 7$.

Die vordere Augenreihe ist ganz schwach procurv; alle vier Vorderaugen sind ungefähr gleich gross, ebenso ihre 3 Zwischenräume; jeder der letztern ist etwas kleiner als ein Augendurchmesser. Die hintere Augenreihe ist ebenfalls schwach procurv, viel breiter als die vordere; der mittlere Zwischenraum ist ca. $2 \frac{1}{2}$, jeder der seitlichen 2 mal so gross als ein Augendurchmesser; alle acht Augen sind wenig an Grösse verschieden, höchstens die hintern Seitenaugen übertreffen die übrigen ein wenig.

Der Cephalothorax ist hellbraun, gegen die Stirn und die vordern Seiten etwas dunkler, aber ohne schwarzen Rand. Die etwas knieförmig vorgewölbten Mandibeln sind dunkelbraun. Das Sternum, die Hüften und Beine sind hell lehmfarben, die Ränder der Brustplatte gebräunt, besonders jeweilen bei den Insertionsstellen der Hüften.

Die Hinteransicht der Epigyne zeigt zwei schmale Spalten, die nach unten (in der Zeichnung! In Wirklichkeit nach oben, dem Körper zu) convergieren; dieselben sind aber nicht so sinuos, wie Kulczynski sie zeichnet, auch enden sie aussen nicht in so deutliche Löcher. An der Ventralansicht der in Alkohol untergetauch- 
ten Vulva fallen vor allem die grossen, dunkeln Samentaschen in der vordern Hälfte des Geschlechtsfeldes auf; sie sind einander ziemlich nahe, ohne sich zu berühren; von ihnen führen zwei sehr deutlich durchschimmernde Kanäle zu den Spalten des Epigynenhinterrandes; diese Kanäle bilden die seitliche Begrenzung eines beinahe rechteckigen, in der Mitte hellgrauen Feldes, auf welchem drei kleinere, durchschimmernde Punkte zu einem Dreieck angeordnet sind.

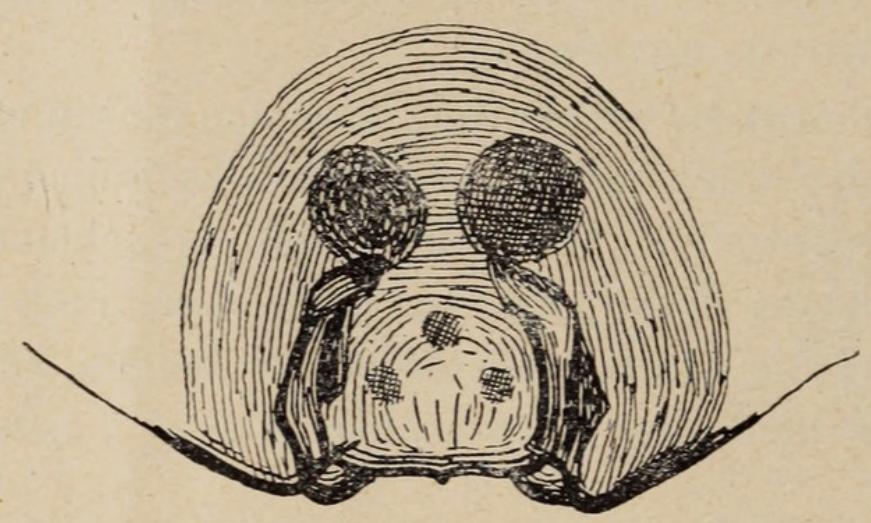

FIG. 12.

Clubiona alpicola Kulczynski, a. sp. aff $\odot$. Epigyne (unter Alkohol).

Chiracanthium lapidicolens E. Simon, a. sp. aff.

Totallänge $7 \mathrm{~mm}$; Cephalothorax $3 \mathrm{~mm}$ lang, $2 \mathrm{~mm}, 5$ breit.

Bein I 11,2mm $(3+1,1+2,8+2,8+1,5)$; II $8,4 \mathrm{~mm}(2,4+1+1,9+2,1$ $+1)$; III $6 \mathrm{~mm}, 7 \quad(1,9+0,9+1,3+1,8+0,8)$; IV $9 \mathrm{~mm}, 7 \quad(2,8+1+$ $2,2+2,7+1)$.

Bestachelung: Femur I vorn im distalen Drittel mit 1 Stachel; II, III und IV wehrlos.

Patellen unbestachelt.

Tibien I und II wehrlos; Tib. III vorn 1, hinten 1; Tib. IV vorn 1. Metatars I unten 1-1, II unten 1-1, vorn 1; III unten 2-1, vorn und hinten je 1-1-1; IV unten 1, vorn 1-1-1, hinten 1-1-1-1.

Cephalothorax nach vorn wenig verschmälert, die Stirne breit; die Profillinie bildet einen fast regelmässigen Bogen, dessen höchster Punkt etwa da liegt, wo sonst die Mittelritze enden würde. Die Kopfbrust ist lehmfarben, hinten und seitlich am hellsten, gegen den Kopf etwas reiner und dunkler braun. Die wenig dichte Behaarung ist anliegend und weisslich. 
Die Augenarea ist nur wenig schmäler als die Stirn. Die vordere Augenreihe ist kaum procurv; die vordern Mittelaugen sind rund; ihr Durchmesser ist annähernd gleich der längern Achse der ovalen Seitenaugen. Der Zwischenraum der vordern Mittelaugen ist etwa so gross wie ihr Durchmesser und halb so gross wie der Abstand von den Seitenaugen. Die hintere Augenreihe ist etwas breiter als die vordere und merklich procurv. Die hintern Mittelaugen sind etwas kleiner als die vordern; ihr Zwischenraum ist fast doppelt so gross als der Durchmesser, ihr Abstand von den Seitenaugen noch um die Hälfte grösser als das Intervall der mittleren. Das Mittelaugenviereck ist hinten etwas breiter als vorn, auch breiter als lang. Der Abstand der vordern von den hintern Mittelaugen ist etwa gleich dem Intervall der erstern, nur halb so gross als dasjenige der letztern.

Die Mandibeln sind etwa $1 \mathrm{~mm}, 5$ lang, an der Basis etwas knieförmig, weiter unten etwas nach hinten gerichtet, im Ganzen aber ziemlich senkrecht; gegen das untere Ende hin sind sie verschmälert, birnförmig, unten von einander klaffend, glatt und glänzend auf der Wölbung, querrunzlig unten und hier mit zerstreuten, langen Borsten versehen. Die Farbe ist oben rotbraun, unten schwarz. Die Zähne der Klauenfurche sind durch dicht stehende Borsten verdeckt. Jede Maxille ist etwa doppelt so lang als breit, distal verbreitert und am Ende aussen abgerundet, innen schräg gestutzt; hier ist sie weisslich, dicht mit Borsten besetzt, sonst ziemlich dunkel braun (am wenigsten im basalen Drittel); die Oberfläche jst deutlich querrunzlig, der Quere nach gewölbt, der Länge nach fast sattelförmig vertieft. Die Lippe ist etwa halb so lang als die Maxillen, so lang wie hinten breit, spitzbogenförmig, mit gestutztem Vorderende; sie ist ziemlich gewölbt und besitzt an den Seiten und besonders vorn einen dem Rand parallel laufenden Eindruck; sie ist querrunzlig, dunkelbraun, vorn etwas heller.

Das Sternum ist schild- oder herzförmig, hinten stumpf endend, etwas gewölbt, glänzend und lang, weisslich behaart; wie auch die Hüften ist es viel heller als die Mundteile, gelblich.

Der Hinterleib ist verhältnismässig dunkel und, besonders nach hinten und an den Seiten, violettbraun; violettbraune Netzmaschen umschliessen gelbliche Lücken; oben-vorn sind die Lücken grösser, hinten und an den Seiten kleiner und durch breitere Maschen getrennt. Ein schmaler, zugespitzter, violettbrauner 
Streifen zieht sich längs der Mittellinie über die Vorderhälfte; derselbe verbreitert sich etwas bis zu seiner Mitte, dann spitztler sich nach dem Ende zu; die vordere Partie ist rot angelaufen und seitlich rot gerandet, die hintere, zugespitzte Hälfte zeigt nur Spuren von roter Färbung; auf der Hinterhälfte des Abdomens fehlt das Rot gänzlich.

Die Epigynenplatte ist gewölbt; hinten hat sie eine nach hinten offene Grube; unter Alkohol ist das Geschlechtsfeld grau, mit breiten schwarzen Seitenrändern; vorn schimmern zwei Paare winklig gebrochener dunkler Kanäle durch; die Grube ist gelblich, vorn und seitlich ziemlich breit braun umrandet, breiter als lang, wie auch das ganze Geschlechtsfeld; ein Unterschied von typischen Exemplaren des Ch. lapidicolens ist kaum bemerkbar.

Zora silvestris Kulczynski.

Wie mir Herr Dr. de Lessert mitgeteilt hat, sind Exemplare von Haueten ob Zermatt von W. Kulcaynski als neue Art bezeichnet worden. Ich kann aber weder aus Beschreibung noch Abbildungen in den Aran. Hungar. wesentliche Unterschiede herausfinden.

9: Cephalothorax $2^{\mathrm{mm}}, 1 \mathrm{lang}, 1^{\mathrm{mm}}, 8$ breit. Im Niveau der hintersten Augen ist der Kopf nur noch ca. $0 \mathrm{~mm}, 8$ breit, also verhältnismässig schmal; an dieser Stelle biegt der Seitenrand erst etwas stärker nach aussen um; so entsteht eine seichte Einbuchtung, hinter welcher ein kurzer, convexer Bogen die Verbindung mit dem Brustrand herstellt. Die Oberfläche des Vorderkörpers ist glänzend, fein und dicht retikuliert, besonders an den Seiten; die Netzmaschen sind etwas der Länge nach orientiert. Die anliegenden Haare sind am längsten und kräftigsten, auch reiner weiss, am Seitenrand und auf der hellen Mittelbinde; ihre Richtung ist hier rein longitudinal; auf den seitlichen Abdachungen sind die Haare feiner, spärlicher, gelber und schräg von unten gegen die Firstlinie gerichtet.

Augenstellung: Die Reihe der hintern Seitenaugen misst ca. $0^{\mathrm{mm}}, 55$, die der hintern Mittelaugen $0^{\mathrm{mm}}, 3$; das durch die vier Hinteraugen gebildete Trapez ist etwa $0 \mathrm{~mm}, 35 \mathrm{lang}$, also richt kürzer als vorn breit. Das Intervall der hintern Mittelaugen ist etwa gleich ihrem Durchmesser, das der hintern Seitenaugen etwa gleich dem dreifachen Diameter; die hintern Seitenaugen sind viel- 
leicht um eine Spur grösser als die mittleren. Die Breite der vordern Augenreihe ist $0^{\mathrm{mm}}, 55$; sie ist nur sehr schwach procurv. Die vordern Mittelaugen sind sehr wenig kleiner als die hintern; ihr Intervall ist deutlich kleiner als ihr Radius, ebenso ihr Abstand von den vordern Seitenaugen; doppelt so gross, also grösser als der Halbmesser, ist der Abstand der vordern von den hintern Mittelaugen. Die vordern Seitenaugen sind etwas schräg gestellt, oval; der längere Durchmesser entspricht annähernd demjenigen der vordern Mittelaugen. Die vier Mittelaugen bilden ein vorn etwas schmaleres Viereck, dessen Länge der grössten Breite gleichkommt.

Der Clypeus ist vielleicht etwas höher als der Durchmesser der vordern Mittelaugen; er ist schwach convex und überall unter den vier Vorderaugen fast gleich hoch.

Die Mandibeln sind etwa $0 \mathrm{~mm}, 7$ lang; ihre Behaarung ist lang aber wenig dicht; der Hinterrand des Klauenfalzes hat zwei, der vordere drei Zähne, von diesen ist der zweite der grösste, der obere der kleinste.

Das Sternum ist etwa $1 \mathrm{~mm}, 1$ breit und ebenso lang; es ist glatt und glänzend, seine Behaarung wenig dicht; an den Seiten ist sie länger, derber, abstehender und weisser, auf der Mitte feiner, kürzer und anliegender.

Bein I $6^{\mathrm{mm}}, 1 \quad(1,8+0,7+1,8+1,2+0,6) ;$ II $\quad 5^{\mathrm{mm}, 7} \quad(1,7+0,7$ $+1,5+1,2+0,6)$; III $5^{\mathrm{mm}}, 4 \mathbf{4}(1,5+0,7+1,3+1,2+0,7) ;$ IV $8^{\mathrm{mm}, 4}$ $(2,3+0,8+2,2+2,2+0,9)$.

Bestachelung: Oberseite von Femur I und II mit 1-1 Stache! (Kulczynski gibt 1-1-1 an); der erste, kräftigere steht auf 1/4 de Länge genau in der dunkeln Mittelbinde, der zweite, dünnere auf $2 / 3$, etwas nach der Innenseite verschoben. An Femur III und IV hat die Oberseite 1-1-1 Stachel. An der Vorderfläche von Femur I steht in der Mitte ein Stachel fast rechtwinklig ab; er ist etwas tiefer eingelenkt, während bei Femur II im Gegenteil der kleine Stachel der Vorderfläche höher oben und etwa auf 3/4 der Länge steht; bei Femur III und IV zeigt sowohl die Vorder- als die Hinterfläche auf $3 / 4$ der Länge oben einen Stachel; bei einem Exemplar finden sich distal von dem vordern-untern Stachel noch drei steife, abstehende Borsten, deren erste fast als Stachel gelten könnte. Die Patellen sind unbewehrt, haben aber auf der Hinterseite eine Warze, die wie ein Stachelansatz aussieht. 
Die Unterseiten von Tibia I und II haben 6 , beziehungsweise 7 Stachelpaare. Tibia III hat oben, vorn und hinten je 1-1, unten 2-2-2 Stacheln; 7ibia IV hat oben 1-1-1, hinten und vorn je 1-1 und unten 1-2-2 Stacheln; Metatars I und II haben unten 2-2 Stacheln, Metatars III oben 1, vorn und hinten je 1-1-1, unten 2-2-1 Stachel: Metatars IV oben 1, vorn und hinten je 1-1-2, unten 2-2-1.

Die Epigyne stimmt mit der $l$. . von Kulczynski gegebenen Zeichnung und Beschreibung überein, höchstens ist die Grube etwas kleiner, ihr Abstand von der Bauchfalte etwas mehr als doppelt so gross als ihr Längsdurchmesser.

Farbe und Zeichnung: Auf den helleren Partien der Kopfbrust ist die Grundfarbe gelb bis bräunlich lehmfarben, auf den dunklern braun bis rostbraun und durch mehr oder weniger ausgeprägte, dunkelbraune bis schwärzliche Aderung noch mehr verdunkelt; die Adern sind etwas radiär gerichtet, aber unregelmässig, und durch zahlreiche Anastomosen verbunden. Die dunkle Färbung bildet zunächst zwei Aussenbinden, die dem äussersten, schmalen schwarzen Rand vollständig anliegen; sie beginnen etwas hinter dem Niveau der Hinteraugen; richtiger ausgedrückt: sie werden von dieser Stelle an von oben sichtbar; sie sind am ausgedehntesten an der breitesten Stelle der Kopfbrust, und ihre innere Grenze ist sehr inegal: die innen angrenzende helle Binde dringt in zwei nicht sehr tiefe, aber breite Buchten hinein, die zwischen drei Vorsprüngen der Randbinde liegen; auch der Innenrand der hellen Seitenbinden ist unregelmässig, doch nicht so sehr; diese hellen Binden haben also sehr ungleiche, abwechselnd grössere und geringere Breiten, die ersten kommen annähernd denjenigen der dunkeln Randbinden gleich, sind aber kaum so breit als die regelmässiger begrenzte helle Mittelbinde; die Ränder der letztern divergieren auf der hintern Abdachung, doch nicht ganz bis zum Hinterrand. Die zwischen die hellen Mittel- und Seitenbinden gelagerten dunkeln Partien sind merklich breiter als jene. Der Clypeus ist dunkel. Jede Mandibel hat eine dunkle dorsale Längsbinde. Das Sternum ist lehmgelb, je nach den Individuen sehr verschieden dicht mit dunkeln Punkten besät; immer jederseits mit drei grössern dunkeln Randflecken, die den Hüftzwischenräumen anliegen; bei einzelnen Exemplaren findet sich längs der Mitte eine fast bindenartige Häufung der dunkeln Punkte. Auch die Unterseite der Hüften 
ist punktiert, aber feiner und spärlicher als das Sternum. Die Oberseite der Hüften hat distal einen schwarzen Rand, der an einer Stelle etwas unterbrochen ist; an diesen Endrand schliesst sich hinten-oben eine abgekürzte Längsbinde an; eine dazu parallele findet sich hinten-unten.

Die Femora I und II haben dunkle Längsstriche; der dorsale ist nicht immer der dunkelste aber zusammenhängend; die beiden an der Aussenseite bestehen aus dicht gedrängten und teilweise verschmolzenen Punkten; der obere geht ganz durch, der untere ist abgekürzt; letzterm parallel zweigt vom obern jenseits der Mitte ein Ast ab; viel ausgeprägter ist aber die dazwischen liegende, helle, breite, scharf und regelmässig begrenzte Linie, die das distale Ende nicht ganz erreicht und etwas nach unten gekrümmt ist; auch Unter- und (schwächer) Vorderseite sind punktiert, doch nicht in Reihen. An den hintern Femora ist die Unter- und Vorderseite punktiert, die Hinterseite fast gar nicht; die Oberseite hat eine dunkle Linie. Patellen, Tibien und Metatarsen aller Beine sind dunkelbraun, einfärbig; nur an den Patellen hebt sich die dorsale Fläche durch schwache Aufhellung von den Seiten ab und ist längs der Mitte von einer dunkeln Längslinie durchzogen. Die Tarsen sind auffallend heller, etwa wie die hellen Binden des Cephalothorax gefärbt.

Das Abdomen gleicht mehr demjenigen von $Z$. nemoralis als dem von Z. spinimana, ist aber weniger dunkel. Die Grundfarbe ist heller oder dunkler lehmfarben, die Zeichnung eine braune Marmorierung oder ein Netzwerk aus rundlichen, kleinen Maschen; die braune Färbung umgrenzt sehr unregelmässig einen mittleren, lanzenförmigen Fleck der Grundfarbe, der vom Vorderrand bis zur Mitte reicht; seine dunkle Umgrenzung setzt sich nach hinten als unterbrochene Linie, eigentlich Punktreihe, bis gegen die Spinnwarzen fort; die Umgrenzung des Lanzenflecks sendet nach den Seiten zwei Paar Aeste aus, das eine in der Mitte des Flecks, das andere vor seinem Hinterende; dadurch werden zwei grössere, unregelmässige Fleckenpaare der Grundfarbe abgegrenzt; die Flecken des vordern Paares sind länglich, die des hintern kürzer. Auf der hintern Partie des Abdomens folgen drei ziemlich unregelmässige, etwas bogenförmige Querreihen von grössern Flecken der Grundfarbe, getrennt durch dunkle Binden. Die Seiten des Abdomens zeigen in der Hinterhälfte etwa drei unregelmässig begrenzte helle 
Schrägbinden. Der Bauch ist heller als die Oberseite und mehr oder weniger dunkel marmoriert oder punktiert.

$\widehat{o}:$ Der Palp stimmt in jeder Hinsicht mit der von Kulczynski l. $c$. gegebenen Beschreibung und Zeichnung überein. Unterschiede könnten höchstens im Bau des distalen Endes der Tibialapophyse vorhanden sein, sind aber aus der zitierten Beschreibung und Zeichnung nicht zu erkennen; in dieser ist nicht sichtbar, dass die eine der distalen Ecken des aufsteigenden Endteiles der Tibialapophyse in eigentümlicher Weise umgebogen ist.

Amaurobius rudolfi nov. spec.

๙ิ : Totallänge $9 \mathrm{~mm}, 5$, Cephalothorax $5 \mathrm{~mm}$.

Bein I $13 \mathrm{~mm}, 5$; II $12^{\mathrm{mm}}, 5$; III $11^{\mathrm{mm}}$; IV $15^{\mathrm{mm}}, 5$.

Bestachelung: Femur I oben 1-1, vorn 2 (in der distalen Hälfte, schräg übereinander); Femur II oben 1-1, vorn 1 oder 0 (links), 1-1 (rechts); Femur III oben 1-1, vorn 1-1, hinten 1 oder 1-1; Femur IV oben 1-1, vorn 1-1 oder 1, hinten 1. Patella III vorn 1, hinten 1 oder 0 ; Patella IV hinten 1 . Tibia I unten 2-2-2; Tibia II unten 2-2-2, vorn 1 oder 1-1; Tibia III und IV unten 2-2-2, vorn und hinten je 1-1. Metatars I unten 2-2-3 (die mittleren schräg hintereinander); Metatars II unten 2-2-3, vorn 1; Metatars III und IV unten 2-2-2, vorn und hinten je 1-2-2.

Augen: Die vordere Reihe ist, von vorn betrachtet, schwach procurv, die obere Tangente ist gerade; die vordern Mittelaugen sind etwa halb so breit als die seitlichen. Der Zwischenraum der Mittelaugen ist etwa so gross als ihr Durchmesser, oder eine Spur grösser, der Abstand von den Seitenaugen ist etwas geringer. Die hintere Reihe erscheint, von oben betrachtet, gerade oder ganz schwach procurv; sie ist breiter als die vordere; ihre Augen sind unter sich ziemlich gleich gross, grösser als die vordern Mittel-, kleiner als die vordern Seitenaugen. Der Zwwischenraum der hintern Mittelaugen ist eher etwas grösser als ihr Durchmesser; der Abstand von den hintern Seitenaugen mindestens das $1 \frac{1}{2}$-fache der Mittelaugendistanz. Das Trapez der Mittelaugen ist etwas länger als hinten breit.

Gestalt und Färbung des Körpers erinnern an A.terrestris (Wider). Der Kopf ist durch wohlausgeprägte Furchen vom Brustteil getrennt, auch die Radiärfurchen auf letzterem sind deutlich, wenn auch etwas schwächer. Der Kopf ist etwa halb so breit als der 
Thorax. Im Profil zeigt sich zwischen Kopf und Brust keine Einbuchtung; vom Hinterrand bis zur langen Mittelritze steigt die Profillinie erst ziemlich steil an, dann nach vorn bis zum Augenfeld schwächer und etwas convex; letzteres fällt dann wieder nach vorn ab. Die Mandibeln stehen stark knieförmig vor. Das Sternum ist etwas hinter der Mitte am breitesten uud nach dem Hinterende rasch zugespitzt.

Die mittleren und untern Spinnwarzen sind subegal, die obern mehr als doppelt so lang wie jene; die Endglieder der obern sind wenig mehr als halb so lang als die vorletzten, diese doppelt so lang als breit; das vorletzte Glied ist annähernd cylindrisch, das Endglied stumpf kegelförmig.

Der Patellarfortsatz des Palps stimmt fast mit demjenigen von A. pickardi überein; von der Seite gesehen ist er schwach sinuos, überall gleich breit; am distalen Ende ist die untere Ecke ziemlich ausgeprägt, die obere vollkommen abgerundet und verwischt. Der Bulb steht demjenigen von $A$. pastor, namentlich von dessen Unter-
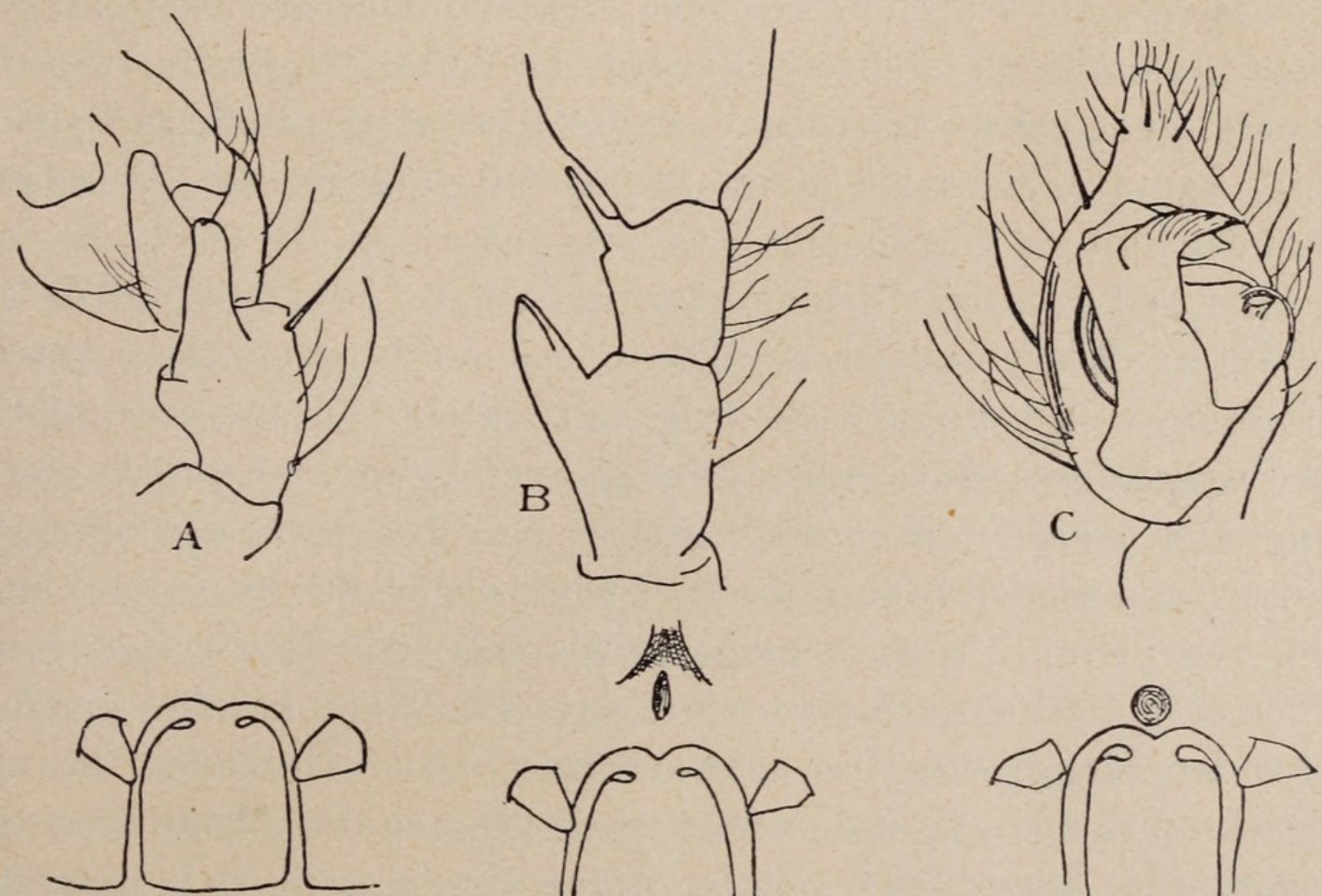

D
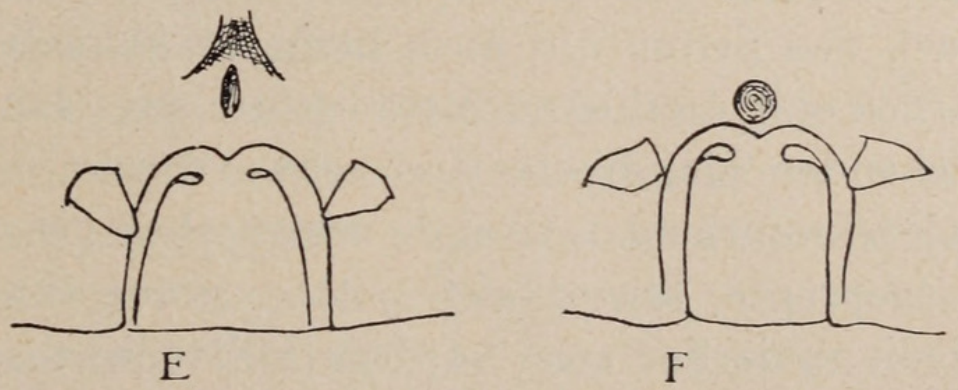

FIG. 13.

Amaurobius rudolfi n. sp.

$\mathrm{A}=\sigma^{\top}$. Patella und Tibia des linken Palps von aussen. $\mathrm{B}=\sigma^{\top}$. Patella und Tibia des linken Palps von oben. $\mathrm{C}=\sigma^{*}$. Bulb von unten. $\mathrm{D}=q$ vom Aerner Galen. Epigyne. $\mathrm{E}=$ ᄋ vom Aerner Galen. Epigyne. $\mathrm{F}=$ ○ vom Rappental.

Epigyne. 
art tirolensis, sehr nahe; der Conductor des Stylums hat aber am Ende nur noch eine Ecke, zeigt also Anklänge an denjenigen von A. inermis, nur ist er lange nicht so schlank und stark gebogen, wohl aber eher schärfer zugespitzt.

: Totallänge $13 \mathrm{~mm}, 5$, Cephalothorax ca. $6 \mathrm{~mm}$.

Bein I $14 \mathrm{~mm}$; II $12,5 \mathrm{~mm}$; III $12 \mathrm{~mm}$; IV $15 \mathrm{~mm}$.

Bestachelung: Femur I-IV oben mit 1-1 Stachel; Femur I vorn 1-2 oder 2; Femur II vorn 1 oder 1-1; Femur III vorn 1-1, hinten 1-1 oder 1; Femur IV vorn 1-1 oder 1 , hinten 1 . Patella III vorn 1, hinten 1; Patella IV hinten 1. Tibien I-IV unten mit 2-2-2 Stacheln; Tibia II vorn 1-1 oder 1; Tibien III und IV vorn 1-1, hinten 1-1 (oder 1). Metatars I-II unten 2-2-3 (vorn 1 an Metatars II); Metatars III und IV unten $2-2-2$, vorn und hinten je 1-2-2 (ausnahmsweise auch 2-1-2 oder 1-1-2).

Vordere Augenreihe deutlicher procurv; auch die hintere Tangente ist etwas gebogen; die Seitenaugen sind nicht ganz doppelt so gross als die mittleren; der Zwischenraum der letzteren ist kaum so gross als ihr Durchmesser, der Abstand von den Seitenaugen etwas grösser. Die hintere Augenreihe ist etwas breiter als die vordere, ganz schwach procurv; ihre Augen sind annähernd gleich gross, kaum grösser als die vordern Mittelaugen; der Zwischenraum der hintern Mittelaugen ist etwas grösser als ihr Durchmesser, der Abstand von den Seitenaugen mindestens doppelt so gross als das Intervall der mittleren. Der Clypeus ist unter den vordern Mittelaugen fast doppelt so hoch als deren Durchmesser, unter den Seitenaugen etwa gleich dem grössern Durchmesser der letztern. Der Kopf ist eher noch breiter und gewölbter als beim $\hat{o}$, dunkler und reiner braun als die Brust, gegen den Stirnrand und nach den Seiten hin noch mehr verdunkelt; der Thorax ist lehmfarben mit dunkleren Strahlenfurchen. Die stark knieförmig vorstehenden Mandibeln sind schwarzbraun. Der Hinterleib ist auf hell lehmfarbenem Grunde schwärzlich gesprenkelt. Eine schwach ausgeprägte, hinten zugespitzte, graue Binde zieht sich über die Medianlinie der zwei vordern Dritteile; median ist dieselbe etwas aufgehellt; zu beiden Seiten wird sie begleitet von drei Paaren verwaschener heller Flecke, die durch schwärzliche seitliche Erweiterungen der Medianbinde von einander getrennt sind. Bei A. mediocris ist die Grundfarbe bräunlicher, die Medianbinde und die hellen Fleckenpaare schärfer ausgeprägt, trotzdem die Flecke 
an sich kleiner sind; bei der neuen Art ist die Zeichnung viel verwaschener.

Das Sternum hat die Farbe des Kopfes, ist also rein braun, nach den Rändern hin etwas verdunkelt. Die Hüften sind viel heller, lehmfarben; ähnlich sind die anstossenden Partien der Beine; nach den distalen Enden hin werden letztere allmählich dunkler.

Die Epigyne ist, trotz der stattlichen Postur der $q q$, kleiner als bei A. terrestris und A. mediocris; der Vorderrand der Grube hebt sich überall scharf von der tieferliegenden Platte ab; er ist median 土 winklig nach hinten vorgezogen und geht aussen ohne Eckenbildung bogenförmig in die Seitenränder der Grube über; diese sind entweder parallel oder weichen nach hinten leicht auseinander, doch nie so stark wie bei A. mediocris. Zum Unterschied von A. pastor sind die Seitenzähne hinter dem Niveau des Vorderrandes der Grube angewachsen. Bei drei Individuen sind Länge und Breite der Grube gleich gross, bei einem dominiert die Länge, bei einem weitern die Breite. Das Exemplar vom Rappental hat vorn, vor dem Vorderrand der Grube, eine deutliche, grubenförmige Vertiefung; bei den Stücken vom Aerner Galen ist dieselbe schwächer ausgeprägt, bei einem kaum angedeutet.

Pardosa blanda (C. L. Koch).

2 우 vom Geisspfad sind auffallend klein (5mm total) und schlank, heller als gewöhnlich, besonders das eine; aber die Vulva stimmt genau mit solchen normaler Exemplare überein; sie ist kurz und hinten breit, hat auf der Fläche die breite Längsgrube und hinten die stark entwickelten, fast hornförmig nach aussen und vorn vorspringenden Hinterecken.

Die gelbbraune Zeichnung des angefeuchteten Hinterleibs stimmt ziemlich mit derjenigen typischer Exemplare überein: Der vordere Pfeilfleck ist seitlich begleitet von zwei schmalen, gelben Strichen und hinten gefolgt von einer Mittelbinde, die sich als abwechselnde Folge plumper Winkelflecke und schmaler Querlinien darstellt. Die helle Mittelbinde des Cephalothorax sendet ihre Spitze vorn zwischen die Mittelaugen und zeigt hinter diesen eine schwache Verbreiterung, wie gelegentlich auch bei typischen Stücken. Beim dunkleren Exemplar sind die hellen Seitenbinden fast normal, nur sind die sie zerteilenden schwarzen Querlinien 
bloss angedeutet; das ist auch beim helleren Stück so, aber die Seitenlinien scheinen hier sehr breit, weil das Tegument zwischen den eigentlichen, hellgelben Seitenbinden und dem tiefschwarzen Rand sehr hell, rötlichbraun gefärbt ist. Während das Sternum bei typischen $P$. blanda schwarz ist und nur einen kurzen, hellen Medianstrich hinter dem Vorderrand aufweist, ist beim helleren Exemplar die gelbbraune Färbung viel ausgedehnter; dunkel ist nur eine aus mehreren Flecken zusammengeschmolzene Hufeisenfigur, die den viel stärker entwickelten Medianstrich umgibt, und ein Marginalkranz schwarzer Flecke, die jeweilen vor den Hüftinsertionen stehen. Die Beine des helleren Exemplares sind wenig verdunkelt, da besonders an den Tibien und Metatarsen die Ringelung lichtgrau statt schwarz ist.

Sitticus muralis noc. spec. ?

ㅇ: Totallänge $6 \mathrm{~mm}, 3$; Länge des Cephalothorax $2^{\mathrm{mm}}, 5$, wovon $1 \mathrm{~mm}, 1$ auf die Augenarea und 1 mm,4 auf die hintere Partie fallen; grösste Breite der Kopfbrust fast $2^{\mathrm{mm}}$; Breite der vordern Augenreihe $1 \mathrm{~mm}, 5$; Breite der hintern Augenreihe $1 \mathrm{~mm}, 4$.

Bein I $4 \mathrm{~mm}$ (Femur 1,2, Patella und Tibia 1,6, Metatars und Tars 1,2); II 3mm,6 (Femur 1, Patella und Tibia 1,4, Metatars und Tars 1,2); III 3mm,6 (Femur 1,1, Patella und Tibia 1,3, Metatars und Tars 1,2); IV 5mm,6 (Femur 1,8, Patella und Tibia 2,1, Metatars und Tars 1,7).

Bestachelung: Tibia I unten 2-2-2, Metatars I 2-2; Tibia II unten 1-2-2, vorn 1, Metatars II 2-2; Tibia III unten, vorn und hinten je 1-1; Metatars III vor der Mitte an der obern Kante der Vorderseite 1-1, an der untern und obern Kante der Hinterseite je 1, am distalen Ende ein Kranz von 6 Stacheln; Patella IV hinten mit 1 Stachel; Tibia IV oben mit 0, vorn mit 1-1, hinten mit 1-1-1, unten mit 2 Stacheln vor dem distalen Ende. Metatars IV vorn mit 1-1, hinten mit 2 und am Ende mit einem Kranz von 6 Stacheln.

Augen: Obere Tangente der vordern Reihe annähernd gerade, kaum recurv. In der Seitenansicht erinnert die Neigung des Augenfeldes an die Verhältnisse bei Menemerus; eine Horizontale durch das Zentrum der Intermediäraugen berührt beinahe den Unterrand der Hinteraugen; dieser befindet sich annähernd so hoch über dem Niveau des Oberrandes der Vorderaugen, als der grösste Durchmesser der Intermediäraugen beträgt. Die hintere 
Augenreihe ist etwas schmaler als die vordere. Der Clypeus scheint beträchtlich höher zu sein als der Radius der vordern Mittelaugen; er ist sehr dicht und lang weissbehaart, was fast an Evarcha arcuata erinnert. Die Haarkränze um die Augen sind auch weiss. Bein III erreicht das distale Ende von Tibia IV nicht; die basalen Stacheln von Metatars I langen nahezu, aber nicht ganz, bis ans distale Ende dieses Gliedes. Metatars + Tars IV sind nur etwa so lang wie die Tibia und die halbe Patella zusammen.

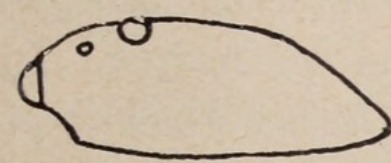

A
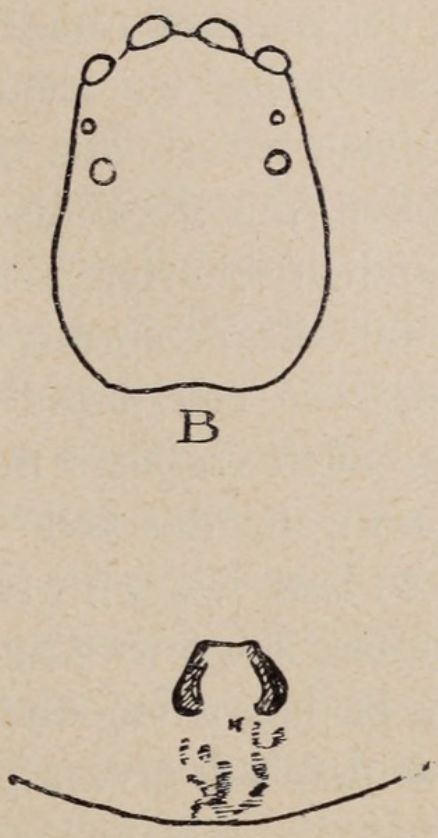

D

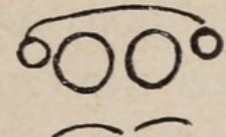

C

FIG. 14.

Sitticus muralis n. sp. ․

$\mathrm{A}=$ Augenstellung von der Seite. $\mathrm{B}=$ Augenstellung von oben. $\mathrm{C}=$ Augenstellung von vorn. $\mathrm{D}=$ Epigyn $\epsilon$.

Das Tegument der Oberseite ist schwarz; die Behaarung ist nicht so dicht wie bei dem ähnlichen Attulus histrio, grösstenteils weisslich, mit nur wenig braun und schwärzlich untermischt; hinter der Augenarea steht ein undeutlicher, weisser Winkelfleck, dessen Spitze nach vorn etwa bis zum Niveau der Hinteraugen reicht. Auf der vordern Hälfte des Hinterleibrückens bilden vier kleine, weissliche Flecke ein Trapez, dessen kürzere Parallele etwa am Ende des 1. Viertels, dessen breitere annähernd in der Mitte des Hinterleibs gelegen ist; auf diese folgt längs der Mittellinie eine Reihe von vier Winkelflecken, deren Spitzen nach vorn schauen. Die Seiten der hintern Hälfte des Abdomens sind in grösserer Aus- 
dehnung stärker weiss gefärbt, bilden nach vorn abgekürzte, nicht sehr deutliche Längsbinden. Das schwärzliche Tegument der Abdominalseiten ist durch zahlreiche helle Pünktchen etwas aufgehellt; der Bauch ist ziemlich hell bräunlichgrau; vier äquidistante Längsreihen gelber Punkte durchziehen ihn, wovon die beiden äusseren die Seitengrenzen bilden.

Das Tegument des Sternums ist metallisch schwärzlich, glänzend; die Hüften zeigen helle Fleckung; die des 1. Paares sind um Lippenbreite von einander getrennt.

Die helle Ringelung der Beine ist nur an den zwei letzten Gliedern erheblich, an den vorhergehenden ziemlich verdunkelt, übrigens unter der langen, zottigen, weisslichen Behaarung verborgen. Die Epigyne hat Aehnlichkeit mit derjenigen von Attulus histrio; ein seitlich und hinten ziemlich scharfer, hier auch etwas geschwärzter Rand umgibt ein beinahe trapezförmiges, helles Feldchen; dieses besteht aus zwei nach vorn convergierenden, länglichen Gruben, die durch ein breites, auch trapezförmiges Kissen von einander getrennt sind. Der Raum, der das helle Feldchen von der Bauchfalte trennt, ist etwa so lang wie der grössere, quere Durchmesser des ersteren; er hat hinten keine winklige Einbuchtung, im Gegensatz zu $A$. histrio, und ist längs der Mitte etwas vertieft und stark gebräunt, auch nicht so deutlich grubig punktiert wie bei jener Art. 


\section{$2 \mathrm{BHL}$ Biodiversity Heritage Library}

Schenkel, Ehrenfried. 1925. "Beitrag zur Kenntnis der Schweizerischen Spinnen-fauna." Revue suisse de zoologie 32, 253-318.

https://doi.org/10.5962/bhl.part.117931.

View This Item Online: https://www.biodiversitylibrary.org/item/148880

DOI: https://doi.org/10.5962/bhl.part.117931

Permalink: https://www.biodiversitylibrary.org/partpdf/117931

\section{Holding Institution}

American Museum of Natural History Library

\section{Sponsored by}

BHL-SIL-FEDLINK

\section{Copyright \& Reuse}

Copyright Status: In copyright. Digitized with the permission of the rights holder.

Rights Holder: Muséum d'histoire naturelle - Ville de Genève

This document was created from content at the Biodiversity Heritage Library, the world's largest open access digital library for biodiversity literature and archives. Visit BHL at https://www.biodiversitylibrary.org. 